
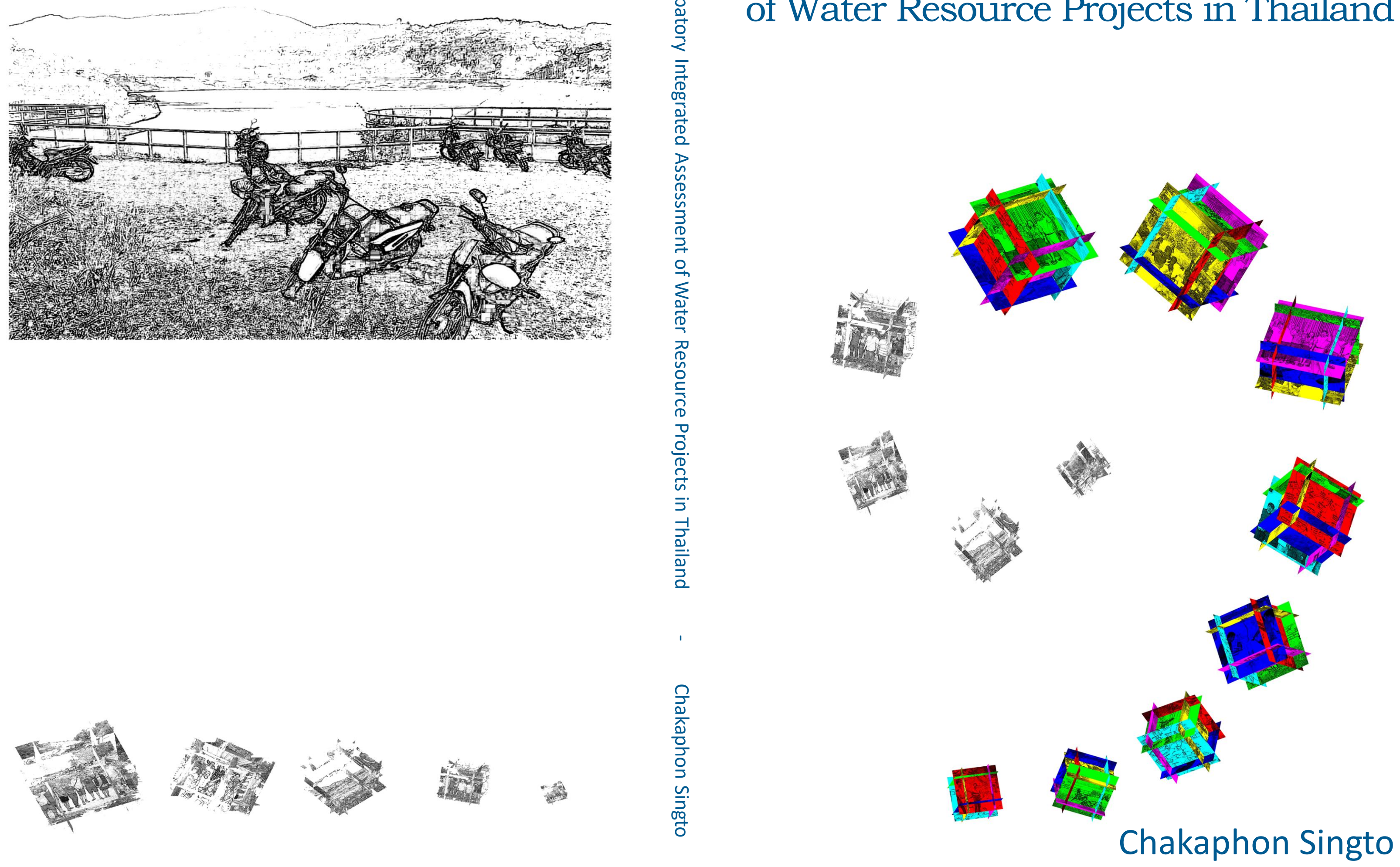

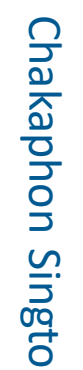




\section{Propositions}

1. Design outcomes of a participatory process become more sustainable if facilitators uncover omitted issues.

(this thesis)

2. Participative modelling techniques make potential impacts of alternative design options explicit and visible for stakeholders.

(this thesis)

3. Economic incentives, rather than awareness of environmental impact, promote the willingness to change behaviour.

4. Human and social capitals are larger determinants of development than financial and infrastructural capitals.

5. People engage in community-based management when they perceive government projects to be ineffective.

6. Involving school children in citizen science projects will promote the interest of society in science.

7. Results from research are useful for researchers, rather than policy-makers.

Propositions belonging to the thesis, entitled:

"Participatory Integrated Assessment of Water Resource Projects in Thailand."

Chakaphon Singto

Wageningen, 30 November 2020 


\section{Participatory Integrated Assessment of Water Resource Projects in Thailand}

Chakaphon Singto 


\section{Thesis committee}

\section{Promotor}

Prof. Dr C.J. Ritsema

Professor of Soil Physics and Land Management

Wageningen University \& Research

\section{Co-promotors}

Dr L. Fleskens

Associate professor, Soil Physics and Land Management

Wageningen University \& Research

Dr J.M.C. Vos

Associate professor, Water Resources Management

Wageningen University \& Research

\section{Other members}

Prof. Dr M.M. Bakker, Wageningen University \& Research

Dr P. Ditthakit, Walailak University, Nakhon Si Thammarat, Thailand

Dr J. Mildorfova Leventon, Global Change Research Institute CAS, Brno, Czech Republic

Dr J.F. Warner, Wageningen University \& Research

This research was conducted under the auspices of the Research School for Socio-

Economic and Natural Sciences of the Environment (SENSE) 


\title{
Participatory Integrated Assessment of Water Resource Projects in Thailand
}

\author{
Chakaphon Singto
}

Thesis

submitted in fulfilment of the requirements for the degree of doctor at Wageningen University by the authority of the Rector Magnificus

Prof. Dr A.P.J. Mol in the presence of the

Thesis Committee appointed by the Academic Board to be defended in public

on Monday 30 November 2020

at 11:00 a.m. in the Aula. 
Chakaphon Singto

Participatory Integrated Assessment of Water Resource Projects in Thailand, 169 pages.

PhD thesis, Wageningen University, Wageningen, the Netherlands (2020)

With references, with summary in English

ISBN: 978-94-6395-559-1

DOI: https://doi.org/10.18174/531971 


\section{Table of contents}

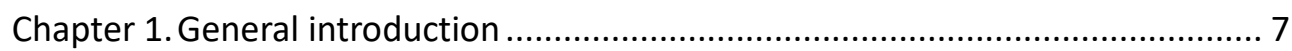

Chapter 2. Institutionalizing Participation in Water Resource Development: Bottom-Up and Top-Down Practices in Southern Thailand ................. 21

Chapter 3. Applying Bayesian Belief Networks (BBNs) with stakeholders to explore and co-design options for water resource interventions

Chapter 4. Ex ante impact assessment of reservoir construction projects for different stakeholders using agent-based modeling

Chapter 5.Compensation for dam building: Representation, languages of valorization and outcomes in Thailand 95

Chapter 6. Synthesis. 121

Literature cited 141

English summary 157

Acknowledgements 163

About the author. 165

Colophon 169 



\section{General introduction}




\subsection{Introduction}

Worldwide, dam construction is seen as an important measure for increasing water supply to agricultural, industrial, commercial and residential sectors. Dams make it possible to regulate water flows and store water between seasons and interannually. Stored water can be used for irrigation, industry, drinking water, aquaculture, and generation of energy. Many of the richest countries in the world have the highest water storage capacity per capita (Grey and Sadoff, 2007). Dams are also valuable for control of floods and management of ecological flows. Clearly, dam construction has resulted in many benefits for society.

However, large dam construction has also led to many problems. First, communities that live and have agricultural land at the site of the dam and reservoir lose their land, houses and cultural heritage sites. Their resettlement and compensation often leave them worse off, as neither the resettlement site nor compensation provide them with sufficient, durable income (Cernea, 2000; WCD, 2000; Schulz and Adams, 2019). Second, the usefulness and durability of the dam are often much less than designed and expected. Total volumes of water stored are often less than predicted, and the life span of dams is compromised due to faster than expected sedimentation of the reservoir by a large sediment load in the contributing river. Third, downstream users are affected by the upstream storage and use of water, not always positively. Fourth, in-river-dams severely affect the aquatic ecology of the river. Many species can go extinct and fish migration is obstructed (Deinet et al., 2020). Reduced fish stocks can severely affect local fisher communities.

All over the world, there is opposition to large dam construction: from local communities, from environmental NGOs, and from downstream riparian countries (see cases of the Nile and Mekong). Local communities, often with support of regional, national and international NGOs, have protested against dam building (Shah et al., 2019). Affected communities struggle for recognition, improved compensation and restoration of their livelihoods. There is increasing interest in finding ways to lessen the negative impacts of large dams and improve their functionality, in order to keep the benefits and reduce the damage.

The seminal report of the World Commission of Dams (WCD, 2000), commissioned by the World Bank and World Conservation Union (IUCN), made an inventory of the effects of over 50 large dams, recognised the above-mentioned problems, and made a series of recommendations. As alternatives to large dams, different policy options have also been promoted by policy advisors, e.g. demand management (through water pricing and awareness raising), water markets, desalinization, and more decentralized smaller dams. Initially the investments in large dams diminished worldwide, but during the last decade many new large dams have been constructed, and many more are planned. The main reason 
for this renewed urgency to build dams is the need for hydropower for growing economies. Construction is often legitimized by referring to hydropower's relatively low carbon emission in comparison with fossil-fuel based energy generation (Crow Miller et al., 2017). The need for buffering for climatic variability also contributes to increased demand for dams (Kurukulasuriya \& Rosenthal. 2013).

In Thailand, many dams have been constructed for hydropower and, to a lesser extent, for irrigation, industry and domestic water supply. These include 97 large dams $\left(>100 \mathrm{hm}^{3}\right)$ with a total of $73,944 \mathrm{hm}^{3}$ storage that have been built to irrigate 2.8 million ha (e.g. Srinagarind, Bhumipol, Sirikit, Vaijiralongkorn, and Rat Cha Prapa). However most dams are medium (860 projects with $5,180 \mathrm{hm}^{3}$ providing irrigation water for 1.1 million ha) and small $(19,392$ projects with $3,288 \mathrm{hm}^{3}$ to irrigate an area of 5.4 million ha) (RID, 2018c) in size. The Royal Irrigation Department (RID) is the main government agency responsible for the planning and construction of small-, medium-, and large-sized dams. In particular, RID proposes suitable interventions to the Thai government and operates the policy process of dam construction for multiple purposes (RID, 2010; 2018a). The Energy Generating Authority of Thailand (EGAT) is responsible for large dams that mainly have a hydropower purpose. Despite the many existing dams, in many regions of Thailand the agriculture and industry sectors require increased water supply.

Building of both large and smaller dams has encountered resistance in Thailand from local communities. Many massive protests have been organized, leading to extended delays and even cancelation of planned dam projects. In Thailand, almost no land is available for resettlement of affected communities. Thus, affected families are mostly compensated with cash payments. One problem is that compensation according to the official rules often is insufficient to sustain the livelihoods of affected families. This is due, partly, to lack of title deeds for the cultivated land, and partly to land value only being compensated in accordance with the relatively low registered land prices. Apart from the difficulties with the compensation, more profound disagreements and grievances exist, related to mistrust of the government, different visions for development, and differences in valuing of local land, crops, property and ecosystems (see examples from Thailand: Käkönen and Hirsch, 2009; Kuenzer et al., 2013; Nippanon et al., 2000 and from other countries: Costa et al., 2016; Riethof, 2017; Thorkildsen, 2018). Without development of planning processes that can integrate diverse perspectives and concerns, conflicts will most certainly persist and likely worsen.

The research presented in this thesis starts from the position that there is need to develop Water Reservoir Construction (WRC) projects in Thailand, despite enduring resistance from local communities. The assumption is that Participatory Integrated Assessment (PIA) might 
be a method to engage communities from the start, co-create knowledge and consult local stakeholders (Ridder and Pahl-Wostl, 2005). Reed et al. (2018) and Van Asselt and RijkensKlomp (2002) stress that participation should also involve decision-making power for the stakeholders to foster equity, trust and empowerment. This PhD project takes an innovative approach to testing the hypothesis by examining the use of models to foster participation of stakeholders, co-creation of knowledge and participatory decision making. Two types of models were constructed and tested for that purpose: one Bayesian Belief Network (BBN) and one Agent Based Model (ABM). To gain in-depth understanding of the process of participatory WRC planning, two cases were selected for comprehensive study: Wang Hip and Klong Klai. After documenting the history of the design process through field research, the models were used in community workshops and focus groups. A complementary study was done on nine dam projects in Thailand to gain understanding of the compensation processes and their outcomes for the affected families. The overall goal of the research was to gain insights into the functioning of PIA for sustainable and equitable WRC project development in Thailand.

\subsection{The research problem: Water reservoir construction planning and participation in Thailand}

The research problem addressed in this thesis is the effect of particular forms of participation on knowledge co-creation, decision making, trust, and WRC project outcomes in Thailand. This is an important topic to investigate because different forms of stakeholder participation can have very different outcomes for the stakeholders. Different forms of participation can facilitate particular types of knowledge co-creation, different degrees of involvement in decision-making, and building of different levels of mutual trust (O'Faircheallaigh, 2010; Bryson et al., 2013).

Beneficiaries of the WRC projects in Thailand are mainly 1) farmers who demand water for their crops during dry seasons, and regulation of water during rainy seasons; 2) residents who require water for daily life; and 3 ) industrial water users who need water for production processes. In all cases, their interests are to have enough water supply and also to mitigate floods.

These beneficiaries exercise their political power via their representatives in national and local elections to express their interests through the bureaucratic processes. Beneficiaries' interests are further communicated to the government and assigned to policy makers to propose WRC projects for social wellbeing. A government, according to Tully (2003), fulfils one of its core roles by using its power for producing social welfare. In Thailand, several 
government organisations at different levels (local and national) participate to balance benefits and impacts between different interests. Process owners (such as RID) may pay more or less attention to particular problems through creating arenas or platforms where stakeholders can participate by sharing interests, knowledge and concerns (Warner, 2006). However, the participation laws tend to focus on completing the process, rather than searching for insights and more acceptable solutions among stakeholders.

In response to conflicts, the Thai government initiated laws and regulations regarding participation in WRC project planning, and designed guidelines for implementing participation. After the Participation Act of 2003 and the new Constitution of 2007, it became a requirement for project owners to organize meetings with affected people, community leaders, and local governors during the planning phase, and collect data on their opinions about the project. The next stage is to complete a prefeasibility report (PR) exploring the engineering possibilities for the project, which obliges to investigate the geological landscape and other aspects in deeper details. This PR stage needs at least one major formal participatory meeting and three smaller meetings depending on the size of the area. Participation can take several forms, i.e. individual interviews, community meetings, focus groups, or talking to community leaders.

Since 2003, RID has conducted participation processes in many projects, but opposition to many projects persists. Many groups, such as NGOs, do not agree with the WRC projects and use the media for organising opposition networks (Chalermsripinyorat, 2004). And many land owners think that what they lose to WRC projects is greater than the positive impacts generated (Käkönen and Hirsch, 2009). For instance, upstream land owners may be forced to migrate from a reservoir construction area, receiving only meagre compensation in exchange for their loss of culture, livelihood and occupations. The Assembly of the Poor (AOP), the strongest NGO in Thailand with the highest negotiation power to debate against the government, has protested in front of the parliament in Bangkok garnering attention from TV news and other media for months (Chalermsripinyorat, 2004). As a result, the government cancelled many WRC projects in 2008 and requested greater participation on several projects. This reflects the strength and success of social coalitions among affected people and their networks.

In Thailand, affected people often refuse to participate in planning arenas arranged by government officials. The involved parties show much mistrust and misrecognition of knowledge and interests of others. Typically, people involuntarily displaced by government land acquisition valorise (and complain about the loss of) community livelihood, income from land-based activities and occupations, while also pointing to poor restoration of their livelihoods, and inequity in benefit sharing (Vanclay, 2017). Affected people are more likely 
to discuss things among themselves and with those they consider trustworthy, rather than with authorities who they do not trust (Van den Bos et al., 1988; Zhen \& Webber, 2020). Communities might ally with powerful NGOs, who usually pay attention to environmental and social issues, for stronger oppositions against WRC projects (Kirchherr, 2018). Pointing to incompatible trade-offs between economic benefits and socio-environmental impacts is a successful strategy used by NGOs to oppose projects (Buchanan, 2013). The NGOs gain power from support of the general public that becomes more aware about loss of fertile agricultural land and forests for dam constructions. They may claim that WRC projects do not lead to sustainable development, and engage in non-violent resistance aiming at cancellation of the project or fair (understand as greater) compensation (Del Bene et al., 2018). There is a dire need for development of more effective forms and/or methods of participation to improve this situation for the benefit of all stakeholders.

There is lack of research on actual practices of participation in WRC projects in Thailand and their effects. Hence, this PhD research project, which seeks to make some first steps in filling this void and exploring possibilities for introducing new approaches to participatory planning of WRC in Thailand. Potential practices and tools are proposed to improve participatory process, encourage co-designed options, limit uncertainties from proposed WRC projects, and introduce recognition for affected communities. Applications of the potential practices and tools aim to mitigate negative impacts and reduce conflicts between government and affected communities, including encouragement of social learning leading to more inclusive designs and equity in the outcomes of the WRC projects

\subsection{Conceptual approach: investigating participation}

The overall conceptual approach of the thesis focuses on the processes and outcomes of stakeholder participation in Thai WRC projects.

Three aspects of stakeholder participation in WRC projects will be investigated:

1. The forms, levels and aims of participation

2. Institutional organisation of stakeholder participation

3. The methods and tools that can facilitate co-production of knowledge and decision making (in particular BBN and ABM models).

Here follows a brief discussion of each of these aspects. 


\subsubsection{The forms, levels and aims of participation}

Conceptual thinking about participation started with the idea of the "ladder of participation" coined by Arnstein in 1969. Arnstein distinguished eight levels of participation, with "manipulation" being the lowest level, and "citizen control" being the highest level. The later conceptualization of, and discussion about, forms, levels and aims of participation can be expressed through five themes: co-creation of knowledge and consultation with local stakeholders; decision making, equity, trust and empowerment.

\section{Co-creation of knowledge and consultation with local stakeholders}

Knowledge co-creation and consultation with stakeholders are the backbone of Participatory Integrated Assessment (PIA) (Ridder and Pahl-Wostl, 2005; Hall et al.; 2016). The main idea is that experts and decision makers should engage with the stakeholders and exchange knowledge and views in order to mutually learn from each other. Stakeholders are to be informed about the project plans and can present their ideas and preferences (see Warner (2007) for more on this cognitive or social learning approach in water governance).

\section{Decision making}

According to Reed (2008) and Bruce and Madani (2015) knowledge co-creation and consultation with stakeholders is not sufficient for effective participation. Local stakeholders should also have some level of decision making power.

\section{Equity}

Marginalized groups are often not heard in participatory processes. It is essential that representatives of these groups, including women, youth, and the elderly, are actively involved in the consultation and decision-making process (Reed, 2008). Questions of social justice often play a role in dam construction projects, as negative effects for some communities and benefits for others should be weighted fairly in decision making (Thorkildsen, 2018).

\section{Trust}

Participation can be used to increase the legitimacy of government interventions (Etxana et al., 2015). However, trust needs to be established among all participants of the process for broad participation in exchanging knowledge, proposing alternative designs and negotiating about options (see Reed, 2008; Woodhill, 2010).

\section{Empowerment}

Several authors mention "empowerment" as a goal of participation: e.g. Reed (2008), Bryson et al. (2013) and Gregory (2000). Empowerment goes beyond decision making. 
Empowerment implies that local stakeholders have at least equal standing with regard to setting agendas, formulating options, and the decision making process.

\subsubsection{Institutional organisation of stakeholder participation}

Woodhill (2010) asserts that a proper incentive structure should be in place to enable and facilitate stakeholder participation. This includes financing of the process as well as education on participation. He gives the example of Australia where local Landcare groups came together to discuss local solutions to combat soil degradation. The structure, practice and culture of these groups focused heavily on learning. However, this neglected the structural causes of the land degradation at higher governance levels. Woodhill suggests that a "dialectical" interaction between governance levels is needed, resulting in a multilayered participation practice. Processes of participation therefore need skilful facilitation and coordination (Warner, 2007; Reed, 2008).

In Thailand there is the Community-Based Irrigation (CBI) method. It is designed to foster participation of local beneficiaries through co-creation of knowledge and negotiation about possible design options for irrigation projects. The $\mathrm{CBI}$ process is a participatory water resource planning method used at sub-watershed level and covering just a few districts. The $\mathrm{CBI}$ participants are representatives of various stakeholder groups assigned to share their knowledge and interests regarding potentials for existing water sources and new development projects. Local stakeholder representation in the $\mathrm{CBI}$ process helps raise awareness of problems and initiate agreeable solutions through facilitations by RID officials (RID, 2018d). The current research scrutinizes how the CBI method works in a case study and offers recommendations how it can be improved for application in other cases.

\subsubsection{Participatory modelling}

Models can be used to structure and better understand problems and likely outcomes of interventions to address these problems. Participatory modelling involves stakeholders in the model development, parameterisation and/or application. Participatory modelling for water resource projects should not only facilitate decision-making but also focus on promoting learning among stakeholders in water planning (Hare, 2011). In this research project, participatory modelling is used for two purposes.

First, participatory modelling is used to aid information exchange processes. In this role, models are used as a systematic process to inform and consult stakeholders, which is essential to enabling participation (Ridder and Pahl-Wostl, 2005). Bayesian Belief Networks 
(BBN) are used for this purpose. BBN are probabilistic graphical models (a type of statistical model) that represent a set of variables and their conditional dependencies via a directed acyclic graph. Bayesian networks are ideal for taking an event that occurred and predicting the likelihood that any one of several possible known causes was the contributing factor. BBN modelling can integrate engineering and socio-economic knowledge, including uncertain data from local stakeholders, and present them in sets of variables and relationships in a single network (Cain, 2001). Although BBN have rarely been used in early participatory WRC planning, it is a practical tool to gain information and consult local stakeholders on variables and relationships (McCartney, 2007).

Second, models can be used for ex-ante assessment of the effects of interventions. Kishor Mahato and Ogunlana (2011) noted that models have the potential to help policy makers manage conflicts and avoid negative impacts of proposed policies, e.g. if, in early WRC planning, the models can simulate stakeholders' behaviours for investigation of the dynamics surrounding predicted outcomes. Agent-based modelling ( $A B M)$ is particularly useful for this purpose. ABM is a class of computational models for simulating the actions and interactions of autonomous agents (both individual or collective entities such as organizations or groups) with a view to assessing their effects on the system as a whole. It combines elements of game theory, complex systems, emergence, computational sociology, multi-agent systems, and evolutionary programming. Monte Carlo methods are used to introduce randomness. Hare and Pahl-Wostl (2002) applied a participatory method for exchange of information among stakeholders, and used the information in ABM to predict the outcomes for designing and monitoring sustainable water resources interventions. Moreover, ABM is useful for PIA promoting stakeholder representation because it can combine behaviours into modelling (Pahl-Wostl, 2002). ABM can be a useful tool for ex-ante assessment of the equitability of project outcomes for affected stakeholders of WRC projects.

\subsection{Research objectives and research questions}

Greater and more effective engagement of stakeholders in determining alternative water resource interventions should be institutionalized in Thailand and elsewhere. To guide this process, research is needed that enhances understanding how variations in participatory processes lead to different outcomes. Therefore, this PhD project develops and investigates a PIA approach in Thailand to explore whether it can support water reservoir construction projects with a focus on sustainability. A PIA enables simultaneous investigation of participation policy and practice for WRC projects, particularly from the perspective of affected people. Having and using a customized PIA framework will enable science based 
improvements to participation policy and practice toward affected people, and more satisfactory outcomes for both dam planners and the population.

The main objective of this research project was to develop and apply a customizable PIA framework to evaluate participatory processes leading to more balanced outcomes that incorporate affected stakeholders' values and perspectives. To accomplish this, there are four sub-objectives as follows:

1. To propose a systematic participatory process for a potential project that includes micro-politics issues to improve stakeholder involvement.

2. To engage stakeholders in sustainability assessment and elicit their perspectives using participatory modelling.

3. To investigate ex-ante outcomes of proposed dams by integrating equity considerations and criteria relating to stakeholders' perspectives in agent-based modelling.

4. To create a framework and set of variables using language of valorisation from affected people's interests and knowledge for use in mitigating conflicts and reaching agreeable outcomes.

The main research question is:

How can Participatory Integrated Assessment (PIA) improve process outcomes of water resource projects in Thailand?

The four related sub-questions are:

RQ1.How are stakeholders engaged in water reservoir construction projects (WRC) and how do their inter-relations influence project outcomes?

RQ2. What role can participatory modelling play in eliciting and reconciling stakeholder perspectives in water resource planning?

RQ3.What are the impacts of WRC on affected stakeholders and what are possible solutions for negotiating better outcomes?

RQ4.How can different languages of valorisation in dam planning conflicts be recognized as relevant criteria in a WRC planning framework to enhance participation and compensation to affected people? 


\subsection{Methodological design}

To find answers to the main question and sub-questions, several research methods were deployed. These research methods included literature research (scientific publications, government legislation and project-related documents), case studies including focus group discussion and interviews, and participatory elaboration of decision models.

The case study sites of Wang Hip and Klong Klai were selected because they are middlesized dam projects in the planning phase. Both are typical of many projects that face opposition from the affected communities. The Wang Hip project planning was top-down and the planning of the Klong Klai project was according to the newly established Community-Based Irrigation ( $\mathrm{CBI}$ ) approach, thus aiming for more bottom-up project design. Wang Hip and Klong Klai are located in the same province where socio-economic factors, problems, and conflicts are similar. The two projects were running simultaneously until, in 2015, CBI was announced and Klong Kai was selected as a pilot project for the bottom-up approach, while in the Wang Hip case negotiation about compensation to affected people began. All this allowed comparison of the outcomes of two projects with divergent - topdown and bottom-up - approaches to key parts of the planning.

For each of the four sub-questions a specific research methodology was designed.

RQ1. How are stakeholders engaged in water reservoir construction (WRC) projects and how do their inter-relations influence project outcomes?

A stakeholder analysis was conducted in the two cases studies areas (see above). The stakeholder classification was based on political power and representation. Hence, consideration of how to organize participation including stakeholder selection criteria were important (Bots and van Daalen, 2008; Stringer et al., 2014). A theory on micro-politics was applied to analyse the participatory process and gain insight into how different perspectives and beliefs about the development projects generated conflicts among community groups based on their interests and worldviews (Horowitz, 2011). It included studying the background of the relation between the communities and the projects. Data was collected through semi-structed interviews and participant observation during the design process. It aimed to determine the stakeholders' attitudes about changes in livelihood due to the reservoir project. The questions related to the scope and valuation of socio-economic changes (Van de Kerkhof and Linnerrooth-Bayer, 2001; Stringer et al., 2006). 
RQ2. What role can participatory modelling play in eliciting and reconciling stakeholder perspectives on water resource planning?

A sustainable WRC framework was developed through Bayesian Belief Networks (BBN), using significant input from government and local stakeholders about variables influencing the positive and negative impacts of dam planning projects in economic, social and environmental terms. The framework sets core contexts and defines the level of acceptance by affected stakeholders as the endpoint of negative impacts, and enhanced farm income as the endpoint of beneficial outcomes. Appropriate field data collection methods were selected to study each indicator through a participatory process. Focus groups and community meetings were the key PIA methods used to involve stakeholders in developing the framework, guided by "what if" questions on probabilistic cause-effect relationships and populating conditional probability tables. Using GeNle 2.1 Bayesian software, the probability of impacts of a dam were computed based on local stakeholders' perspectives and concerns, and sensitivity analyses were performed to assess the most influential variables in the network. For validation, results were discussed with the local community, RID officials, and local governments.

$R Q 3$. What are the impacts of WRC on affected stakeholders and what are possible solutions for negotiating better outcomes?

An agent-based model (ABM) was built and a scenario analysis was conducted based on a combination of stakeholders' perspectives. To structure the $A B M$, results from RQ1 and RQ2 entered into an $A B M$ computer programme. The $A B M$ model is capable of simulating the impacts of building a dam on farmer income and level of satisfaction, where satisfaction of affected people is dependent on the level of compensation as well as uncertainty experienced during delays in a dam project. The ABM model simulates farmers' reactions to changing environments and other stakeholders, during the dam planning process and after dam building, on the basis of investment decisions, evaluation of satisfaction, and negotiation on compensation. To demonstrate the model, it was set up for the Wang Hip watershed area. Simulations were run for 30 years and the average and distribution of probabilities of 200 model runs were analysed. The predicted changes in accumulated patterns of farmers' incomes and satisfaction levels served to identify alternative compensation payments and effects of (minimised) project delays.

RQ4. How can different languages of valorisation in dam planning conflicts be recognized as relevant criteria in a WRC planning framework to enhance participation and compensation to affected people?

The processes and outcomes of compensation to affected communities of nine WRC projects were analysed and compared. Data collection was mainly based on project reports, EIA studies, project evaluations, government regulations, NGO reports and scientific 
publications. These data were complemented with field studies in three WRC projects. Cases were selected to represent, respectively, the situation before the Constitution of 2007 and projects started after the Constitution marking the move to a more participatory approach to project design. The World Bank (2004) Guidelines for the design of dam construction projects were used to evaluate the projects. Data was collected on the amounts of compensation requested, offered and paid. Data was also gathered on the issues raised by the affected communities, paying attention to the specific languages of valorisation used to describe the issues.

\subsection{Thesis outline}

This thesis on "Participatory Integrated Assessment of Water Resource Projects in Thailand" is presented in six chapters. This first chapter has presented an overview of the thesis, the research problem, conceptual framework on participation, research questions and research methodology.

In Chapter 2, the study of stakeholder engagement and influence in the planning of the WRC projects in Wang Hip and Klong Klai is described. The eight features of participation defined by Reed (2008) were scrutinized with questions derived from the micro-politics approach. The analysis provides insight into how micro-politics affects the different responses of the villages.

Chapter 3 documents the participatory establishment of a sustainability assessment framework and its application in the Wang Hip and Klong Klai cases. The assessment framework takes the form of a Bayesian Belief Network (BBN) which allows different stakeholders to contribute variables important to them, and their perspectives. The findings show how interventions and events affect project outcomes, helping social learning.

Chapter 4 presents the development of an agent-based model (ABM) and results from running it for assessment of the impact of dam building on farmers' livelihoods and satisfaction. Results from RQ1 and RQ2 informed the behaviour of different types of farmers under different water availability conditions and the requirements for a WRC project. The ABM model presents scenarios with different compensation strategies for affected stakeholders, resulting in insights into policy alternatives.

Chapter 5 contains our analysis of the compensation process and outcomes for communities affected by WRC projects. The recognition of interests and languages of valorisation were 
studied. The findings can be used by policymakers to understand the interests, livelihoods and worldviews of different stakeholders.

Finally, Chapter 6 presents the discussion and conclusions of this PhD project. It reflects on the findings, concepts and methodologies used, contributions made and, importantly, the implications and applications. Recommendations regarding participation in water reservoir projects are also included.

Figure 1.1 shows the logic and interconnection between the chapters. Chapter 2 describes two cases of water resource project planning processes in the South of Thailand. The two cases set the scene for the participation tools presented in Chapters 3 and 4 . Chapter 3 describes the development and use of BBN as a tool to co-creation options for the case studies introduced in Chapter 2. Chapter 4 presents the use of ABM as a tool to discuss impacts of water resource projects with stakeholders in one of the cases. Chapter 5 broadens the scope to nine water resource projects across Thailand to assess effects on displaced communities. Chapter 6, finally, brings together the insights gained from the different cases and research methods, draws conclusions, and discusses the research findings, methodology, and implications, as well as providing recommendations.

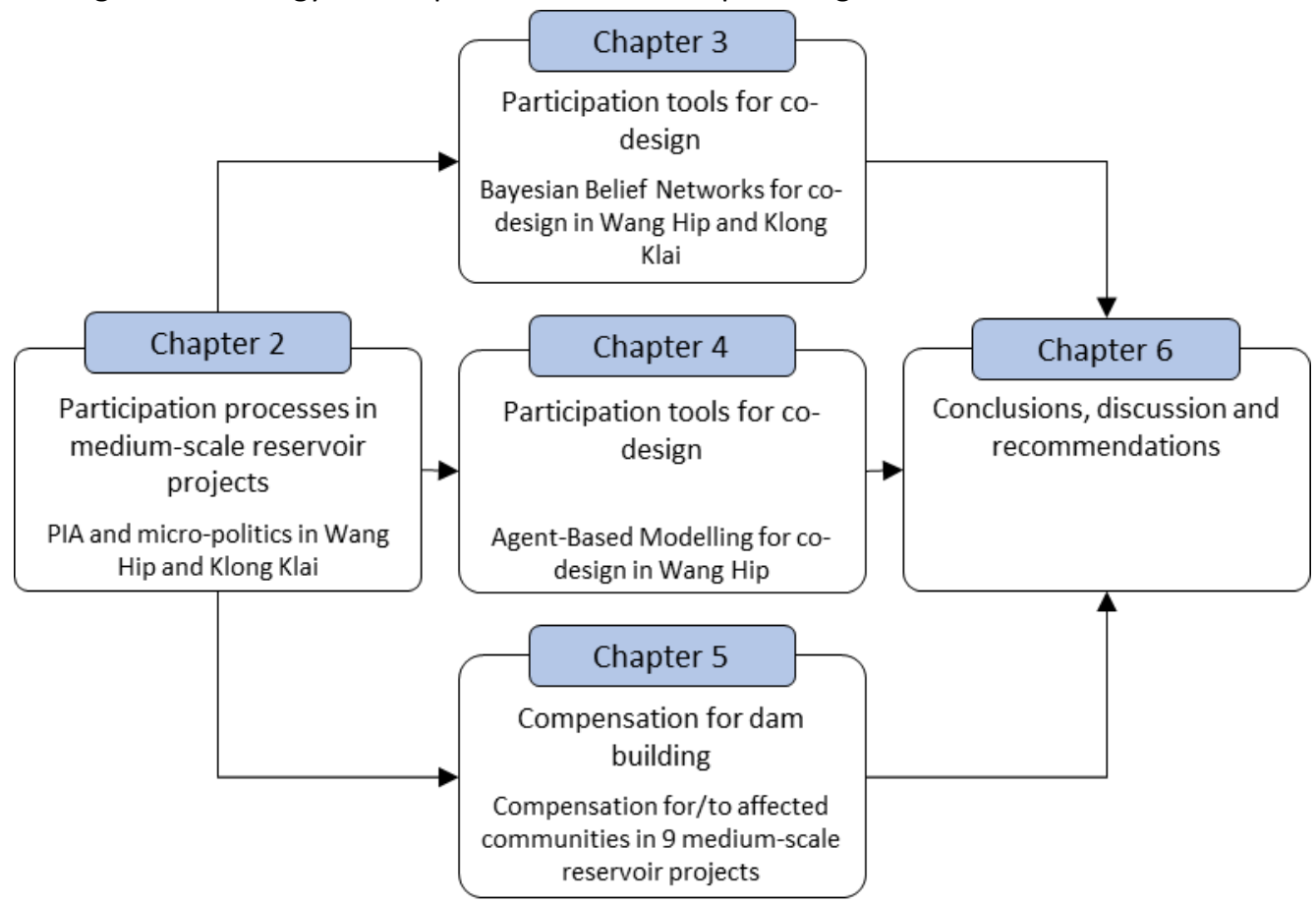

Figure 1.1 Framework of the research project: Participatory integrated assessment of water resource projects in Thailand. 


\section{Institutionalizing participation in water resource development: Bottom-up and top- down practices in Southern Thailand}

Substantive stakeholder engagement is increasingly recognized as essential for effective water resource development. Infrastructure development projects and strategies are however typically designed by engineers first before initiating discussions about impacts with stakeholders. In altering this sequence, designing meaningful participatory planning processes needs careful attention. This requires an innovative approach taking into account the institutional and discursive structure of the negotiation arena. This study uses eight features of participation and related micro-politics questions to scrutinize the design process of two water resource development projects in Thailand. The research shows that in one case some of the affected stakeholders were excluded, and in the other case, a lack of trust made one village obstruct the design process from the start. In both cases, the capacity to facilitate the negotiation about alternative designs and compensation was deficient. It is concluded that participation should be institutionalized and facilitated in a way that fosters accountable representation by all stakeholders, builds trust, and recognizes stakeholder interests and knowledge. The approach taken helps to understand the outcomes of the planning process and is useful to design planning processes that foster the accountable representation of all stakeholders and the recognition of their interests and knowledge.

Based on:

Singto, C., Fleskens, L., \& Vos, J. (2018). Institutionalizing participation in water resource development: Bottom-up and top-down practices in southern Thailand. Water, 10(6), 781. 


\subsection{Introduction}

During recent decades, governments have faced opposition to many water resource development projects they proposed to mitigate the problems of water scarcity, flooding, and seawater intrusion. Struggles surrounding water resource interventions have been explained by various authors, especially focusing on opposition by the affected people (Awakul and Ogunlana 2002; Magsi and Torre 2014; Rothman and Oliver 1999). Many large dam construction projects lack institutionalized processes of negotiation with all affected stakeholders (Dubash 2009). Participation in decision-making by all stakeholders may assist to set key problems, enhance legitimacy, respond to demand, negotiate interests, incorporate local knowledge, and compromise conflicts (Sinclair, Kumnerdpet, and Moyer 2013). Studying stakeholders' perspectives in the planning process prior to designing interventions can be useful in promoting sustainable development (Ricart and Clarimont 2017). However, opportunities for participation may not match the stakeholders' needs and interests (Manowong and Ogunlana 2006). Moreover, governance processes may limit opportunities for participation from an early stage (Gualini and Majoor 2007). Therefore, institutionalized forms of representation and negotiated decision-making need to be implemented to increase opportunities for community engagement (Jacob and Bernard 2013).

Several scholars have studied innovations in participatory decision-making processes, with a focus on building in bottom-up approaches from the design stage to increase inclusiveness and sustainability in natural resources management (Furlong et al. 2016; Reed 2008; Roncoli et al. 2016). It is important for initiators of new water resource development projects to understand the stakeholders' needs and interests in relation to positive and negative impacts of water infrastructure. In addition, the project managers have to identify key stakeholders for the prevention of potential conflicts and respond to their expectations (Bourne and Walker 2005). Fleskens and Stringer (2014) sketched the need for a multistakeholder analysis of impacts in deciding on land management and policy responses in order to: (1) Define and estimate effects of problems; (2) Assess and propose intervention impacts; and (3) Make and investigate responses for interventions. Stakeholders can be identified from what interests, power and attitudes they have regarding an intervention (Ricart, Ribas, and Pavón 2016). All stakeholders should be invited into the participatory process to share problems and knowledge, align interests and objectives, and devote time for building trust (Faysse et al. 2018).

To involve stakeholders in the design process of infrastructure projects, the Government of Thailand implements laws and regulations for participatory design processes. This started with the decentralization of the Thai government initiated by the Thai Constitution in 1997. 
The Good Governance Act 2546 (2003) and Prime Minister Office Regulation 2548 (2005) stipulate that each public organization needs to consult citizens, inform the public about the benefits of its mission, and adjust operational processes before starting projects to find an effective approach to mitigate potential negative impacts. Moreover, the Constitution 2550 (2007) defines that each public development project affecting the environment, natural resources, and health must conduct an Environmental Impact Assessment (EIA). These laws and regulations require the Royal Irrigation Department (RID) to inform and consult stakeholders about any water resource development project from its conception phase. However, the laws do not require any further collaboration nor defer decision power to the local communities (RID 2008). Therefore, the RID arranges the participation of local communities to meet the compulsory processes for medium and large-scale water infrastructure projects by informing stakeholders and by proposing alternatives as solutions to issues raised in community meetings or by community leaders, regional authorities, or other stakeholders.

However, poor outcomes of participation occur as a result of many factors, such as inadequacies in information provisioning, unequal power in decision-making processes and unclear procedures for negotiation compensations. As set out by the Eleventh National Economic and Social Development Plan (2012-2016), the RID needs to construct more reservoirs to increase the irrigated area with 200,000 rai (32,000 ha) each year. However, the RID has not been able to start several of the planned projects because of the opposition of local communities and stakeholders, such as environmental NGOs. As a consequence of the opposition, the RID developed 466,133 rai out of 600,000 rai of planned irrigated land (77.7\%) during 2012-2014 (RID 2015).

In response to the difficulties with gaining legitimacy and acceptance, the RID proposed to change their reservoir construction planning processes from engineer design to public participation design. Hence, in 2015 RID initiated the policy of Community-Based Irrigation (CBI) with voluntary representatives of local communities participating as "CBI members" in focus groups to work in a more bottom-up approach from the initial stages of water resource development projects. The Klong Klai basin was selected as the first pilot of the $\mathrm{CBI}$ approach to make a participatory water development plan. The CBI was expanded to five additional projects across the country during 2016-2018.

The present study is the result of the field research that the first author did as a PhD researcher at Wageningen University. The objective was to understand the participation, interests, and attitudes of the stakeholders in the planning process for developing a water development project and to compare two planning processes: one with the standard process (the dam project in Wang Hip) and one with the new CBI process (the water 
development project in Klong Klai). Both cases study sites are in Nakhon Si Thammarat Province, southern Thailand (see Figure 2.1). A micro-political approach was used to analyze the cases to see how the participatory process unfolded in each case and to see what factors determined the outcome of the process.

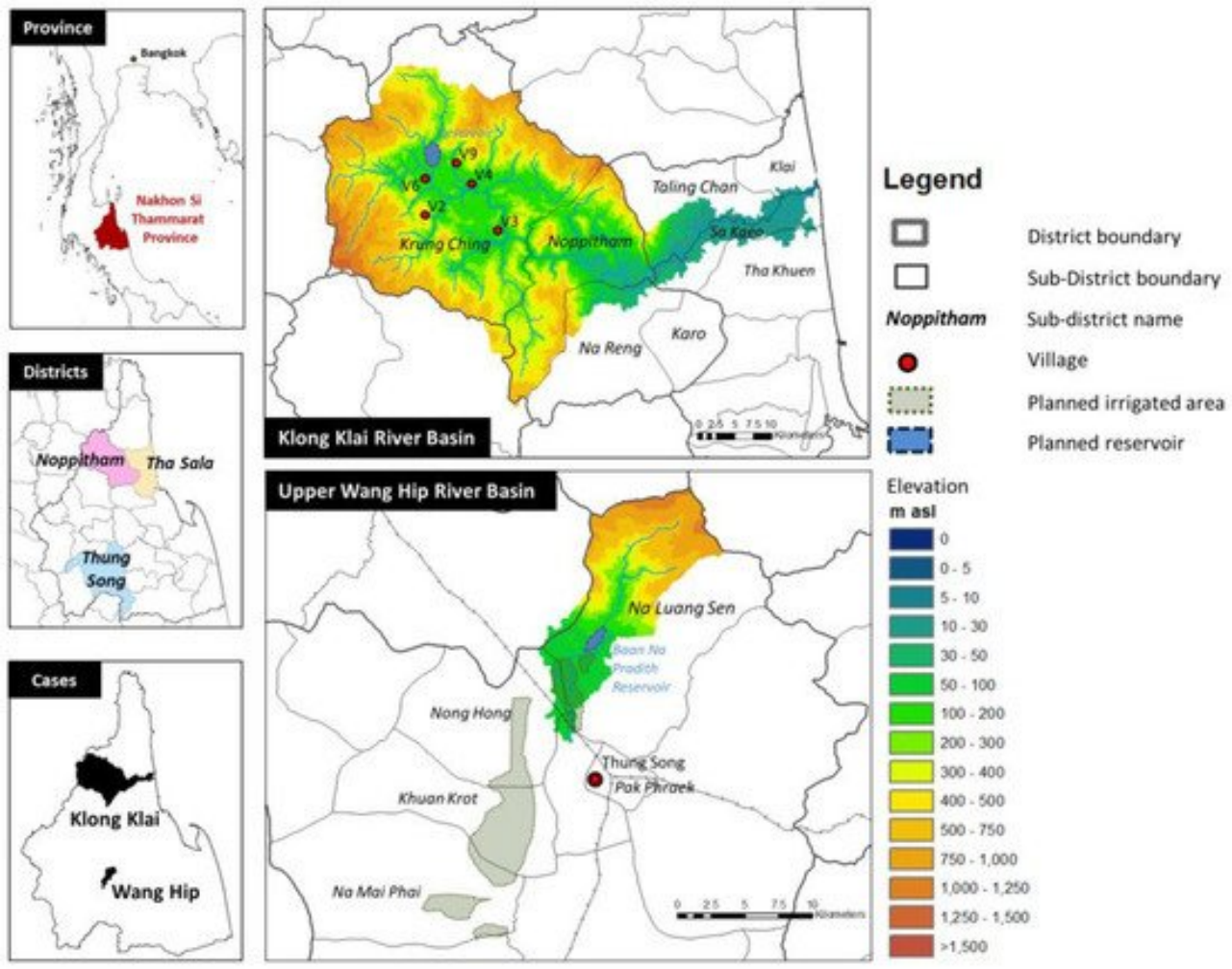

Figure 2.1 Case study locations in Nakhon Si Thammarat Province, Southern Thailand.

\subsection{Conceptual framework}

Participation of local stakeholders can have different forms, objectives, and degrees. Arnstein (1969) notes that the "ladder of participation" indicates the degree of delegation of decision making from government to local stakeholders. A high degree of participation of local stakeholders facilitates the inclusion of local knowledge and preferences, encourages social learning, helps to establish a social license for government plans, and can potentially empower the local stakeholders. However, the delegation might also imply a devolution of responsibility and costs to vulnerable groups (Kesby 2005; Morinville and Harris 2014; Ribot 2002). Planning processes with high degrees of local stakeholder participation encounter several contradictions and challenges: local interests might conflict with general and specific 
interests of other groups; local groups might have different and difficult to reconcile interests; representatives of interest groups might not be sufficiently accountable towards their "constituency"; not all local interest groups might be represented; some dominant group might set the agenda and issues to be negotiated; and negotiation processes tend to become lengthy and costly (Warner 2006).

To analyze multi-stakeholder negotiation on the planning of water infrastructure, the participation process and its institutional embedding were investigated, as well as the different interests and representation of stakeholders in the arena of negotiation and consultation. Reed (2008) reviewed what made participation work in environmental management and defined eight features as a basis to enhance effectiveness (Table 2.1). A dimension of micro power analyses was added to get a deeper understanding of the actual practices of stakeholder participation in the cases under study. A micro power analysis allows the identification of who is represented in the process, how accountability to the constituencies of the representatives works, who sets the agenda and objectives for the process, what knowledge and languages of valorization (Martinez-Alier 2003) are used in the debates, and how the negotiation between the representatives takes place (Barnes et al. 2004; Haselip 2011; Horowitz 2011; Rasch and Köhne 2016; Shinn et al. 2014).

Table 2.1 Overview of features of "best practices of participation" according to Reed (2008), with reflection from the point of view of micro-politics.

Features of “Best Practice Participation” Reed (2008) Micro-Politics Questions

\begin{tabular}{|c|c|c|}
\hline 1 & $\begin{array}{l}\text { Participation needs to be underpinned by a philosophy } \\
\text { emphasizing empowerment, equity, trust, and } \\
\text { learning; }\end{array}$ & $\begin{array}{l}\text { Who decides who will participate, and in whose } \\
\text { "project"? } \\
\text { How are different values and interests considered in } \\
\text { dialogue and negotiation in the decision-making } \\
\text { arena? }\end{array}$ \\
\hline 2 & Participation as early as possible; & Who controls the process? Who sets the stages? \\
\hline 3 & Stakeholders analyzed and represented systematically; & $\begin{array}{l}\text { How are the representatives of the different } \\
\text { stakeholders selected and by whom? }\end{array}$ \\
\hline 4 & $\begin{array}{l}\text { Clear objectives to be agreed with stakeholders from } \\
\text { the outset; }\end{array}$ & $\begin{array}{l}\text { Who sets the agenda? Is the agenda known and } \\
\text { accepted by all stakeholders? }\end{array}$ \\
\hline 5 & Methods should be appropriate; & $\begin{array}{l}\text { Is use made of multi-criteria negotiation? Who can } \\
\text { participate in the negotiation process? }\end{array}$ \\
\hline 6 & Highly skilled facilitation; & $\begin{array}{l}\text { Is mutual social learning and negotiation fostered by } \\
\text { the facilitator of the process? }\end{array}$ \\
\hline 7 & Local and scientific knowledge should be integrated; & $\begin{array}{l}\text { Who decides whose knowledge and values are } \\
\text { considered? }\end{array}$ \\
\hline
\end{tabular}




\begin{abstract}
Features of "Best Practice Participation" Reed (2008)
Micro-Politics Questions

8 Participation needs to be institutionalized.

Does participation have to be institutionalized, or can

it also be informal and spontaneous?

Representatives of interest groups might be formally elected by the members of the interest group they represent, present themselves, or be selected by the government agency. The representation functions through processes of communication, consultation, and accountability. The quality of this process relates strongly with the degree of legitimacy of the process and thus the acceptance of the reached agreements (Roncoli et al. 2016; Jeronimo, Rap, and Vos 2015; Ruiz-Villaverde and García-Rubio 2017). Actors forge alliances and agree on trade-offs between envisioned benefits and costs for different groups. Meanwhile, mindsets might change, and knowledge might be shared and gained ('social learning').
\end{abstract}

\title{
2.3 Case study selection and data collection
}

Two cases of participation practices in water infrastructure planning in Thailand were analyzed using the above-developed analytical framework. These cases were selected because they are situated in the same province and represent two different approaches to participation applied by the RID (Table 2.2). In the Wang Hip case, the intervention plan concerned the construction of a reservoir. This case followed a conventional approach, where RID presented a plan, and representatives of communities that participated in the process were informed and a negotiation on compensation was started. In the Klong Klai case, the new $\mathrm{CBI}$ approach was followed; RID did not have any pre-set intervention plan and started the design process with many rounds of consultation with representatives of local stakeholders. Importantly, this case is set in a context where a conflict originated from a former reservoir project that was proposed in 1996 but was cancelled in 2008 because of the opposition of affected people.

Field data was collected during various field visits in the period from 2007 to 2017. Official rules and regulations, practices, agenda setting, stakeholder's representation, and processes of negotiation were examined (Table 2.3). Furthermore, data from the Department of Local Administration under the Interior Ministry were reviewed. Moreover, legislation relevant to participation in medium-scale construction projects was analyzed from RID water resource planning manuals and annual reports. 
Table 2.2 Overview of basic information of the two cases.

\begin{tabular}{|c|c|c|}
\hline Basic Information & Wang Hip & Klong Klai \\
\hline Main problems & $\begin{array}{l}\text { Water shortage and flooding of town of } \\
\text { Thung Song and } 20 \text { villages } \\
\text { Water shortage for irrigation }\end{array}$ & $\begin{array}{l}\text { Water shortage for irrigation of } \\
\text { fruit trees in } 52 \text { villages } \\
\text { River bank erosion } \\
\text { Flooding } \\
\text { Salinization through sea water } \\
\text { intrusion }\end{array}$ \\
\hline $\begin{array}{l}\text { Water storage capacity of } \\
\text { proposed dam }\end{array}$ & 20 million m3 & 62 million $\mathrm{m} 3{ }^{* *}$ \\
\hline Total area of catchment & $50 \mathrm{~km} 2 *$ & 599 km2 \\
\hline Number of beneficiaries & 40,200 inhabitants & 44,000 inhabitants \\
\hline Benefited area & $\begin{array}{l}\text { The town of Thung Song with ca. } 27,000 \\
\text { inhabitants and } 3 \text { rural sub-districts }\end{array}$ & 52 villages in 5 sub-districts \\
\hline Main group of beneficiaries & $\begin{array}{l}\text { The population and industry of the town of } \\
\text { Thung Song and } 20 \text { villages } \\
\text { Farmers }\end{array}$ & $\begin{array}{l}\text { Farmers in the middle and } \\
\text { downstream sections }\end{array}$ \\
\hline $\begin{array}{l}\text { Residents affected by planned } \\
\text { dam and reservoir }\end{array}$ & 68 residents & 64 residents $* *$ \\
\hline $\begin{array}{l}\text { Water resource planning } \\
\text { approaches }\end{array}$ & Conventional approach & CBI approach \\
\hline
\end{tabular}

* Catchment area of upper Wang Hip; the town of Thung Song and irrigation areas are situated outside of this area.

** Refers to previous cancelled plans; the $\mathrm{CBI}$ approach has no predetermined plans.

Table 2.3 Research methods and participatory activities for data collection of the two cases.

\begin{tabular}{|c|c|c|}
\hline $\begin{array}{l}\text { Participatory Research } \\
\text { Activities (Both Cases) }\end{array}$ & Wang Hip & Klong Klai \\
\hline 1. Interviews & $\begin{array}{l}132 \text { questionnaires } \\
\text { A focus group meeting in } 2017\end{array}$ & $\begin{array}{l}79 \text { semi-structured interviews } \\
\text { Key informant interviews in } 2017\end{array}$ \\
\hline $\begin{array}{l}\text { 2. Participation in planning } \\
\text { activities }\end{array}$ & $\begin{array}{l}2 \text { site visits } \\
5 \text { meetings with stakeholders } \\
\text { during } 2007 \text { to } 2009 \\
3 \text { meetings and an excursion in } \\
2014 \\
2 \text { community meetings in } 2015\end{array}$ & $\begin{array}{l}51 \text { out of } 52 \text { village level meetings in } 2015 \\
4 \text { out of } 5 \text { sub-district level meetings in May } \\
2016 \\
\text { A drama performance about the Klong Klai } \\
\text { basin's water problems in May } 2016\end{array}$ \\
\hline
\end{tabular}

During February and March 2016, 79 residents (41 male and 38 female, from 30-89 years old) representing two groups in the Klong Klai basin, were interviewed. One group was comprised of 36 residents of four downstream sub-districts who were expected to benefit from water resource development; another group of 43 residents was from the Krung Ching 
area, where some residents feared the infrastructure might affect them negatively. The snowball method was used to select interviewees located close enough to the river to have a stake. Local students helped with translating local dialects. A semi-structured interview guide was used focusing on the following topics: (1) Socio-economic conditions, used water sources, and problems related to water; (2) How they perceived the situation and their preferred solutions; and (3) Their perspectives on their participation in water planning. The interviews were not recorded because of the sensitivity of the issues discussed. During the interview, notes were taken, which were complemented after the interview. The interviews were analyzed with qualitative and quantitative methods.

In the negotiation process at the case level, the representation of the stakeholders in the deliberation and decision-making process and the process of agenda setting were observed. Stakeholders' representation in each participation arena was investigated based on lists of participants of the meetings, and respective meeting reports were utilized to follow the results of each meeting. The background, participation process and negotiation of the Wang Hip project were collected from the EIA report and several project reports documenting two site visits and five meetings with stakeholders during 2007 to 2009, three meetings and an excursion in 2014, and two community meetings in 2015 (RID, 2016). At several these meetings, a total of 132 questionnaires were conducted to survey the participants' perspectives on the project; these were used to reconstruct the level of support for the project.

For the Klong Klai project, the main author participated in the series of meetings at the subdistrict and basin levels during March-June 2016. At these meetings, interviews with the stakeholders' representatives were conducted. Observations and opinions of stakeholders were used to assess the features and questions surrounding the process and discourse of participation. Information from the community meeting reports at the village level in 2015 was analyzed through observations of the bottom-up $\mathrm{CBI}$ focus groups about the water problems across the basin and in respective communities. Several interviews were performed with key informants, e.g., benefiting and affected residents, community leaders and $\mathrm{CBI}$ focus group members, about their individual perspectives on water resource problems and planning priorities. More interviews were conducted in March 2016 with a RID official responsible for the initial planning of participation in projects to cross-check the documents about the $\mathrm{CBI}$ process and its objectives, and on 12 May 2016 with another RID official about the $\mathrm{CBI}$ process, its results, and how to develop the results into the interventions. Additionally, in May, two key informants explained the Klong Klai history and the residents' opinions about the area's development and water-related problems, and how these changed over time. 
In this study, after a general introduction to the governance structures and procedures relevant to water resource development in Thailand, each case is first described in terms of the purpose, initiative and expected impacts of the planned project. Next, the main stakeholder groups' perspectives towards the project, the process that was followed, and its outcomes are presented. Finally, the cases are compared considering features that influence the success of stakeholder participation according to the conceptual framework, and the micro-politics questions that relate to each feature.

\subsection{Governance structures and procedures relevant to water resource development in Thailand}

In the Thai government governance structure (Figure 2.2), two community leadership structures of authority reside under the Interior Ministry related to water resource development: local administration (with representation at provincial and sub-district levels) and regional administration (at provincial, district, sub-district, and village levels). Under the local administration structure, sub-district administrations are headed by a president who is elected every four years in normal situations. However, during the study, Thailand was under military rule, banning elections at every level. The role of sub-district administrations concerns local economic, social, and cultural development, with a budget partly from local tax collections. They also make decisions on approval of communal land to be used for reservoir construction in the sub-district. Conflicts between different stakeholders are a priority in the sub-district level decision making. The presidents focus mainly on ensuring the community acceptance of projects to avoid opposition against a project during construction. Under the regional structure, a provincial governor is appointed by the Ministry. One level lower is the district, which is governed by the assigned district chief. At the sub-district level, the chief is selected by village headmen at the lowest level. Chiefs mainly are coordinators between regional governments and villagers. Their role includes resolving conflicts between the regional government and local administration and acting as the resident representative defending negatively affected residents. The headmen are elected for life and take office until their retirement at sixty years old, or earlier. They have a strong influence on villagers' perspectives towards reservoirs and other water infrastructure projects and in negotiating compensations. Hence, village headmen are the community leaders and are powerful actors in conflicts between the government and affected stakeholders. 


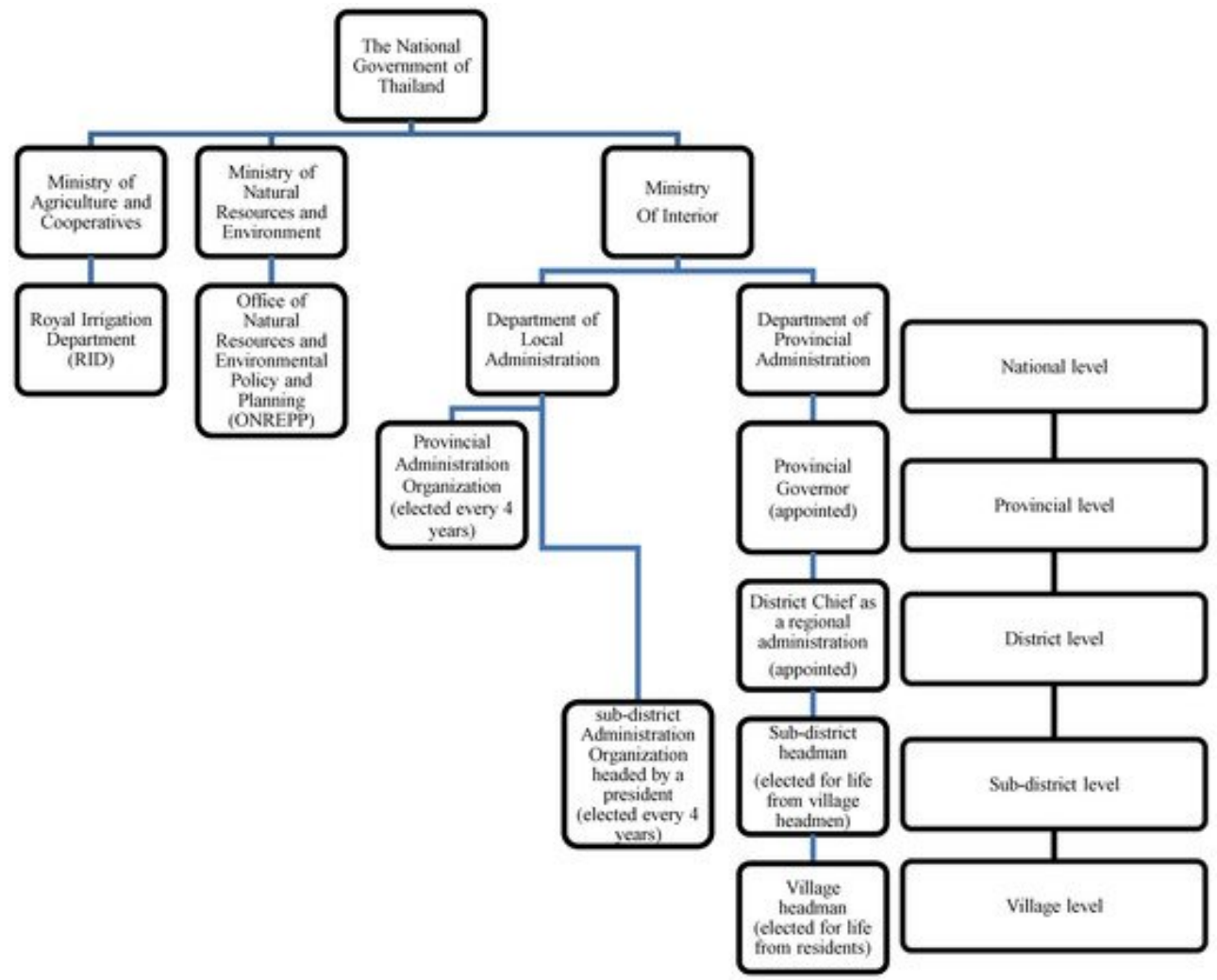

Figure 2.2 Multi-level governance structures relevant to water resource development.

The RID resides under the Ministry of Agriculture and Cooperatives and is the national agency concerned with the development of rural multi-purpose water engineering projects. The RID regional offices report directly to the national RID office in Bangkok. The RID needs the approval of the EIA by the Office of Natural Resources and Environmental Policy and Planning (ONREPP) under the Ministry of Natural Resources and Environment before requesting permission from the national government cabinet to execute the project (RID 2008). The EIA process is usually conducted by employing consultant companies and is subsequently presented for approval to the national cabinet. If the president of the subdistrict of the community of affected people agrees formally with the project, then the RID will announce officially to construct the reservoir or another infrastructure project. Therefore, community leaders can influence project implementation in two ways: through village headmen negotiating conflicts between affected residents and officials and through the sub-district administrator's approval of communal land use for the reservoir project.

In addition to the ONREPP, the Department of Water Resources and Forest Department are government agencies in water resource development. The first department is responsible 
for developing water resource policies at the national level. The latter department is responsible for forest conservation. The Forest Department must grant permission to RID for the construction of dams that are built in forest areas. However, in the early planning stage, these three departments do not coordinate activities.

\subsection{Results}

\subsubsection{The Case of the Wang Hip Project}

The idea for the Wang Hip project was proposed in 1990 by King Rama IV, who requested the RID to study the project to build a dam for which it needed an approved EIA. Two consulting companies were employed to finish the EIA in 2009. During the period 20072009, the consultants organized two site visits and five meetings with stakeholders to provide information on the project's benefits and inform the provincial governor about the progress of the elaboration of the EIA. In 2009, the EIA was not approved because of some incomplete information. Consequently, the EIA was revised and updated until it was approved in 2015.

The project aimed to build a multi-purpose dam in the Thung Song district, bringing water to the town of Thung Song for domestic and industrial use. The upper Wang Hip basin, where the reservoir would be constructed, is covered with forests, which include para-rubber (see map in Figure 2.1). Two weirs are present in the river. In the lower parts, the urban district is located as well as para-rubber plantations and homesteads, some of which are irrigated. The dam would have a storage capacity of 20 million m3. Presently, the town has an insufficient and irregular water supply with low pressure in the dry season, and only 13 out of the 20 villages are served by a piped water system; the rest use groundwater. In the town of Thung Song, some 27,000 inhabitants would benefit from improved water service. In the three rural sub-districts (Nong Hong, Khuan Krot, Na Mai Phai), the population would benefit mainly through an increased supply of piped water and irrigation extended from the current 160 ha used by 400 households and 2000 residents in three villages, presently served by the Baan Na Pradith reservoir with a capacity of 117,000 m3 to a planned 2080 ha of total irrigated land in 24 villages in four sub-districts. In total, the beneficiary population would comprise 40,193 people in 12,821 households (RID 2016). According to RID officials, the Wang Hip River contributes to the flooding of the Thung Song district in the lower (urbanized) part of the river basin during the rainy season (May-December). However, this is disputed by the upstream people whose land would be affected by the dam project. 
The dam project would negatively affect people because of inundation of the land of 68 residents with a total area of 150 ha, with 24 buildings and one para-rubber factory, pararubber plantations, and forest. The land holdings are partly on informally occupied forest land. Farmers, however, do sell this land without title (deeds) to other farmers against market prices.

The Main Stakeholders in the Wang Hip Case

Broadly, six main stakeholder groups can be distinguished in the Wang Hip case:

1.The RID who proposed the reservoir project. The RID is the project owner and controls the budget and implementation.

2.The regional government authorities. The Provincial Governor agreed with the reservoir. His deputy was the chairman of the first meeting that informed local stakeholders about the project. He visited the area on the 24th of March 2015 (as seen on the media, saying that he would support the project and solve the problems to complete the project). The district chief of Thung Song has been the chairman of most meetings.

3.The tap water plant, owned and managed by the Provincial Waterworks Authority-Thung Song, now serves 21,618 residents. They lack water in the dry season to satisfy their users' needs. It is their aim to provide better service to the 27,000 inhabitants in the town of Thung Song and 13 surrounding villages and to connect the seven villages more. The population in the town is projected to grow because of increased urbanization.

4.The population of the town of Thung Song and the 20 villages that would benefit from improved tap water services, represented by the provincial Waterworks Authority-Thung Song.

5.The farmers of the homesteads that presently use river water for irrigation of fruit trees and vegetables for their own consumption and selling on the local market, represented by their community leaders.

6.The affected farmers at the site of the reservoir. In total, 68 residents have land in the dam site and the area that is designed to be inundated by the reservoir. The affected farmers are supported by an NGO. Affected residents acquire project information mostly from the community leaders. Some affected residents state that they were not invited to assist at any information meeting and did not get any information from the RID. They did not accept the low compensation offered for the expropriation of their land. Some downstream people fear the dam might break or believe the RID should first use the existing two weirs in the Wang Hip River to obtain water.

The Negotiations about the Compensation for the Expropriation of the Land at the Dam Site in Wang Hip 
The local stakeholders were not consulted on the location of the reservoir. The RID designed the dam considering engineering, environmental, and socio-economic factors. The expected runoff flow into the reservoir was estimated to be on average 27 million $\mathrm{m} 3$ per year. Thus, the reservoir capacity of 20 million $\mathrm{m} 3$ would be almost the complete annual runoff at that point in the river.

The RID organized two site visits to meet and survey the potentially affected residents at their homes in 2008 and 2014 and ask about their willingness to move (Table 2.4). The surveys showed that the affected residents not willing to move decreased from 55 to 22 percent. The affected residents who stated they would be willing to move-in case RID provided them with fair compensations for their land-increased from 32 to 74 percent.

Table 2.4 Percentage changes of perspectives of affected residents in Wang Hip project from 2008 to 2014.

\begin{tabular}{|c|c|c|}
\hline Perspectives & $2008(\%)$ & $2014(\%)$ \\
\hline Not willing to move & 55.00 & 22.22 \\
\hline Willing to move if fair compensations are offered & 31.67 & 70.83 \\
\hline Move & 3.33 & 2.78 \\
\hline No comments & 10.00 & 4.17 \\
\hline
\end{tabular}

Source. Surveys conducted by RID after community meetings ( $n=60$ in 2008, $n=72$ in 2014).

From February 2015 to February 2016, five meetings with some of the prospective beneficiaries and affected residents were organized by the regional RID to negotiate with the resident representatives about the compensation offered for the land to be inundated. Not all residents were represented. In the first meeting of 25th February 2015, 14 men and 4 women attended. They expressed their concerns mainly on compensation for their lost livelihoods. One representative said: "We all want to know how RID will take care of us: please clarify the acquisition process, compensation regulations of homesteads and our plantations. We don't know where our new locations will be and if those are good for our plantations, and a clear indication of the reservoir location is also needed to inform us" (pers.com., 25-2-2015).

Some affected residents did not agree with the land compensation prices as they expected much higher compensations in return for the lost income from the land. The farmers required 500,000 baht per rai $(90,000$ US\$ per ha), but RID could only pay 230,000 baht per rai $(41,000$ US\$ per ha). The low prices were the result of official rules for the compensation, the first component of which was based on land purchase prices registered officially with the Land Department. Real market prices are much higher, due to the custom of underreporting transaction prices to evade taxation. The other component was based on the 
estimated annual returns from the crops on the land. The price was higher when trees were planted on the land, but the para-rubber is planted informally inside the forest and was thus not considered.

The solution for the low compensation was discussed in a meeting on 20 January 2016: the RID officials were able to offer a somewhat higher compensation, against the presentation of a land valuation report. The water plant manager was able to offer an additional amount of compensation per rai. The farmers in the lower part of the district offered to sell part of their land to the affected farmers. This opened the way for the approval by the Sub-district Administration Organization, after the National Cabinet's approval of construction. However, the affected community claimed they were not invited in the consultation process and started to intensify their protests against the construction of the reservoir with the help of a regional environmental NGO, making the project insecure. They used other, not recognized, languages of valorization, such as love for the forest and the intrinsic beauty of the river. They "dressed" the trees in the forest with yellow cloths (referring to Buddhist monks) to symbolize the value of the trees. The dam was not built as of the end of the field work (April 2018).

\subsubsection{The Case of the Klong Klai Project}

In Klong Klai, the construction of a medium-scale reservoir was first proposed in 1996 as part of a Southern Seaboard Development Project, to support industrial activities and expand the agricultural area under irrigation. The reservoir would be constructed in the Klong Klai River, a $70 \mathrm{~km}$ long river flowing through the districts of Noppitham and Tha Sala (see Figure 2.1). The storage capacity would be 62 million $\mathrm{m} 3$ and inundate 28 buildings and 95.2 ha of agricultural area in two villages, affecting 64 households in the Krung Ching subdistrict (Noppitham district). The initial plan raised strong opposition and was eventually cancelled by Cabinet Resolution in 2008. In 2013, a flood affected 730 people living near the river in 278 households and 312 ha of agricultural area. In the period 2010-2015, the RID only maintained small weirs and constructed some new weirs; however, in 2015, the RID took up the development of a new Klong Klai Mitigation Plan through the new bottom-up $\mathrm{CBI}$ process to address the water management issues in the basin for a current water demand of 39 million $\mathrm{m} 3$ per year, which is projected to increase to 49 million m3 in 30 years.

The average annual rainfall in the basin is $1879 \mathrm{~mm}$, which mainly falls during the monsoon (September-January) as heavy showers $(1384 \mathrm{~mm}$ ) followed by a dry period of several months. The average annual discharge of the river amounts to 614 million $\mathrm{m} 3$. The total 
number of villages in the districts is 52 , with some 44 thousand inhabitants. The upstream area (Krung Ching) is forested and partially used for para-rubber and durian plantations. The middle section is steep and narrow. Due to ideal climatic conditions and the availability of irrigation water, the banks of the river are used for the growing of the very highly valued durian fruit, with water pumped from the river. Unstable slopes, together with sand mining from the riverbed, lead to an elevated risk of landslides. A reservoir would enable better availability and scheduling of irrigation, act as a buffer for flash floods, and reduce flood risk and river bank erosion. Towards the coast, the topography flattens out, and apart from floods occurring annually because of monsoon rains, seawater intrusion is also increasing, mainly because of overdraft of groundwater. The mitigation of this issue is also required.

Interviews with 36 residents in the four sub-districts constituting the downstream area confirmed that rural livelihoods relied predominantly on marine life and tobacco, next to para-rubber plantations. Residents planted coconut palms, constructed shrimp farms near the sea, and grew para-rubber trees and durian fruit in the area more distant from the sea. Most respondents (53\%) reported to have changed their crops in response to market prices. For irrigation of crops, 56\% depended on groundwater, and others pump from the rivers. For the downstream respondents, the water shortage during the dry season (42\%), flooding (33\%) and insufficient tap water (25\%) were the main water-related problems experienced. In response to the drought, some farmers dig deeper wells to water their crops, while others waited for their village's headmen to participate in the project.

In the upstream area (Krung Ching), the residents lived near the forest area, some close to the river, where $42 \%$ of 43 respondents grew their crops on land without land title deeds, which leads to feelings of insecurity. They grew para-rubber and durian fruit using irrigation from the Klong Klai River (93\%). The residents staying in some villages further away from the river (58\%) experienced water shortages in the dry season. Landslides happened when flash floods occurred. The residents further away from the river did not think about what problems might happen in the next twenty years and they believed that not much would change. If there would be any problem, they expected to have a strong community negotiation power to improve their land tenure security.

\section{The Main Stakeholders in the Klong Klai Case}

There are five main stakeholder groups in relation to the Klong Klai project:

1.The RID that took a renewed interest in the Klong Klai basin to respond to stakeholderreported problems by exploring options for interventions. To circumvent the strong opposition witnessed in the earlier dam proposal, RID officials established a participatory planning process to develop $\mathrm{CBI}$ jointly with stakeholders. 
2.The regional government authorities-When RID re-entered the area in 2015, the CBI process was meant to be executed in a bottom-up fashion. Hence, collaboration was sought with authorities at sub-district levels (headmen and local administrators). At the beginning of a series of village-level meetings in 2015, neither provincial nor district governors were invited to attend the meetings because RID aspired the local communities to identify acceptable interventions without top-down influences.

3.In 2014, a group of farmers in the middle and downstream sections requested options to mitigate water shortage and seawater intrusion which, in turn, started the CBI pilot in 2015. An ex-village headman in the downstream area said: "Many villagers need the reservoir, but in the past, they were convinced by NGOs not to agree with the project. They had limited information about the benefits of the reservoir. Residents were easily persuaded by NGOs and elites who argued to avoid environmental destruction" (pers.com., 11-5-2016).

4.The potentially affected farmers at the site of the previously planned reservoir and their representatives. The reservoir would displace 64 households in Krung Ching, most significantly in village $\mathbf{V} 6$ which manifested strong opposition. Officially, most of the subdistrict is, since 1957, registered as a forest reserve area, and many local inhabitants have no title deeds. The village leader of $\mathrm{V} 6$ is the same person who led protests against the original dam project and is a Krung Ching representative. Profits from durian cultivation, both in the affected area and potential benefiting area, are very high at around 8400 US\$ per ha per year (OAE. 2016).

5.NGO; Assembly of the Poor. The affected residents protested the originally proposed project with the support of the Assembly of the Poor (the biggest NGO against dam construction in Thailand at that time). The protest was organized in Bangkok in 2002 by uniting protestors against other dam projects in a big march in front of the Parliament. The project was halted and eventually cancelled by Government announcement in 2008.

The Fruitless Negotiations for RID Intervention through the Klong Klai Mitigation Plan In 2015, the process followed the following steps. In a first session, the RID officials visited the area to inform community leaders and resident representatives about the background, objectives, and process to develop the plan; called for volunteers to contribute to the plan as CBI members in so-called "focus groups"; and, in this informal role, coordinate between villagers and RID officials and make an inventory of other residents' water problems. The community leaders and representatives proposed lists of $\mathrm{CBI}$ members from headmen and knowledgeable farmers. Second, a series of village-level meetings were arranged to study water problems and causes by discussing timelines and problem trees from residents' perspectives. These meetings were held in 51 out of 52 villages in five sub-districts, except V6 of Krung Ching. The third step involved sub-district level meetings to combine problems from the village level. These meetings could be held in 4 out of 5 sub-districts, except Krung Ching. 
In the second year (2016), water resource information in each sub-district was collected by the CBI members. In March, the RID arranged meetings in every sub-district to present the results of the former year and to remind villagers about their responsibility. These meetings were accomplished as planned, except for Krung Ching, where a representative argued that the $\mathrm{CBI}$ would bring conflicts to the area. An ex-CBI participant said in the meeting on 8th of March 2015: "If I participate with RID, I will be instrumental for RID to construct the dam. I will feel sorry about being accused" (pers.com., 8-3-2016).

At the end of March, the RID arranged a sub-district level meeting again in Krung Ching. This time the district chief of Noppitham District was invited to be the meeting's chairman. The V6 representative attended to insist that he did not want a large dam which he strongly believed featured in RID's hidden agenda. However, he would agree with the dam if it would be constructed more upstream, deeper in the forest. Expressively, RID insisted that the new plan would not take the old project into account. The meeting continued with several the village representatives reporting about problems being experienced, such as water shortages (V3, 4, 5, 9, 10), flash floods (V2) and landslides, and adhered to the need of a water resource development plan. However, there was considerable disagreement over interventions to address these issues. For example, V4 suggested weirs instead of a large dam, V5 wanted a pipeline from V6, but V6 argued that V5 could get water from V8. A representative of V3 asked for a dam. He said: "I do not understand why V6 is not mindful of the water shortage problem, we should have a dam in Krung Ching. We need water for our agriculture". V6 interrupted: "Can we exchange our land, OK?". The district chief concluded that "...Durian is an economic crop that can make much revenue for Krung Ching people, especially in V6, 7, and 8 . They are afraid that they cannot grow durian in newly allocated land" (pers.com., 27-3-2016).

In April 2016, the RID had an appointment with the sub-district headman to visit V6 and 9, the most disputed areas, but the headman called in the morning to stop the RID officials. Obviously, the V6 villagers were not satisfied with the $\mathrm{CBI}$ approach, and blamed RID for not following the proper bureaucratic steps and coming directly to villagers without the endorsement of the provincial governor or district chief.

Additionally, in May 2016, RID arranged a drama performance about the Klong Klai basin's water problems, performed by local children. The play's objective was to remind the villagers about water resource problems at the basin level and find approaches for their resolution. During the discussion after the performance, an upstream villager from Krung Ching said they had opposed the plans for a long time, and conflicts were to intensify as more people started growing out-of-season durian. A provincial parliament member 
explained that he built a sandbag and bamboo weir in the Nopphitam district to regulate water flow and suggested to construct many more weirs in other stream branches. Downstream villagers raised the issue of seawater intrusion and proposed some interventions for solving the problem. The Klai sub-district representative said that seawater invaded in groundwater wells that had been used for several decades because of reduced water flow in the river. He claimed that this problem could be solved by bamboo weirs and he did not agree with big dam construction. The Sa Kaeo and Taling Chan sub-districts argued that a water-gate or weirs should also be constructed in Taling Chan, in the downstream part of the river to stop seawater intrusion.

According to a RID engineer, the option of a water gate would provide water for only a relatively modest irrigation area of approximately 320 ha. The water gate would mainly serve for protection against seawater intrusion. For agricultural activities, farmers would have to pump up water to their fields themselves. The construction would require the evacuation of approximately 5 to 10 households. The suggestion had come up as an option during community meetings in 2013 in three sub-districts. Other options that arose as options from the CBI process would not be followed up by RID. These included the suggestion from $\mathrm{V} 6$ to construct a reservoir deeper into the forest that may not be allowed by the Forest Department.

\section{Comparison of the Case Studies}

The comparison of stakeholder's engagement and project outcomes is summarized in Table 2.5 With the conventional participatory process, the Wang Hip dam project was approved by the government in 2016, but it caused intense conflicts and opposition from the affected residents. The conflict is similar to what happened in the first Klong Klai dam project, where the lack of engaged participation led to intense opposition of the affected residents supported by the NGO network until the dam project was cancelled in 2008. RID started discussions about a second plan using the new $\mathrm{CBI}$ process which implied starting discussions with no preconceived plan. This initially led to confusion and mistrust as villagers suspected the RID would produce a plan for a dam, most probably the same plan as the first, cancelled plan. After much discussion, more trust has been built with most of the villages, and discussion has started on new locations for one or more dams and other possible solutions such as bamboo weirs. 
Table 2.5 Comparison of project implementation and project outcomes in Wang Hip and Klong Klai.

\begin{tabular}{|c|c|c|}
\hline $\begin{array}{l}\text { Project Implementation and } \\
\text { Project Outcomes }\end{array}$ & Wang Hip & Klong Klai \\
\hline 1. Project initiatives & Initiated in 1990 & First plan initiated in 1996 \\
\hline 2. Project milestones & $\begin{array}{l}\text { EIA was studied during } 2007-2009 \\
\text { EIA was revised and updated until } \\
\text { it was approved in } 2015\end{array}$ & $\begin{array}{l}\text { First plan cancelled in } 2008 \text { because of the } \\
\text { opposition of affected people } \\
\text { In } 2013 \text {, a flood affected } 730 \text { people in } 278 \\
\text { households and } 312 \text { ha of cropland } \\
\text { In } 2015-2017 \text { the RID took up the } \\
\text { development of a new plan through CBI } \\
\text { process }\end{array}$ \\
\hline $\begin{array}{l}\text { 3. Engagement of government } \\
\text { authorities }\end{array}$ & $\begin{array}{l}\text { The provincial governor visited the } \\
\text { area in } 2015 \\
\text { The district chief participated in } \\
\text { most meetings in } 2015\end{array}$ & NO engagement of government authorities \\
\hline 4. Project outcomes & $\begin{array}{l}\text { The dam project was approved by } \\
\text { the government in } 2016 \\
\text { Intense opposition from local } \\
\text { residents with no trust from } 2016 \\
\text { Local knowledge applied in the } \\
\text { opposition platforms }\end{array}$ & $\begin{array}{l}\text { The dam intervention was proposed by } \\
\text { locals far from the residential area in } 2017 \\
\text { More trust from locals after CBI approach } \\
\text { Local knowledge applied in the participatory } \\
\text { planning arenas }\end{array}$ \\
\hline
\end{tabular}

This section analyses the participation processes in the two cases studies. This analysis follows the eight features of successful participation (see Table 2.1). In the Wang Hip case, participation was used to inform local stakeholders and negotiate compensation. In the Klong Klai case, the recently introduced CBI participation method was used to have the local stakeholders discuss their water related problems, and then have them suggest and discuss possible solutions. In both cases, the process did not come to consensus over the intervention as in both cases a group of villagers opposed the project.

Feature 1 for successful participation, as suggested by Reed (2008), is about the philosophy of empowerment, equity, trust and learning. In the Wang Hip case, a group of potentially affected residents claimed they were excluded from the participation process. They fiercely opposed the dam building and were only willing to engage in dialogue if the dam and reservoir would not affect their land. This option was not on the table; thus equity, trust and learning did not happen. The CBI participation method in the Klong Klai case was supposed to foster success in planning by empowering local residents to propose and negotiate interventions. The RID, based on recommendations by community leaders and residents' representatives, assigned $\mathrm{CBI}$ members to participate in the planning. However, the representative of one village opposed the project, and only wanted to agree with a solution 
(the reservoir in the forest) that was not acceptable by the RID. The lack of trust of V6 in the government institutions obstructed the dialogue and learning.

Furlong et al. (2016) argue that stakeholders' expectations are better discussed at the initial planning stage (Feature 2). Smith and McDonough (2001) comment that determining options before participation means that stakeholders can only adjust details, but decisions on key issues have already been taken. In Wang Hip, the participation only started after the final design of the dam, and this clearly caused problems with the negotiation over compensation of the affected people. In Klong Klai, the $\mathrm{CBI}$ approach was expected to reap benefits from the early participation. It arranged the first participatory meetings without any specific proposal for the intervention. From the findings, there is a trade-off between entering an area with a blank plan in which case knowledge issues may surface, and a predetermined plan where the affected people did not have the opportunity to propose and negotiate alternative solutions.

For stakeholders to be identified and have proper representation (Feature 3), Reed (2008) proposes different stakeholder analysis methods. In the Wang Hip case, the identification of stakeholders and involving their representatives failed in the case of the affected villagers. In the Klong Klai case, the CBI practitioners identified the key stakeholders, but did not consider the different stakeholders' background, and paid little attention to relationships between stakeholders. The accountability of the appointed CBI members towards their "constituency" was not monitored. From a micro-politics perspective, representation surfaced as an important pitfall in both the cases. It was found that residents often followed instructions given by, or awaited endorsement of, community leaders. However, community leaders did not express strong support and showed little responsibility for the projects.

Clear objectives should be agreed upon with stakeholders from the outset of the participation process (Feature 4). In Wang Hip, the intervention was supported by regional and local administrations from the beginning. The participants of the planning process agreed on the agenda and objectives. However, some of the potentially affected residents were excluded from the consultation process. This led to fierce opposition to the dam project by these villagers. The RID came to Klong Klai with an open project without prefixed solutions. However, it was challenging to have stakeholders suggest possible interventions. The RID avoided speaking out in favor of any specific solution, waiting for stakeholders to raise the possible interventions. This lead to unclear objectives of the process to stakeholders in terms of interventions. Consequently, the villagers assumed from their knowledge and perceptions that RID would build a reservoir and would acquire their land. Negotiating in a politically tense context proved difficult (Gaventa and Valderrama 1999). 
Both cases show the key factors to be considered are trust, clear agendas from the outset and inclusiveness of the participation process.

According to Reed (2008), the methods and activities applied to foster participation should be appropriate (Feature 5). In Wang Hip, a conventional top-down process was followed. Given the contested nature of the proposed intervention, this was not an appropriate process. In Klong Klai, the RID deployed a new bottom-up process, but this process itself was opposed by $V 6$. The inventory of water problems through the $\mathrm{CBI}$ focus group members worked well; however, the outcomes did not lead to new validated alternatives for the intervention. In both cases, no negotiation about different alternatives came about. It shows the importance of well-structured and inclusive representation, recognition of different values, languages of valorization and interests, and methods to deal with the multi-criteria negotiation about project alternatives.

Highly skilled facilitation (Feature 6) is vital in guiding towards converging interests in participation (Hubacek and Reed 2009). In Wang Hip, the facilitation was successful, except for the fact that part of the affected people was not involved in the process. In Klong Klai, stakeholder feedback included criticism for not inviting regional officials, and not sharing meeting reports with the attendants. This was an indicator of suboptimal facilitation. On the other hand, the $\mathrm{CBI}$ process was started up successfully in 51 out of 52 villages, illustrating a dedicated effort. The absence of higher-level government authorities and lack of clarity on the interventions being on the table probably made it difficult to manage the process. Little social learning took place as only limited dialogue and negotiation on possible interventions materialized. The children's theatre proved to work well as way to facilitate discussion.

According to Reed (2008), local and scientific knowledge should be integrated (Feature 7). In Wang Hip, the affected people did not get clear information about the design and location of the dam. This hampered the dialogue on the design. In the discussions over compensation, local perspectives on the value of land were acknowledged and considered, perhaps helped by the relatively small number of affected people compared to the number of beneficiaries of the project. This increased the compensation offered; however, a group of potentially affected villagers continued to oppose the dam altogether. Their languages of valorization and interests were not considered. In Klong Klai, the $\mathrm{CBI}$ process was conducive to bottom-up ideas about potential interventions. Options, such as a water-gate and weirs, were considered interesting ideas by RID. In both cases, however, no real mutual social learning seemed to have taken place between communities and the RID staff.

Participation needs to be institutionalized (Feature 8). The process in the Wang Hip case followed the institutionalized process of informing and consulting stakeholders, offering 
limited scope for participation to influence the (technical details of) the project. Nevertheless, discussions about compensation ensued informally after a deadlock in the formal process. Moreover, regional government officials attended the meetings and supported the intervention. However, the affected community was excluded from the consultation process and fiercely resisted the dam construction. In the Klong Klai case, the RID anticipated that a customary top-down process might not meet stakeholder's needs and developed and piloted the CBI process. This case clearly illustrated that participation needs to be institutionalized. There was a lack of explicit political support for reaching harmony among stakeholders. When the district chief was invited, he did not explicitly show his position on the mitigation plan. The chief did not assign the headmen to support or compromise the conflict over the interventions. Subsequently, some headmen did not even participate to avoid agonizing over the affected residents.

Table 2.6 provides an overview of the above comparison of the participation processes in Wang Hip and Klong Klai according to the eight features of participation suggested by Reed (2008). Political power in representation needs more scrutiny of the process design to include accountable representatives into the arena. In facilitating participatory processes, careful consideration of stakeholders' interests is required, with a focus on generating an exchange of ideas, social learning, and a negotiation of interests. The complexity of these considerations calls for high quality facilitation and institutionalization of accountable representation of stakeholders in the arena for participative decision making.

Table 2.6 Comparison of the participation processes in Wang Hip and Klong Klai according to the eight features of participation suggested by Reed (2008).

\begin{tabular}{|c|c|c|c|}
\hline & $\begin{array}{l}\text { Features of "Best Practice } \\
\text { Participation" Reed (2008) }\end{array}$ & $\begin{array}{l}\text { Wang Hip (Top-Down } \\
\text { Approach) }\end{array}$ & Klong Klai (Bottom-Up Approach) \\
\hline 1 & $\begin{array}{l}\text { Participation needs to be } \\
\text { underpinned by a philosophy } \\
\text { emphasizing empowerment, equity, } \\
\text { trust, and learning }\end{array}$ & $\begin{array}{l}\text { Top-down approach } \\
\text { Informing local residents }\end{array}$ & $\begin{array}{l}\text { Bottom-up approach } \\
\text { Consulting local residents }\end{array}$ \\
\hline 2 & Participation as early as possible & $\begin{array}{l}\text { A pre-determined plan } \\
\text { Difficult to motivate } \\
\text { stakeholders to respond with } \\
\text { alternative solutions }\end{array}$ & $\begin{array}{l}\text { Discussion at the initial planning stage } \\
\text { Difficulty to identify options and } \\
\text { imagine effects or consequences }\end{array}$ \\
\hline 3 & $\begin{array}{l}\text { Stakeholders analyzed and } \\
\text { represented systematically }\end{array}$ & $\begin{array}{l}\text { Left a part of the opposition } \\
\text { outside the consultation } \\
\text { process }\end{array}$ & $\begin{array}{l}\text { Stakeholders' political background not } \\
\text { considered } \\
\text { Little attention paid to relationships } \\
\text { between stakeholders }\end{array}$ \\
\hline 4 & $\begin{array}{l}\text { Clear objectives to be agreed with } \\
\text { stakeholders from the outset }\end{array}$ & $\begin{array}{l}\text { The agenda of the project } \\
\text { and the participation was } \\
\text { clear }\end{array}$ & $\begin{array}{l}\text { An open project } \\
\text { Villagers did not trust the open } \\
\text { agenda }\end{array}$ \\
\hline
\end{tabular}




\begin{tabular}{|c|c|c|c|}
\hline & $\begin{array}{l}\text { Features of "Best Practice } \\
\text { Participation" Reed (2008) }\end{array}$ & $\begin{array}{l}\text { Wang Hip (Top-Down } \\
\text { Approach) }\end{array}$ & Klong Klai (Bottom-Up Approach) \\
\hline & & $\begin{array}{l}\text { Part of the affected villagers } \\
\text { did not agree with the } \\
\text { agenda }\end{array}$ & \\
\hline 5 & Methods should be appropriate & $\begin{array}{l}\text { No negotiation about } \\
\text { different alternatives, this } \\
\text { proved to be inappropriate }\end{array}$ & $\begin{array}{l}\text { The } \mathrm{CBI} \text { focus groups worked well, but } \\
\text { the outcomes did not lead to new } \\
\text { validated alternatives for the } \\
\text { intervention }\end{array}$ \\
\hline 6 & Highly skilled facilitation & $\begin{array}{l}\text { Able to generate a solution } \\
\text { accepted by the participating } \\
\text { representatives } \\
\text { Left an opposition group } \\
\text { outside the process }\end{array}$ & $\begin{array}{l}\text { Lack of clarity on the interventions } \\
\text { being on the table } \\
\text { (Consequently) difficult to manage } \\
\text { the process, exacerbated by complex } \\
\text { history }\end{array}$ \\
\hline 7 & $\begin{array}{l}\text { Local and scientific knowledge should } \\
\text { be integrated }\end{array}$ & $\begin{array}{l}\text { Few options for integrating } \\
\text { different types of knowledge } \\
\text { existed } \\
\text { No real mutual social } \\
\text { learning }\end{array}$ & $\begin{array}{l}\text { Conducive to bottom-up ideas about } \\
\text { potential interventions } \\
\text { No real mutual social learning }\end{array}$ \\
\hline 8 & $\begin{array}{l}\text { Participation needs to be } \\
\text { institutionalized }\end{array}$ & $\begin{array}{l}\text { Limited scope for } \\
\text { participation to influence the } \\
\text { project }\end{array}$ & $\begin{array}{l}\text { A lack of explicit political support of } \\
\text { regional politicians for reaching } \\
\text { harmony among stakeholders }\end{array}$ \\
\hline
\end{tabular}

\subsection{Conclusions}

Government plans for water infrastructure development often encounter stakeholders' oppositions even if beneficiaries outnumber the affected people. In top-down decision making, such opposition can only be dealt with through negotiations at an advanced planning phase, with the risk of failure leading to cancellation of the project. Embedding participation from the design stage seems to be a practical way to draw stakeholders into the exchange of ideas, social learning, negotiation of interests and the decision-making process. The Thai government has recently adopted the $\mathrm{CBI}$ approach as a bottom-up water resource development process to pre-empt project failure and foster more sustainable outcomes of interventions. However, such bottom-up processes may be hampered by some stakeholders refusing this opportunity to set their requests as an agenda and to negotiate project outcomes and compensation. In the presented research, micro-politics was used as a framework to analyze the institutional design and practices of representation and negotiation. 
The Wang Hip project's pre-determined aim to construct a reservoir to enhance water supply for domestic consumption and irrigation was finally accepted by the participating representatives and approved by the government but was fiercely opposed by a group of affected families that was not represented. The lesson drawn from the Wang Hip case is that a clear dam construction plan was on the negotiation table, allowing stakeholders to position themselves. However, the negotiation process did not include some of the affected families, leading to fierce protests.

In Klong Klai, the goal was to design a plan to mitigate flood, drought, and seawater intrusion problems through the new $\mathrm{CBI}$ bottom-up participatory planning process. This process was initially paralyzed by mistrust and conflict, originating from the former, cancelled, mediumscale reservoir project, and the misconception that this same project was the hidden agenda of the government for the new project. After several rounds of discussion, most villagers now engage in constructive discussion on the possible solutions.

Thus, the $\mathrm{CBI}$ approach showed several limitations: the open agenda was not communicated convincingly to most local communities, the representativeness and accountability of the $\mathrm{CBI}$ members were not clear, and the negotiation process did not allow for recognition of different languages of valorization nor mutual social learning.

Studying the $\mathrm{CBI}$ pilot contributed importantly to the understanding of the micro-politics of participation and the validation of the $\mathrm{CBI}$ process. Participation in water infrastructure planning can be improved by enhanced stakeholder's representation of all relevant stakeholders and ensure adequate accountability towards the groups they represent, and by explicitly targeting participation in agenda setting, including on the objectives, decisionmaking procedures and methods. A limitation of these recommendations is that the planning process might become more lengthy and costly. The current impasse in the two observed consultation processes suggests that a profound participation process is difficult to organize in a conflict situation, despite being indispensable for sustainable, equitable and viable water resource interventions. 


\section{Applying Bayesian Belief Networks (BBNs) with stakeholders to explore and co-design options for water resource interventions}

Bayesian Belief networks (BBNs) are a useful tool to account for uncertainty, and can be used to incorporate stakeholder understandings of how a system works. In this study, BBNs were applied to elicit and discuss local stakeholders' concerns in conflicts over water resource planning in two cases in southern Thailand. One concerned the construction of a dam proposed by a top-down project. The other concerned a bottom-up participatory process at catchment scale to assess the need for water resources interventions and explore perceptions on alternative design options. In the top-down project, the responses of participants during the elaboration of the BBN showed that potentially affected stakeholders were particularly concerned about limited consultation and lack of shared benefits, which led them to oppose the dam project. In the bottom-up project, local stakeholders expected and agreed with the benefits of a dam, proposing to locate the dam upstream of community land. The BBN method did not facilitate dialogue in the top-down dam building project because no alternative design options could be discussed and potentially affected stakeholders did not want to discuss compensation because of mistrust and differences in valuation of effects. In the bottom-up project the BBN method did facilitate dialogue on alternative intervention options and their effects. The replicable $B B N$ framework can support policy-makers to better understand water conflict situations in different stages of planning. Its application supports exploring a wider repertoire of options, enlarging the scope for more inclusive and sustainable solutions to water resource conflicts.

Based on:

Singto, C., Fleskens, L., Vos, J., \& Quinn, C. (2020). Applying Bayesian belief networks (BBNs) with stakeholders to explore and codesign options for water resource interventions. Sustainable Water Resources Management, 6(2), 1-17. 


\subsection{Introduction}

Water resources development may cause conflicts as stakeholders do not have compatible interests and may not easily reach consensus. To avoid paralysis of the planning process, stakeholders' interests need to be carefully considered. In order to find solutions, there is a need for stakeholders to find common ground in relation to problems and solutions in the early planning stages (Reed, 2008). This way, alternatives can be proposed in a participatory process, empowering stakeholders who have different backgrounds, interests, knowledge, and perspectives to share ideas and negotiate better outcomes. Empowerment requires more attention to be paid to decision-making in the planning process (Julian et al., 1997). For example, to safeguard that proposed interventions support equity, sustainability and efficiency, relevant evaluation criteria should be included (Bromley et al., 2005). Outcomes for stakeholders further depend on how they are included in the decision-making process, e.g. whether they are only informed, or consulted and have had the chance to co-design interventions and make decisions (Singto et al., 2018).

Dams are often presented to stakeholders as interventions that will provide benefits (e.g. more irrigated farmland, more water storage capacity supporting irrigation and flooding mitigation, and more secure water supply for urbanization). Nevertheless negative environmental and societal impacts cannot be neglected, and are commonly described in Environmental Impact Assessment (EIA) reports. However, several studies find that stakeholders whose land is inundated by newly constructed reservoirs lose farm income due to poor livelihood assets after resettlement on new unproductive land (e.g. Bui et al., 2013; Devitt and Hitchcock, 2010; Duarte-Abadía et al., 2015). Access to suitable agricultural land is crucial to set up a new livelihood after resettlement (Sayatham and Suhardiman, 2015). Moreover, dams might negatively affect farm income because the social capital needed to adapt to the new situation is often lacking in resettlement contexts (Tilt and Gerkey, 2016). These examples illustrate the concerns of affected stakeholders, which often leads to disagreement on positive and negative dam impacts. When concerns are adequately aired, solutions can be found. For example, Singer et al. (2014) mention that benefit sharing could be promoted, allowing project beneficiaries to reach out to affected stakeholder and mediate the negative impacts to their livelihoods.

In conflicts, affected stakeholders often claim that participatory tools are biased and limit their engagement in the dam planning process (Singto et al., 2018). Elicitation methods and discussions with affected people need to systematically improve to engage affected stakeholders (Van Asselt and Rijkens-Klomp, 2002). To enable solutions in deadlock situations, policy-makers should hence carefully design more participatory processes. This premise underpins Participatory Integrated Assessment (PIA) which entails the systematic 
measurement of participatory processes for improving project planning (Ridder and PahlWostl, 2005). Modelling may be one method that can be deployed in a PIA to further engagement, manage conflicts and avoid negative impacts of proposed policies (e.g. Mahato and Ogunlana, 2011), as ex-ante models can provide a safe environment for discussions about impact. Various models have been used with stakeholders to explore the likelihood of impacts and so support decision-making (Lynam et al., 2007). Bayesian Belief Networks (BBNs) are one such model that has been used in co-designing and planning of interventions (Bromley et al., 2005) but has so far rarely been applied in practice for dam planning. This paper poses the question: could Bayesian Belief Networks (BBNs) be a useful tool to facilitate participatory processes in conflict situations in dam planning projects?

BBNs are probabilistic models that represent a set of variables and their conditional dependencies. The relation between directly related variables is described in Conditional Probability Tables (CPTs). BBNs can combine socio-economic and environmental variables related to water into a framework and engage stakeholders in planning (Carmona et al., 2011). Applying BBNs can enable estimation of possible future outcomes based on many variables, and information about the relations between variables (in the CPTs) can be updated (Castelletti and Soncini-Sessa, 2007). BBNs can help estimate outcomes before alternatives are chosen and implemented (Levontin et al., 2011). Moreover BBNs can manage qualitative data which other models cannot do. In addition, BBNs permit use of incomplete data variables in the network (Bouejla et al., 2014). Uncertainty of impacts from alternatives can be addressed in BBNs to support the choice of agreed solutions (Phan et al., 2016).

Bertone et al. (2016) used BBNs to deal with incomplete data and variables by involving experts and linking qualitative and quantitative data together in the participatory study of water quality risk assessment of reservoirs, investigating the sensitivity of effects related to alternative interventions options of interventions. Likewise, Carmona et al. (2013) used BBNs as a participatory modelling tool in water management allowing policy-makers to better understand local perspectives and be better able to consider the most acceptable options. BBN tools can make it easier to reconcile the various valuations and knowledge of participants in a more hypothetical way, which relieves some of the problems of dealing with sensitive issues.

The above experiences show significant potential for applying BBNs in the context of water resources planning, and in particular to deploy BBNs as a tool to engage stakeholders in decision making in conflict situations. However, so far, BBNs have been developed as casespecific tools without considering whether models can be designed so that they can be adapted to explore and co-design options for water resource interventions in multiple 
places. Therefore, this paper aims to a) develop a general BBN framework that can be used in a participatory planning process with stakeholders for planning water resource development projects; b) apply the framework to two distinct cases to test the adaptability of the general framework and document its adaptation process in participatory sessions with local stakeholders; and c) assess, based on stakeholder opinion and expert knowledge, the BBNs and their usefulness in the planning process.

\subsection{Bayesian Belief Networks for dam planning projects}

BBNs are increasingly applied to support participatory decision making under uncertainty (Levontin et al., 2011), and are also becoming popular in water resources planning (Phan et al., 2016). BBNs can also be used for creating a framework to predict probability under uncertain situations (Roozbahani et al., 2018). One area of recent BBN application concerns decision-making, e.g. considering variables affecting stakeholder behaviour in an irrigation system (McKee, 2015). BBNs are also applied to find agreeable solutions for water conflicts among stakeholders; for example, by managing trade-offs between farming and environment to meet the EU Water Framework Directive targets in Spain (Zorrilla et al., 2010) and assessing the effects of a water pricing policy in northwest China (Mamitimin et al., 2015).

BBNs can be used when experts and stakeholders cooperate in developing graphical networks (Phan et al., 2016). Such networks can be used as a decision-support tool, facilitating intervention decisions based on enhanced understanding of the links between several variables (Hoshino et al., 2016). BBNs can also assess the impacts of proposed interventions as perceived by different stakeholders, which is particularly relevant in cases of conflicts over natural resources (Xue et al., 2017). In the case of uncertain or disputed impacts, tools need to be easily understood (and operated) by stakeholders, and allow them to include their knowledge and valuation in the assessment. This means that it is imperative to combine various sources of knowledge and not only allow numeric data (Phan et al., 2016). Stakeholder knowledge can for example inform the design of interventions for reducing uncertain expected negative impacts (Baillergeau and Duyvendak, 2016).

BBNs are mostly developed using a software program to understand key issues affecting the performance of a system that may be represented by a mix of quantitative and qualitative variables (Lynam et al., 2007). A graphical network of variables relates causes and effects (parent and child variables) and highlights their relationships by arrows linking between them. BBNs accommodate integration of variables with different scales (Ticehurst et al., 2007). In a BBN diagram, data for each variable is given in a CPT (Marcot et al., 2006). The 
relationships between variables defines the conditional probability in child variables (Levontin et al., 2011). When there is a lack of data, expert and stakeholder judgments can inform probability assessment for CPTs (Pollino et al., 2007). As such BBNs have the ability to integrate information from stakeholders as well as experts (Farmani et al., 2009; Keshtkar et al., 2013).

In developing BBNs with stakeholders, Bromley et al. (2005) used stakeholder consultation to construct preliminary networks incorporating stakeholder concerns through linking variables and determining states. These BBNs were then completed by collecting data for the CPTs. A CPT should have the fewest number of possible states to support ease of understanding (Cain, 2001; Mamitimin et al., 2015), particularly when eliciting expert knowledge (Chen and Pollino, 2012). To facilitate populating the CPTs with stakeholderelicited probabilities, Bromley et al. (2005) use single numbers as indicative percentages. Editing information in the CPTs is straightforward and helps users raise questions and consider problems and promotes stakeholder insight (Castelletti and Soncini-Sessa, 2007). Expert knowledge and field data reconciliation is a widespread method in constructing BBNs and populating CPTs, in which experts fill in information missing in field data (Mkrtchyan et al., 2015). Expert and stakeholder elicitation can be used to fill in CPTs when data is limited, and can be updated with quantitative or qualitative data for higher model accuracy as soon as more data becomes available (Phan et al., 2016).

Parameterization methods described by Pollino et al. (2007) can serve as guidelines to develop BBNs using qualitative and quantitative data and deal with data and knowledge gaps. In constructing a BBN, it is helpful to identify the endpoint of the model first. Subsequently, variables affecting the endpoint should be identified, and arrows should connect these variables to the endpoint in the network to study the impact of the variables' change. A further hierarchy of variables indirectly conditioning the value of the endpoint can be constructed, which should include interventions and procedural decisions as management parameters. Involvement of experts and stakeholders in workshops can help in parameterizing the CPTs. A BBN framework can be developed as a starting template to use in workshops, allowing stakeholders to discuss and define variables and states on each variable. The probability derived from stakeholder perspectives can be elicited by asking "What if" questions.

The BBN should ideally be validated with data from observations and/or measurements, but when empirical information is limited, sensitivity analysis can be used to analyse the variance distribution of critical variables. For example, GeNle BBN software has been used to analyse the sensitivity of variables influencing reliability of drilling for kick control operation (Sule et al., 2018). In addition, discussion with experts helps to identify the 
robustness of variables and to consider the reasonableness of the BBN (Hoshino et al., 2016; Flores et al., 2011).

\subsection{Methodology}

\subsubsection{BBN framework}

A BBN framework was developed following the steps of Bromley et al. (2005) for designing networks through stakeholder consultation. Water-related issues were identified from secondary data and related literature and were used to establish a preliminary framework of dam planning, notably resulting in interconnected variables describing both positive and negative impacts in economic, social and environmental terms. The secondary data was taken from manuals on water resources development in Thailand. Reviews of EIA reports were performed to grasp the main criteria and data shaping positive impacts (e.g. rainfall, water storage capacity, benefits to stakeholders such as more farm income), negative impacts (e.g. deforestation, displacement of stakeholders), and mitigation measures (e.g. resettlement, compensation). We also reviewed the concerns of affected stakeholders of dam planning in Thailand (Swain, 2004), Laos (Sayatham and Suhardiman, 2015), and Vietnam (Bui et al., 2013). Losing farm income is one of the crucial concerns causing conflicts in dam planning.

The preliminary framework starts with setting core contexts, and defines the level of acceptance of affected stakeholders as the endpoint of negative impacts and enhanced farm income as the endpoint of beneficial outcomes. This framework connects main processes and brings in a significant number of variables from government and local stakeholders to be taken in consideration. The core government agency tasked with water resources development in Thailand is the Royal Irrigation Department (RID). The conceptualization of the generic BBN framework was presented in a meeting on 2-05-2017 to four RID officials responsible for the two studied cases to discuss and co-determine water problems, to outline the preliminary framework, and identify critical variables. The preliminary BBN framework formed the basis for workshops in both the top-down and bottom-up case studies.

\subsubsection{Applying the BBN framework in the case studies}

The study was designed to understand the affected stakeholders' perspectives in conflict situations. Therefore methods of stakeholder consultation outlined by Bromley et al. (2005) 
and parameterization by Pollino et al. (2007) were applied in the two case studies in Nakhon Si Thammarat province, Southern Thailand (Figure 3.1). One case, Wang Hip, is a top-down project, where the government has set a plan to construct a medium-scale dam to supply more water to increase irrigated farmland, to produce tap water and reduce flooding in Thung Song municipality. Another case, Klong Klai, demonstrates a bottom-up approach, where the government has initiated a number of participatory meetings in search of agreed interventions to supply water for an increasing demand and to mitigate flooding, in which representatives of different villages discuss the options.

To adapt the general BBN framework to the local context, local stakeholder engagement was sought in upstream areas. Two workshops for each case were arranged in June 2017 to elicit and define the variables, their potential states, and to populate the CPTs with probabilities. "What if" questions, for example: "What are your concerns if a dam is built in the upstream area?" were asked for this purpose and, where relevant, variables were added for specific issues/concerns. Each workshop was held with ten selected participants to avoid discussions becoming excessively lengthy and repetitive. The first author acted as the workshop moderator together with a co-mediator, and four local students acted as support staff.

At the first meeting, the mediators outlined the workshop objectives and provided a basic description of BBNs to the participants. They then defined variables by discussing the preliminary framework, variables, and links. Flipcharts and post-it notes were distributed to the participants, and they were asked to write down their water problems and expectations with regard to benefits from interventions. Next, participants were asked to identify possible interventions such as dams and weirs, followed by the negative impacts that could result from those interventions - guided by "what if" questions. Hereafter, the staff collected and classified the post-it notes as groups of variables in the BBN. Subsequently, variables were grouped by economic, social, and environmental issues by the mediators. Participants were asked to focus on the negative impacts and tasked with agreeing on impact mitigation options. Following through cause and effect chains, the need for additional links between variables was considered. Questions included "Do you agree with the variables and links?", "Do you agree if variables are grouped together?", "Do you agree if this variable is added to connect those variables in terms of causes and effects?", "Do you agree to remove this variable because it is off topic?", or "Do you agree to include a link to connect these variables?". Finally, the mediators closed the first workshop by presenting a network with variables and links between them as the result of the day's deliberations. After the first meeting, the network was reviewed to align it with the general BBN framework, and some variables and links were edited. Moreover, laws and regulations for project planning were also added to the network. 
The second workshop in both locations was mostly focused on understanding the CPTs for each variable. The mediators stimulated participants to discuss states, and to populate the CPTs with probabilities. To kick off the second meeting, the mediators reminded the participants of the results of the first meeting, explained what edits were made to the network, and asked for acceptance. Then the mediators asked the participants to qualify the states of every variable in simple terms, e.g. low, medium, high, or alternatively as a binary yes or no. Flipcharts and post-it notes were used as the main tools to populate the CPTs. The participants were questioned about the likelihood of events, for example what is the possibility that a child variable will be in a particular state if the parent variables are in particular states. Through discussion the participants reached agreement on the probability of each state. Accordingly, the probabilities of states of the child variables were established, cumulatively adding up to 100 percent for each child variable. The states of root variables (variables with no further parents) were populated with equal probabilities. The mediators then summarized the results and finished the session. At the end of the workshops, the mediators asked the participants to express the usefulness of the BBN workshops.
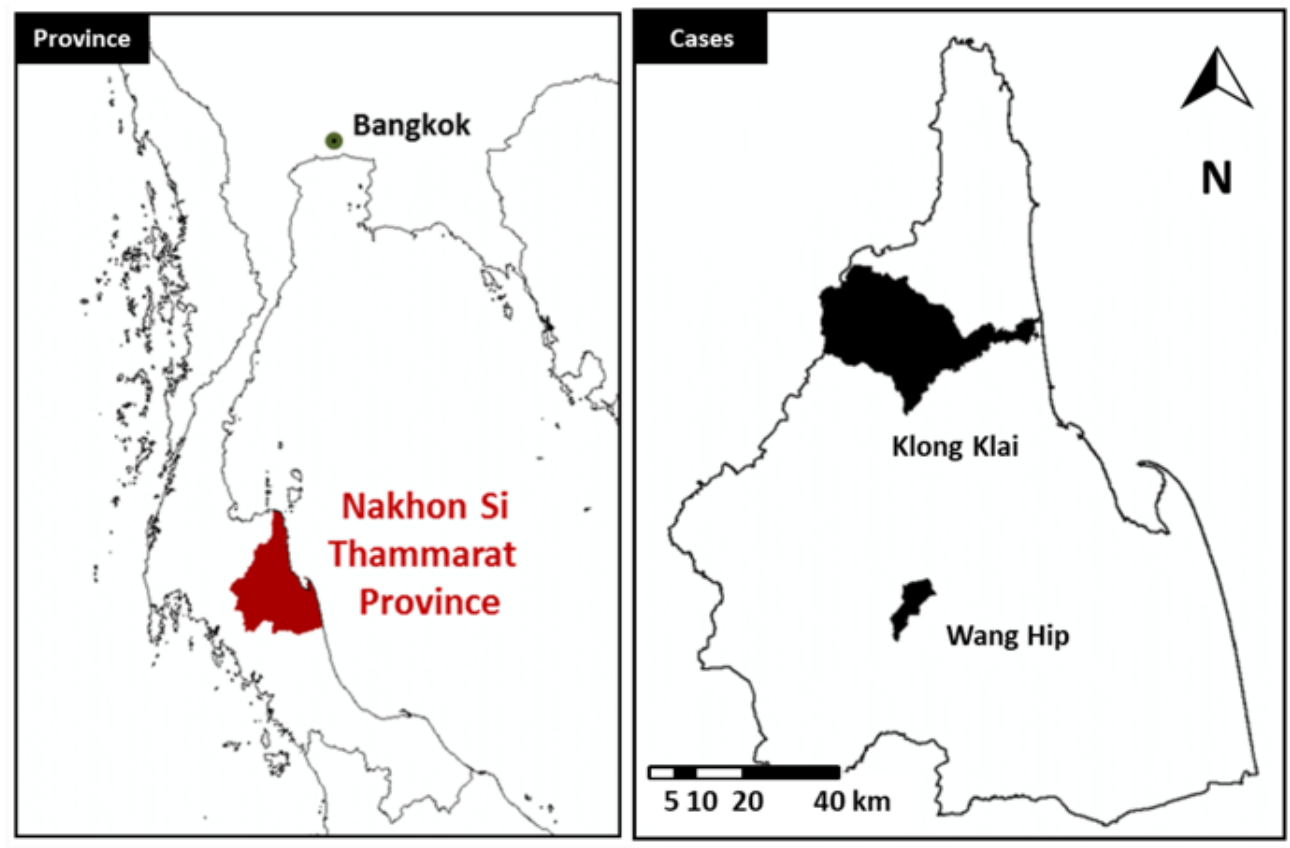

Figure 3.1 Case study areas.

\subsubsection{BBN software, sensitivity analysis and application for policy-making}

The data from the two case studies were used to create BBNs using GeNle 2.1 Bayesian software. Each variable was constructed from the start (the key water-related problems, drought and flooding, were identified from RID reports and literature, and reaffirmed in a meeting with RID officers and during the workshops with affected communities) to the 
alternative options for interventions, and to the end variables (more income and local acceptance), followed by inserting links between variables. The probability of impacts of a dam were computed based on local stakeholders' perspectives and concerns. We followed the manual of GeNle Modeler (BayesFusion, 2017) to run sensitivity analysis of the end variables (i.e. more income and local acceptance). We used the software to produce Tornado plots to assess how changes in influential variables effected the endpoint variable local acceptance for the case that a decision to build a dam has been made. This allowed us to verify the most important entry points for raising acceptance by affected stakeholders.

We paid particular attention to analysis of the negative impacts of the two case studies on affected stakeholders to see if the differences in variables affected acceptance. Apart from the sensitivity analysis, the general framework and the case study results were presented to experts during September and November 2017 to understand beneficiary perspectives. In the top-down case, the BBNs were discussed during interviews with the mayor of the municipality, the deputy president of the Thung Song sub-district and the sub-district's headman as representatives of beneficiaries and local politicians, and an environmentalist who had gained the trust of affected residents and opposed the dam project. In the bottomup case, we interviewed the president of the Krung Ching sub-district to discuss the variables and links in the BBN network.

\subsection{Results}

\subsubsection{BBN framework}

The developed BBN framework (Figure 3.2) explains several features of the variables and their relations, starting from the initiatives and following through a participatory planning process which takes stakeholders' interests and concerns regarding interventions into consideration. The outcome variables are the benefits (linked to objectives) expected from the interventions, as well as the level of acceptance by affected stakeholders experiencing negative impacts from the interventions (Table 3.1). 


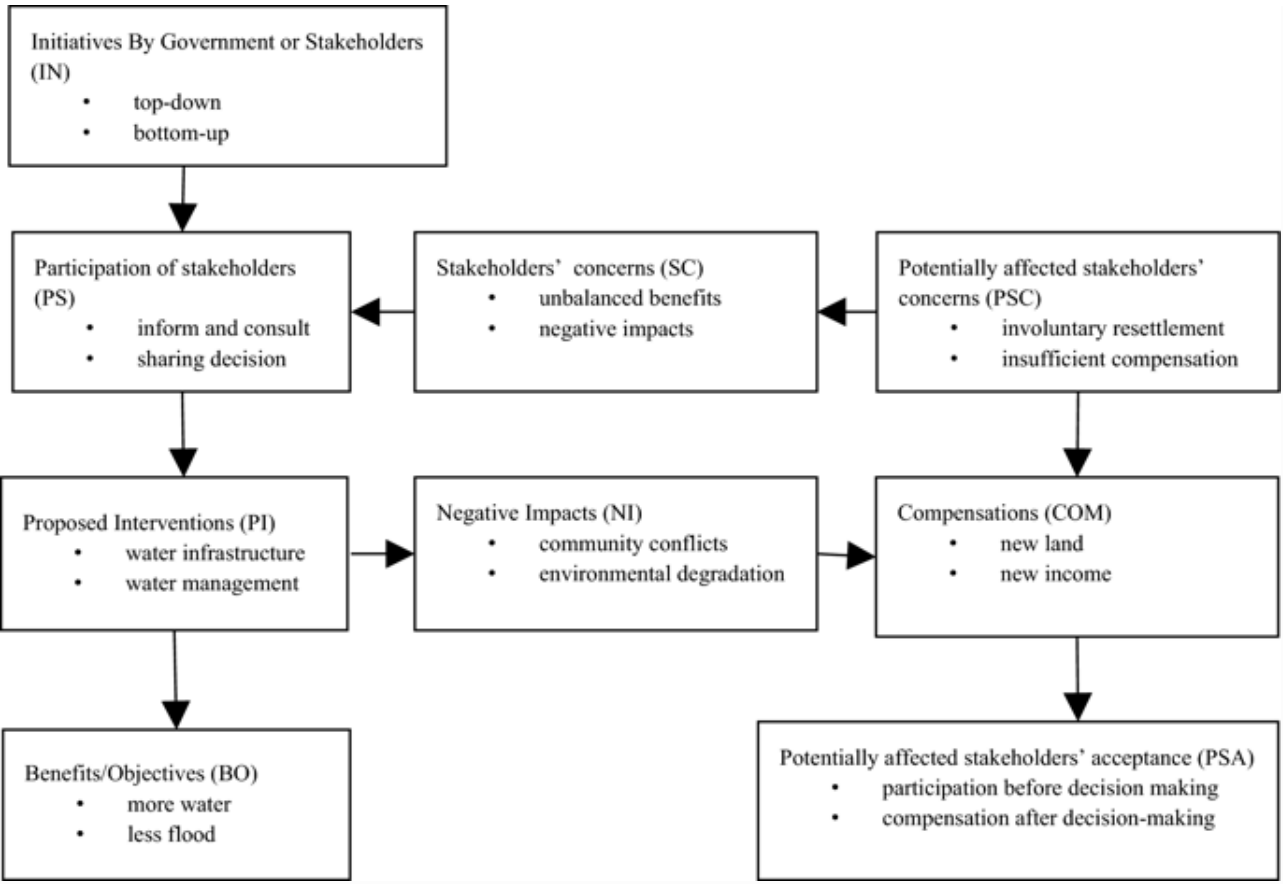

Figure 3.2 Bayesian Belief Network Framework of medium-scale water resources development planning distinguishing different planning features with attention to stakeholders' concerns.

Table 3.1 Planning features and key elements in two case studies.

\begin{tabular}{|c|c|c|}
\hline Planning features & Wang Hip case & Klong Klai case \\
\hline Initiatives (IN) & Top-down & $\begin{array}{l}\text { Bottom-up (emerging from the } \\
\text { process) }\end{array}$ \\
\hline Participation of stakeholders (PS) & Inform & Consult \\
\hline Proposed interventions (PI) & Dam & Dam, weirs, water gate \\
\hline Benefits/objectives (BO) & $\begin{array}{l}\text { More water for farming } \\
\text { More water for urbanization } \\
\text { Less flooding downtown }\end{array}$ & $\begin{array}{l}\text { More water for farming } \\
\text { Less flooding and land slides }\end{array}$ \\
\hline Stakeholders' concerns (SC) & $\begin{array}{l}\text { Unbalanced benefits } \\
\text { Negative impacts }\end{array}$ & $\begin{array}{l}\text { Unbalanced benefits } \\
\text { Negative impacts } \\
\text { Dam location }\end{array}$ \\
\hline $\begin{array}{l}\text { Potentially affected stakeholders' concerns } \\
\text { (PSC) }\end{array}$ & $\begin{array}{l}\text { Involuntary resettlement } \\
\text { Insufficient compensation }\end{array}$ & Involuntary resettlement \\
\hline Negative impacts (NI) & $\begin{array}{l}\text { Community conflicts } \\
\text { Environmental degradation }\end{array}$ & Community conflicts \\
\hline
\end{tabular}




\begin{tabular}{lll}
\hline Planning features & Wang Hip case & Klong Klai case \\
\hline Compensations (COM) & $\begin{array}{l}\text { New land } \\
\text { New income }\end{array}$ & Not yet discussed \\
& & \\
\hline Potentially affected stakeholders' & Participation before decision & Participation before decision \\
acceptance (PSA) & making & making \\
& Compensation after decision- & \\
& making & \\
\hline
\end{tabular}

\subsubsection{Adaptation of the BBN framework in the case studies}

The key variables from the BBN framework are applied in two cases in Wang Hip and Klong Klai (Table 3.2).

\section{Adaptation of the BBN framework in Wang Hip}

The Wang Hip project was proposed by the government in 1990, and after a very long EIA study it was approved in 2016. The local governments at provincial, district and sub-district levels agreed with the project but did not actively promote it.

When we asked the participants to identify intervention nodes for drought problems, they proposed better water management and maintenance of existing weirs. No one mentioned the dam. But the proposed dam intervention node was raised by the facilitator in order to be considered and the participants agreed for the dam to be included as one of the intervention nodes so as to discuss their concerns that the dam was likely to have low influence on water problems. When presented with the BBN framework, some affected stakeholders claimed that they were not aware of some of the activities in the 'participation variable' (IM3). One of the participants stated that "the dam intervention would not have been proposed if we had been involved in the project in the early stages" (pers. comm. 136-2017). They provided several reasons why the dam should not have been proposed for Wang Hip, including misleading objectives. The dam (I3) was proposed as an intervention to respond to downstream water problems (P2 and P3). The participants did not believe in the links between the dam intervention and its objective variables and provided low probability to all objective variables (O2 and $\mathrm{O} 3$ ).

In the 'compensation variable' (IM4), the affected stakeholders mentioned that "a higher compensation rate would not contribute significantly to our acceptance" (pers. comm. 176-2017), which contributed to the low probability of acceptance in their 'acceptance variable' (O4). The government pays compensation at the official land purchase rate (C4) monitored by the Land Department, which is significantly lower than market price. Moreover, official compensation rates for crops on the land are low, as rates do not consider 
crop yield in the long-term. Given the dominance of tree crops (rubber, durian) in the area, long lead in times before new plantations become fully productive are a major concern to farmers.

Table 3.2 Key variables in water resources planning as derived from the BBN framework.

\begin{tabular}{|c|c|c|}
\hline Variables categories & Wang Hip case & Klong Klai case \\
\hline \multirow[t]{4}{*}{ Objectives } & O1 Seawater intrusion mitigation & O1 Seawater intrusion mitigation \\
\hline & O2 Sufficient water & O2 Sufficient water \\
\hline & O3 Flood mitigation & O3 Flood mitigation \\
\hline & O4 Local's acceptance & O4 Local's acceptance \\
\hline \multirow[t]{3}{*}{ Interventions } & I1 Natural weirs & I1 Natural weirs \\
\hline & 12 Water gate & 12 Water gate \\
\hline & I3 Dam & I3 Dam \\
\hline \multirow[t]{3}{*}{ Intermediate factors } & P1 Seawater intrusion & P1 Seawater intrusion \\
\hline & P2 Water shortage & P2 Water shortage \\
\hline & P3 Flood and landslide & P3 Flood and landslide \\
\hline \multirow[t]{4}{*}{ Controlling factors } & C1 Crops & C1 Crops \\
\hline & C2 Population & C2 Population \\
\hline & C3 Rain average & C3 Rain average \\
\hline & C4 Law and regulations & C4 Law and regulations \\
\hline \multirow[t]{6}{*}{ Implementation factors } & IM1 Construction plan & IM1 Construction plan \\
\hline & IM2 Government approval & IM2 Government approval \\
\hline & IM3 Participation & IM3 Participation \\
\hline & IM4 Negotiation of compensation & IM4 Negotiation of compensation \\
\hline & IM5 EIA & MA5EIA \\
\hline & IMGDam site & IM6 Dam site \\
\hline \multirow[t]{3}{*}{ Additional Impacts } & A1 Promoting tourism & A1 Promoting tourism \\
\hline & A2 Reducing sand mining & A2 Reducing sand mining \\
\hline & A3 Tap water for urbanisation & АЗ Tap water for urbanisation \\
\hline
\end{tabular}

Strike-through variables were not considered or omitted from the BBN framework

\section{Sensitivity analysis for Wang Hip}

The benefits of intervention are shown in Figure3.3, where the farm income variable is set as a target variable. Sensitivity analysis was performed in GeNle to find the variables that most influence farm income. The darker red variables show highest impact on the target variable. The paler shades of red show variables with lower influence on the target variable. We found that the amount of rainfall affects uncertainty of farm income the most. The second highest impacts are exercised by the variables 1) drought, 2) water storage and 3) irrigation water. Among these factors, rainfall is not controllable, but the rest can be partially managed by interventions or policies. 


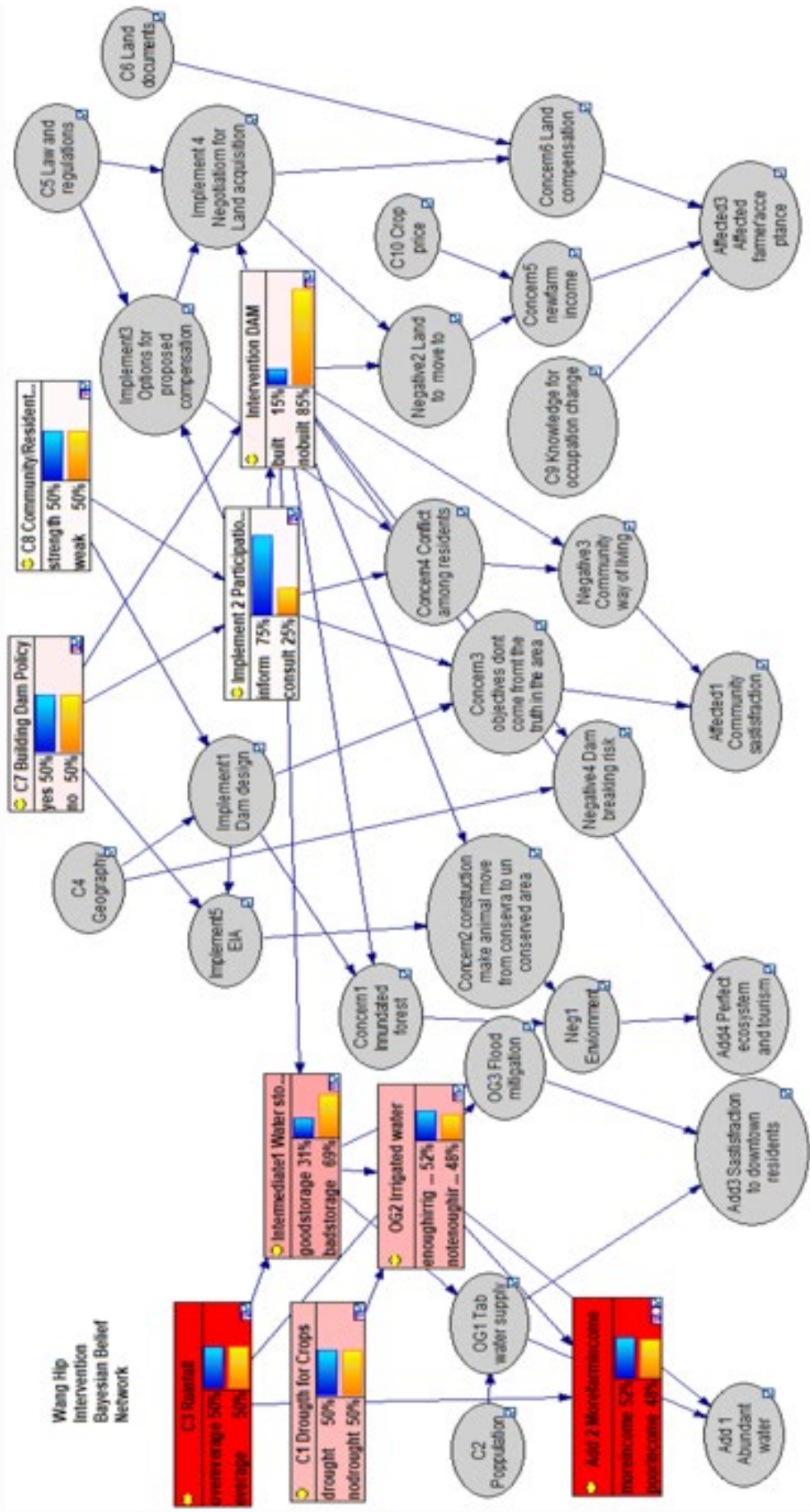

Figure 3.3 The BBN and key variables for beneficial impacts of the dam in Wang Hip. 
To analyse the negative impacts we set acceptance of the potentially affected villagers as the target variable (Figure 3.4). The sensitivity analysis indicates that the dam construction variable and dam building policy are the most influential variables. The second most influential factor is community rights, a variable characterising the power of local stakeholders over decision-making in government projects in their area, and the third is participation in planning. This means that if the dam is constructed, it decreases the acceptance of affected households. However, paying attention to the rights of local communities and engaging affected stakeholders in the participation process before making a decision can enhance the acceptance level. Pink variables represent the variables with less influence on acceptance, which are the variables related to compensation. The variables show that compensation can only result in a slight change in acceptance by affected stakeholders.

The sensitivity analysis (Figure3.5) shows that the affected stakeholders' acceptance is most sensitive to the decision to build the dam. This leads to uncertainty about farm income when they have to move; in particular, they fear the new land will not be productive enough to grow profitable crops. However if the dam is definitely built, strengthening the combination of 'new farm income', 'new farm land', and 'crop price' will render acceptance less sensitive.

\section{Adaptations of the BBN framework in Klong Klai}

The Klong Klai case describes a bottom-up water resources development approach at the river basin level. The initiative was framed by the villagers asking for some interventions. Participatory meetings at sub-district and village levels were arranged. At first, conflict was severe, but after two years of participation meetings conflict declined slightly. Stakeholders' concerns focused on the dam site location, community livelihoods, and conflict among stakeholders. 


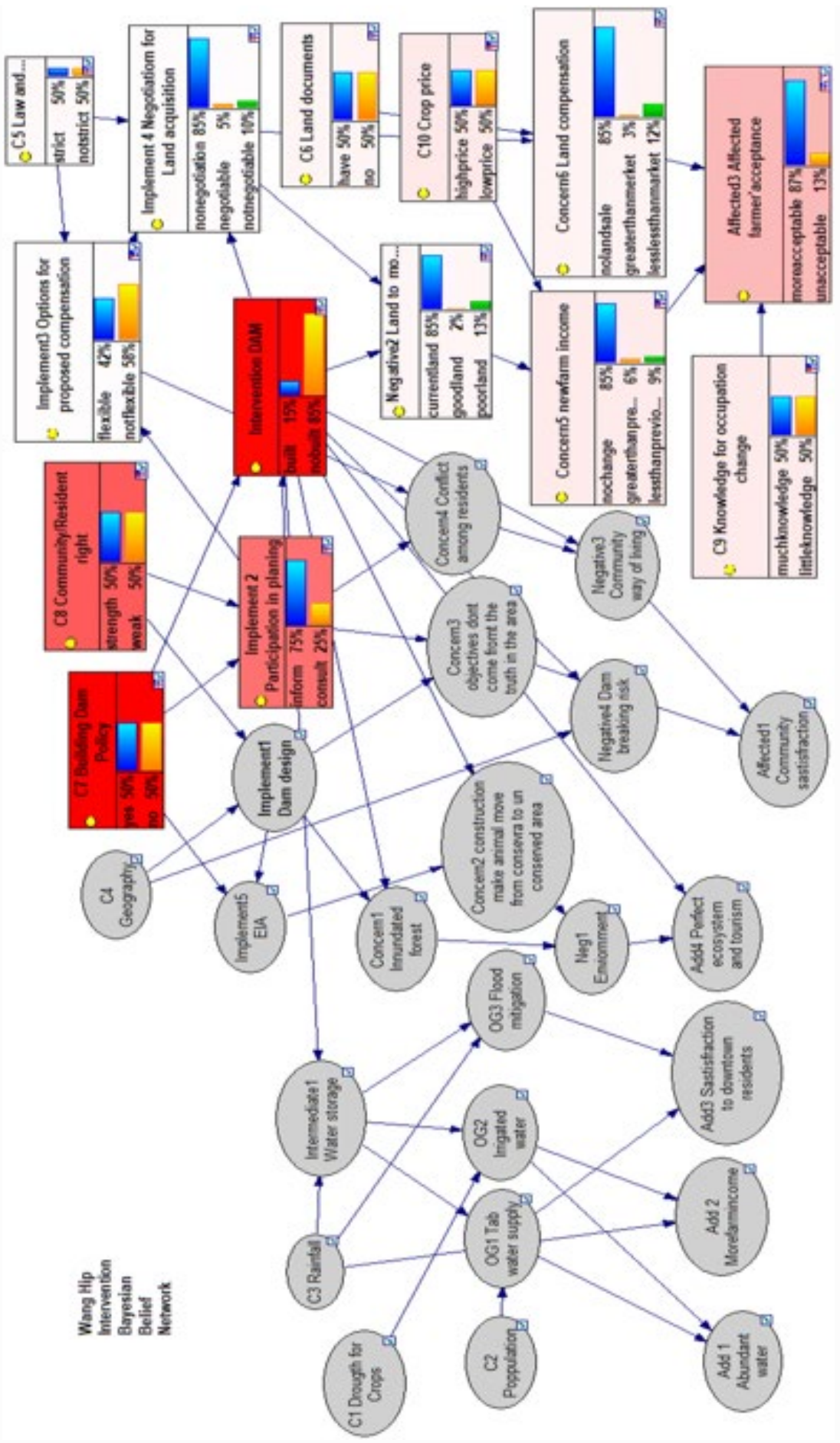

Figure 3.4 The BBN and key variables for the negative impacts of the dam in Wang Hip. 


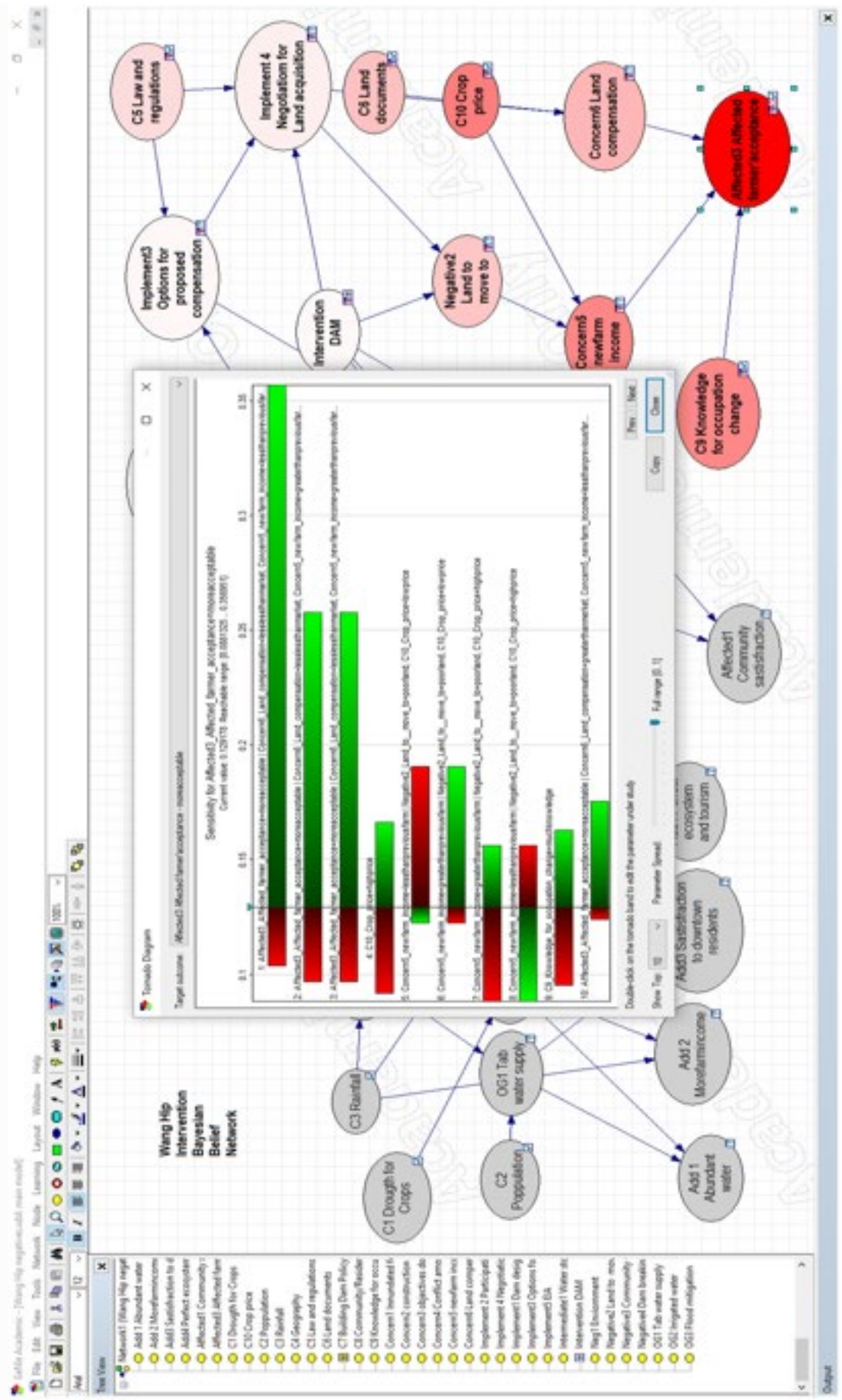

Figure3.5 Sensitivity analysis for the variables with the highest impact on local stakeholders' acceptance in Wang Hip. 
Droughts and floods were identified as the main problems and were defined as starting nodes. Then we asked participants to explain their expectations if those problems were solved; the answers pointed to increased farm income, which was set as an end node of the benefit nodes. We then asked participants to think about possible interventions to put nodes in between the problem and expectation nodes. The participants identified bamboo weirs (I1) which were built in a sub-district nearby by the community and local networks. Better water management and maintenance of existing weirs were proposed next, followed by a water gate (12) and finally a dam (I3) was mentioned by a participant. Seawater intrusion mitigation (O1) was added as one of the objectives or benefits in the BBN, but the main aim remained to increase water storage capacity for enabling the cultivation of higher yielding crops (C1). Local stakeholders preferred to select the dam location. So the 'dam site' variable (IM6) was added in the workshops. The stakeholders showed uncertainty concerning livelihood options and concern that relationships within the community may be changed. The sense of community and concerns over the quality of farmland meant that they were not willing to relocate. The local stakeholders felt uncomfortable discussing compensation, saying that compensation should cover total farm income from their crops. In their opinion, the compensation rate may not be high enough to sustain their life in the long run or not enough to settle on new farmland.

\section{Sensitivity analysis for Klong Klai}

A sensitivity analysis was performed using the GeNle software to investigate the variables with the greatest impact on the farm income of beneficiaries and affected stakeholders' uncertainty concerns. As shown in Figure 3.6 when we set farm income as the target variable, the different shades of red show that rainfall, water reservoir, and water storage are the variables that most influence farm income. The second most important variables comprise the dam policy, drought for crops, and seawater intrusion. These variables are similar to the Wang Hip case, except seawater intrusion.

The sensitivity analysis of variables determining negative impacts on affected stakeholders shows that dam construction, government approval, and the proposed intervention by the community have the largest effect on the affected stakeholders' acceptance (Figure 3.7). The next most influential variable is the affected stakeholders' participation in the planning process. 


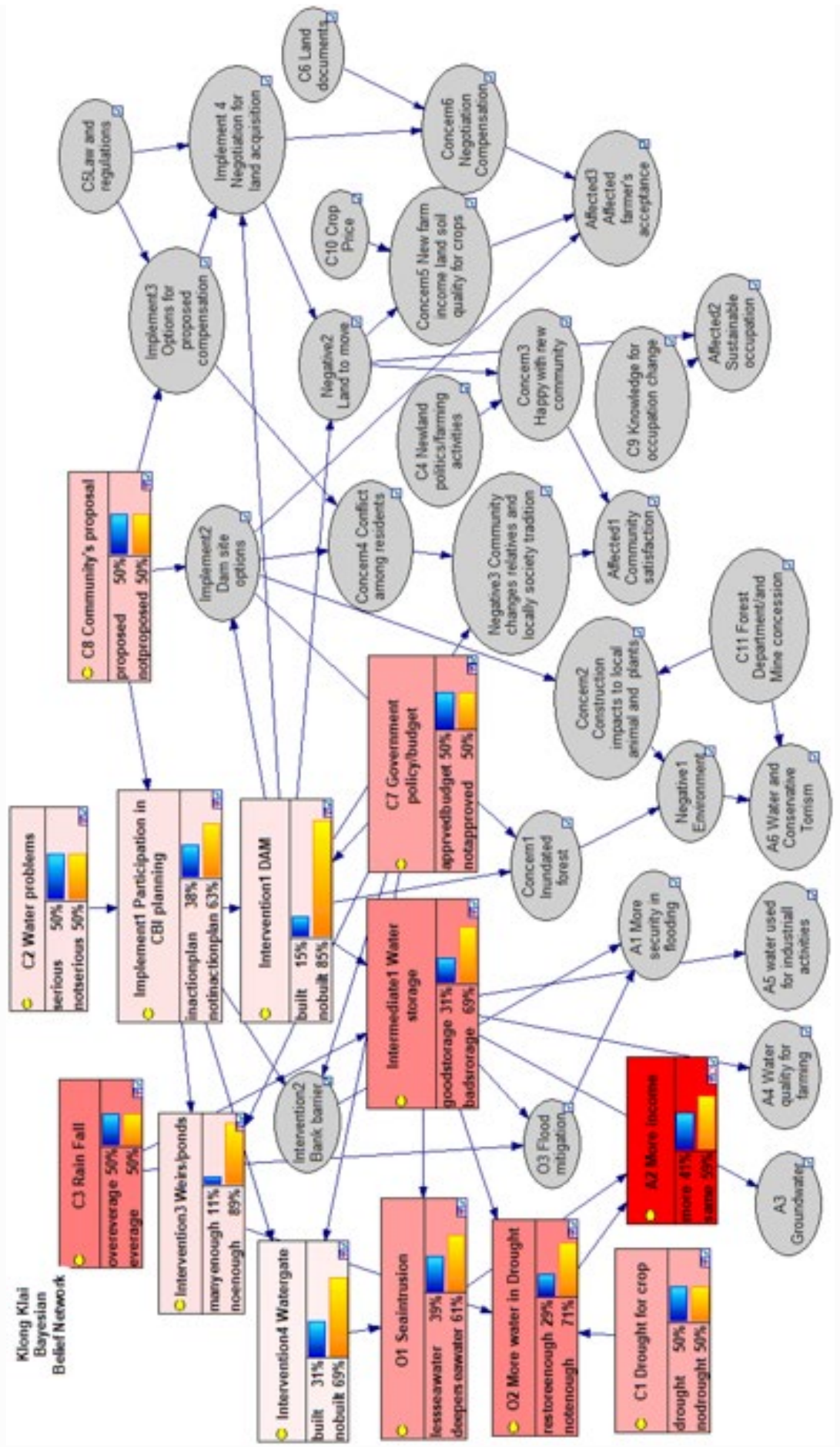

Figure 3.6 The BBN and key variables for farm income benefits in Klong Klai. 


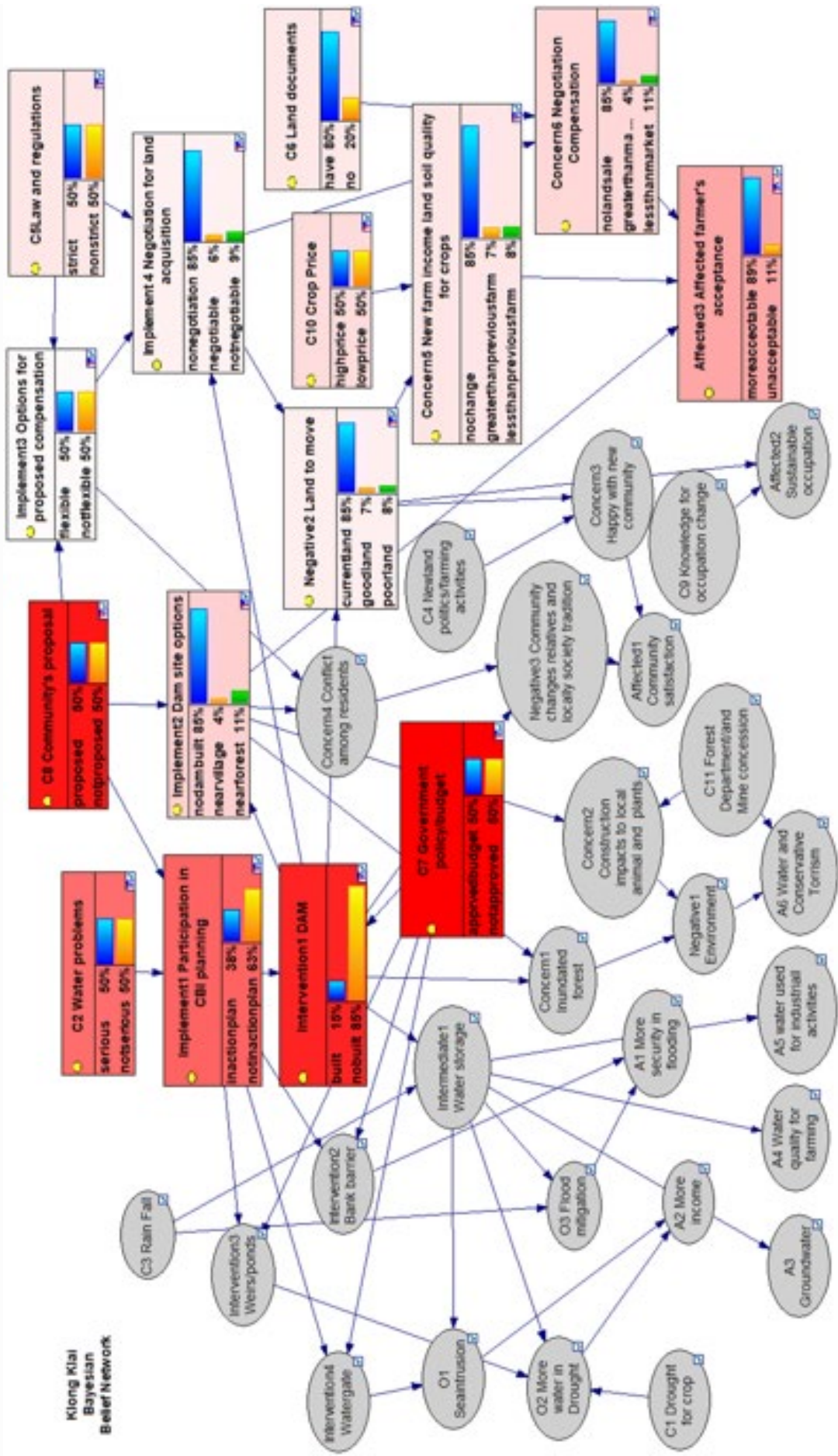

Figure 3.7 The BBN and key variables for acceptance of local stakeholders in Klong Klai. 
To analyse the sensitivity in the Klong Klai case, we used Tornado analysis (Figure 3.8), assuming the dam was selected to be the only intervention in the basin, to investigate the impacts on affected stakeholders' acceptance. We found that if we did not determine if the dam has to be built or not, the most influential variable was government approval to construct the dam (Government policy = approved). We also simulated the BBN sensitivity to other factors in the planning process. A combination of the variables 'dam site' near the forest, local stakeholders can propose interventions, and the dam is built (dam site option = near forest; community's propose = proposed; dam = built) appears as the most sensitive (Figure 3.8). This result means that if the government allows the community to propose interventions such as a dam, and the dam site is far from the residential area, the local stakeholders will have a higher level of acceptance.

\subsubsection{Usefulness of BBNs in the planning process}

\section{Wang Hip}

From the stakeholders' perspective, there is only limited probability of reaching the objectives of mitigating water shortage and floods, and improving beneficiary's income (Figure 3.9). The CPTs demonstrate local concerns about the uncertainties of resettlement, compensation rates, and new farmland. The different practices of participation cannot raise the level of acceptance if the decision is made to build a dam (13\% in a situation where the dam is constructed vs $100 \%$ without the dam). This shows explicitly that local stakeholders' acceptance may not easily be changed after the government decides to build the dam. Moreover, compensation to support the affected stakeholder's income may not substantially raise the stakeholders' acceptance level (23\% vs $7 \%$ ). Affected stakeholders also do not perceive the dam to bring great benefits to beneficiaries ( $55 \%$ with dam vs $51 \%$ without) which means that they do not agree with the proposed dam benefits.

The RID officials agreed with the general BBN framework and the affected stakeholders' variables. In addition, the sensitivity analysis were understandable. However, the District governor argued that "more capacity for water storage will help to regulate the water balance of highly variable intra-annual rainfall" (pers. comm. 23-11-2017).

Although it was challenging to discuss the compensation variable in the workshop, the RID engineer commented that it could be considered within the framework. He provided the response that "The process of negotiation about compensation is being implemented but legal constraints may obstruct compensation, and it is difficult to make the affected stakeholders satisfied" (pers. comm. 14-11-2017). 


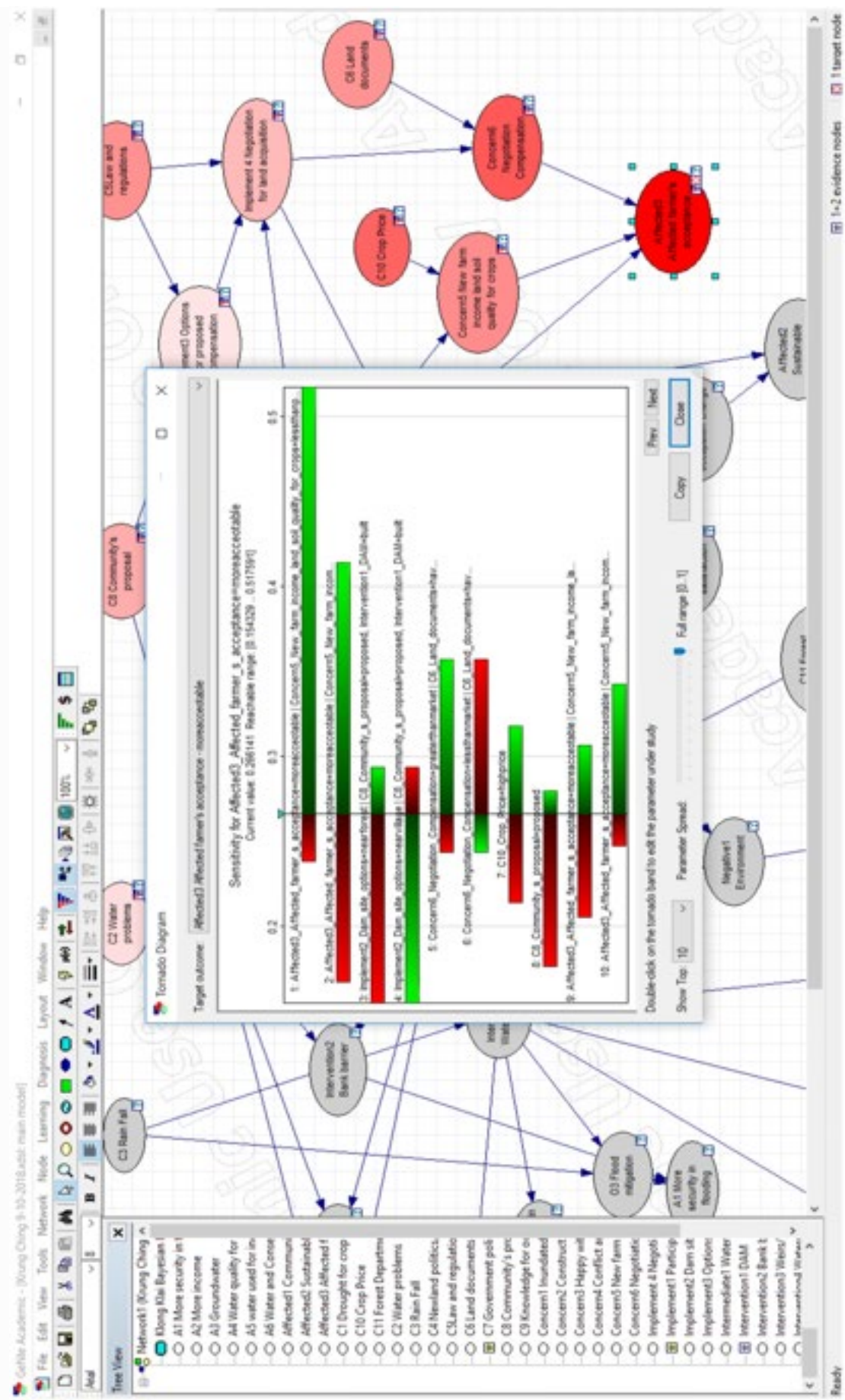

Figure 3.8 Sensitivity analysis for the variables with the highest impact on the acceptance of local stakeholders in Klong Klai. 


\section{Wang Hip}

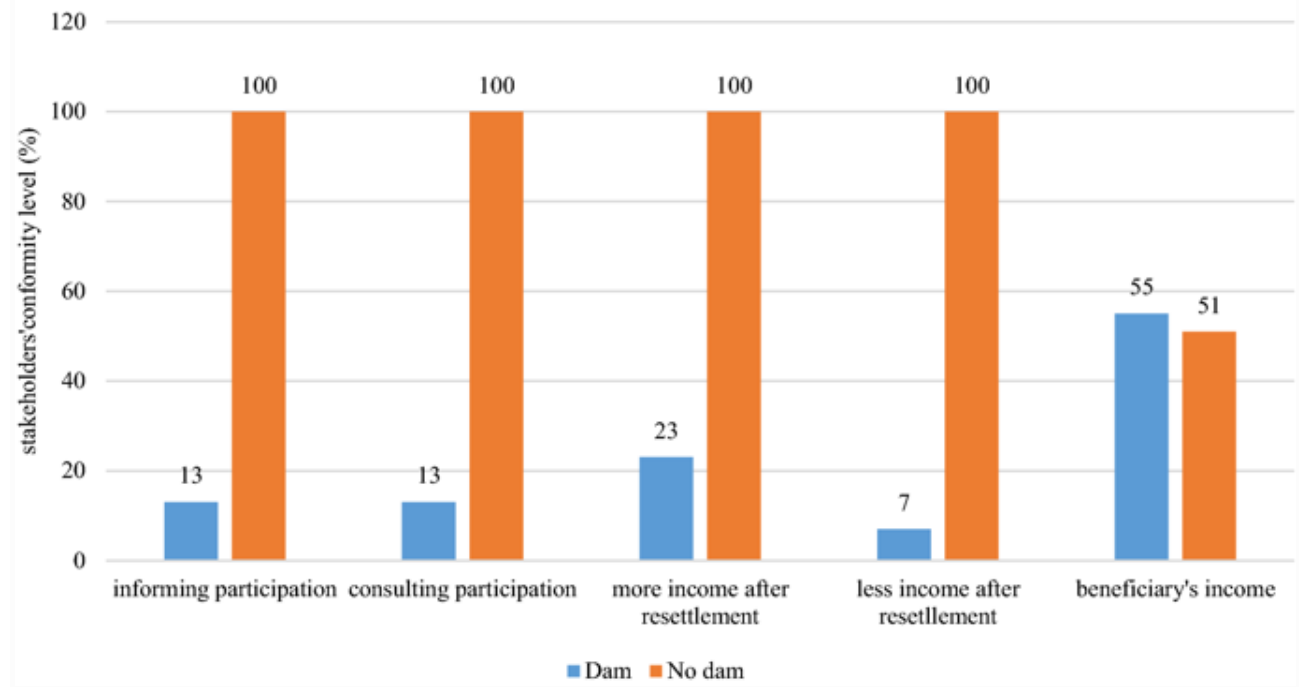

Figure 3.9 Wang Hip stakeholders' acceptance in response to different intervention modalities and their perceived impacts on beneficiary's income.

\section{Klong Klai}

The intervention of building a dam (Figure 3.10) generates profoundly negative impacts on the local community and on forests, more significant than the other interventions. The local stakeholders' key concern is where to locate the dam. Stakeholder consultation during the early stages of the planning process enhanced acceptance more than restricting participation to only informing stakeholders ( $28 \%$ vs $18 \%$ ). Constructing the dam deeper in the forest will satisfy the villagers more than constructing the dam near the village (stakeholders' acceptance $31 \%$ vs $15 \%$ ). If compensation can elevate their farm income above their current income, this will bring more acceptance by affected stakeholders ( $42 \%$ vs $15 \%)$.

We also presented the Klong Klai BBN results to RID officials on 18-9-2017. From the RID's environmental specialist's perspective, locating the dam in the forest raises the question as to whether the dam would have the same water storage potential as in other locations further upstream. "This question needs to be studied more in-depth in the next step, but it is good to let the local stakeholders propose the ideas, then we can negotiate" (pers.com 29-11-2017). 


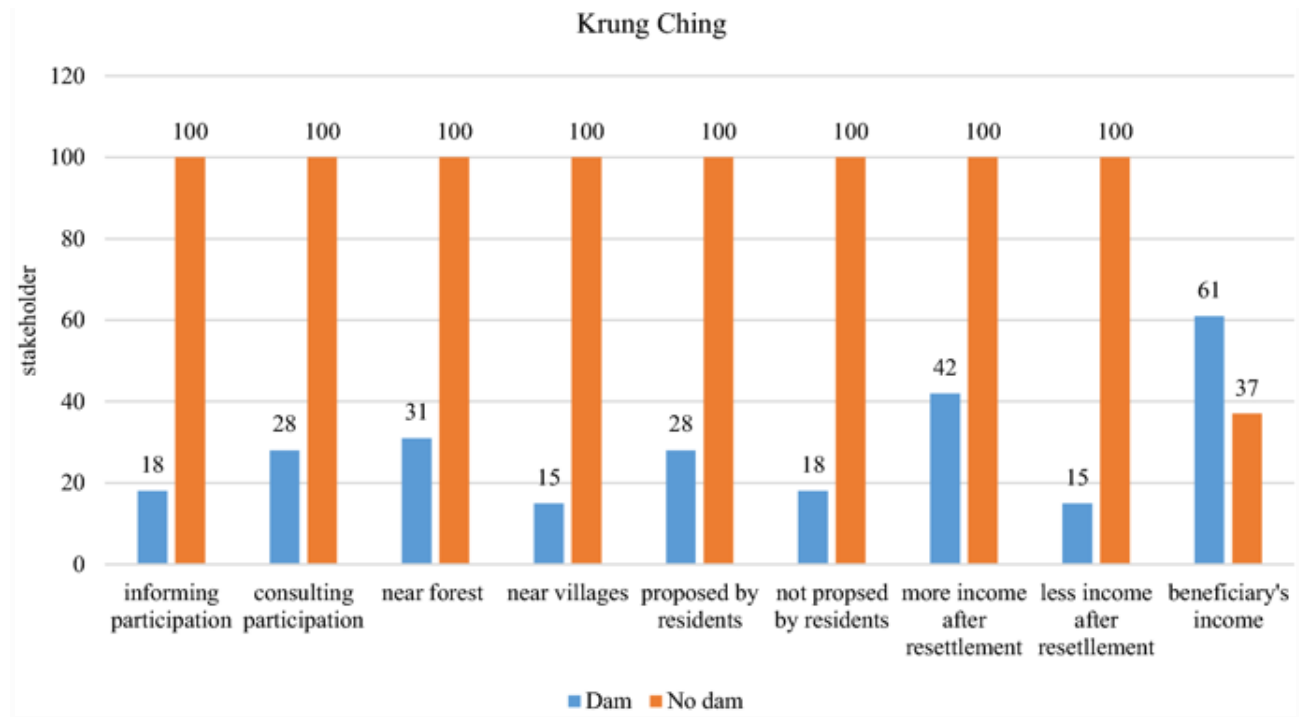

Figure 3.10 Krung Ching stakeholders' acceptance in response to different intervention modalities and their perceived impacts on beneficiary's income.

\subsubsection{The use of BBNs in building systems knowledge}

The affected communities in Wang Hip saw that the BBN could foster the sustainability of development projects by highlighting critical issues to the government. The participants of the BBN workshops learned about factors for decision-making in water resource development from the variables and their links by discussing the probabilities between parent and child variables. The BBN provided better understanding of the interaction among variables in the system. They agreed with the government attempting to solve water problems, but felt the proposed dam would not be a suitable solution in this area because water shortages and flooding were not critical. Accordingly, the participants focused on the suboptimal objectives of the projects. The dam would negatively affect the forest, the local economy and houses. There would be a higher probability that the villagers would agree with the dam if the government could solve these negative impacts, but they believed that the government could not solve all of the negative impacts.

The BBN workshops facilitated participants to put forward their concerns about the impacts of the dam on their livelihoods and helped them to define issues about which the government would need to negotiate. The process helped participants in preparing more concrete arguments to deal with the government. A participant in Wang Hip mentioned at the end of the second workshop "The workshops made us see a high possibility that the government cannot solve our problems and how we should argue to the government with 
good reasons and block the government from running the project". However, the participants also shared the concern that if the government uses a BBN in project planning for assessing the probability of acceptance, they may claim that local stakeholders agree with the dam project.

Developing the BBN allowed the villagers to share their perspectives. However, many villagers that are very critical of the dam plan did not participate in the BBN workshops. A participant in Klong Klai asserted "We enjoyed participating in the workshops even though we've been asked by some villagers whether we are being used by the government as a tool to build the dam". Another participant articulated "It's good to come to ask the villagers' opinions and what we want, if there will be a change in the area". However, the local stakeholders would not agree with the dam if they could not share in the benefits.

\subsection{Discussion}

\subsubsection{Potential role of using BBNs with local stakeholders for water resources planning}

BBNs can be applied in top-down and bottom-up planning processes, as BBNs can simulate outcomes from various (conflicting) angles and interests (Henriksen et al., 2007: Henriksen and Barlebo, 2008). BBNs offer opportunities to define key variables and their relations taking into account the knowledge, values and interests of local stakeholders. The cocreation of one unique system of variables and their relationships enabled the participants of the workshops we held to share their knowledge and discuss their understandings of the relations between variables. Moreover, the co-created BBN was used to discuss and evaluate the estimated impacts of different alternative interventions among the participants. Although affected stakeholders insisted on their opinions, such as not wanting a dam built, the process did catalyse their thinking about other interventions at a smaller scale such as using better water management and existing infrastructures, when the participants were asked to build intervention nodes to link between problem and expectation nodes. These suggestions may contribute to finding better solutions in a severe deadlock situation, where policymakers may see limited scope to solve water problems.

Unlike Landuyt et al. (2013), who claimed that BBNs are increasingly applied in ecosystem analysis, BBNs have barely been applied for dam planning. Our experiences show that in a conflict situation, the discussion between government planners and local stakeholders on impacts of different intervention options by means of a BBN can support policymakers in project planning. Lynam et al. (2007) argue that BBNs outperform other models in engaging 
with stakeholders because of the visual way in which variables can present likelihood of impacts.

This is consistent with the argument of Carmona et al. (2013) that developing BBNs and the development of CPTs with stakeholders can help to identify possible interventions and enables stakeholders to voice their perception of the risks, challenges, negative impacts, costs and benefits of each of the proposed interventions. However, local stakeholders initially struggled to understand the probability assessment, and it took time to explain and elicit the probability for each variable, as was also reported by Henriksen et al. (2007) in a BBN study on groundwater planning.

\subsubsection{Social dynamics in developing BBNs with local stakeholders}

This study focused on promoting understanding of the system and building trust among participants. A dam brings conflicts to the community because some agree while others do not. As a result, some villagers who agreed with the dam did not share their opinions to avoid arguing with neighbours. The affected stakeholders were the most crucial stakeholders, whose interests, perceptions and arguments need to be understood by policymakers (Grimble and Wellard, 1997). Prioritization of their perspectives, knowledge, values and interests may reduce conflicts during project implementation (Bal et al., 2013).

Stakeholders show distinctive perspectives on what are positive and negative impacts (Tilt and Gerkey, 2016). For example, some of the potentially affected residents were afraid of living far away from their relatives while workshop participants that lived more downstream agreed with building the dam for better water management. In both top-down and bottomup approaches, the main variables affecting the stakeholders' concerns were resettlement and insufficient compensation, which is similar to results of other dam impact studies (Bui et al., 2013; Sayatham and Suhardiman, 2015). When confronted with resettlement, potentially affected stakeholders raised issues of ecological problems as key reasons for opposition against dam projects.

Comparison of the BBN variables in the case studies shows that the top-down and bottomup processes led to different variable selections. In the bottom-up approach, the assessment of water resources was more exploratory, and as a consequence there was a larger variety of objectives and of intervention options being assessed. However, as the stakeholders consulted were village representatives, they focused on issues and interventions that were of interest from a local stakeholder perspective, and did not consider other demands for water for e.g. industrial development. On the other hand, the top-down approach led to a 
narrow assessment of objectives in line with a predefined planned intervention. This left little room to consider alternative interventions and other impacts. While Bromley et al, (2005) state that BBN can combine all variables related to equity, sustainability, and efficiency, it is important to notice that in both cases presented here, some sensitive variables were left out of the BBNs i.e. displacement and compensation. In the bottom-up approach, government actors avoided talking about potential levels of compensation to prevent creating a strong opposition in the early planning period. Similarly, local stakeholders did not raise the subject of environmental issues. While they discussed that moving the dam location upstream would solve the social impacts for affected stakeholders, they did not consider that this location in the protected forest area could have serious environmental implications. The EIA may not be approved by the government departments that are responsible for forest area protection for water sources and wildlife habitats. In the top-down case, policymakers initially focused more on economic development benefits for downstream stakeholders and paid less attention to upstream stakeholders affected by the dam. Reed (2008) suggests that all important issues need to be considered from the beginning. In our cases, characterised by strong conflict, sensitive issues such as a dam intervention were not raised by the participants. Although Lynam et al. (2007) cautions that facilitators should not disrupt unexpected results, we followed Reed's (2008) advice and raised the issue of the dam so that it could be discussed in this participatory platform. By creating BBNs, these sensitive variables can be put in the network and linked to other related variables so that all important impacts of interventions are addressed. It is hence important to verify that such sensitive variables are not overlooked.

Sensitivity analysis can test the robustness of the outcomes to the state of related variables in a BBN, provided that a single target node is investigated. The acceptance by local stakeholders was set as the target node for the sensitivity analysis in our cases. The Tornado plots resulting from the sensitivity analysis contributed to developing interventions and policies for mitigating conflicts in dam planning. This correspondKjaerulff and van der Gaag (2000) and Sule et al. (2018) who found that the BBN sensitivity analysis was of practical use to understand how a single target outcome was influenced by various variables and hence helped to direct interventions to those with the largest influence, respectively for medical and environmental management cases. 


\subsection{Conclusion}

A BBN framework for water resources development was constructed based on a review of policy documents and context and applied in two cases in Southern Thailand characterised by conflicts over water resources and incomplete data.

In the first case, with bottom-up assessment of water resources planning, the BBN framework was effective in stimulating stakeholders to see the positives and negatives from different options for water resources interventions. Villagers found common ground in selecting variables and completing CPTs. BBNs proved capable of directly and indirectly linking all factors in a way that was easy for them to understand. The villagers could also understand other stakeholders' interests, opening up opportunities to negotiate solutions and sharing of benefits and impacts.

In the top-down case, the potentially affected villagers opposed the dam and did not want to negotiate compensation. Their concerns were mostly about the uncertainty of finding new productive farmland for resettlement. Therefore, higher land compensation could be an option, although higher compensation only provided marginally higher levels of acceptance in the two cases.

Based on the two case studies, we can conclude that in order to increase the level of acceptance and reduce conflicts, the government should pay more attention to sharing decision power through participation before making decisions; and after making a decision, increase compensation rates, assist in finding good quality farmland, and show more concern for community livelihoods.

This study contributes a method to better understand affected stakeholders' concerns about water development projects and identify ways to take their perspectives into consideration in the planning process to increase their acceptance of the outcomes. By focussing on the affected stakeholders' perspectives, the BBN development process became about giving these stakeholders a voice, and getting their perspectives heard.

Policy-makers involved in water resources planning should adopt elicitation methods that allow affected stakeholders to provide their system understanding (such as the BBNs in this study) and use the predicted outcomes of the model to find more acceptable solutions, and/or to better inform communities about planned projects, e.g. through presenting benefits and impacts in a whole system diagram including dynamic relations among them. Moreover, policy-makers should apply BBNs in consulting and negotiating over acceptable solutions in early dam planning stages for equitable benefit-sharing. 
The BBN framework can be adapted to other cases, and could also be used to integrate perspectives of different stakeholders. By considering different types of data e.g. quantitative and qualitative data, the models could be further developed and, to some extent, validated. While the current study did not attempt this, the study was instrumental in helping planners to take the emerging sensitivities into account in the decision-making process by putting more effort on the specific issues of conflict. A new insight of this study is that the elicitation of local knowledge and perceptions with specific attention to local stakeholders in conflict situations helped building trust while creating the BBN. 


\section{Ex ante impact assessment of reservoir construction projects for different stakeholders using agent-based modeling}

Reservoir construction projects are frequently met with fierce opposition. As a consequence, environmental and social impact assessments are usually mandatory to mitigate potential negative impacts. Stakeholder perspectives are often only implicit in such assessments, and medium-term effects of mitigating actions could be more systematically assessed using scenario analyses. In this paper, we design and apply an agent-based model (ABM) built on stakeholder information to make an ex ante assessment of the impact of a reservoir construction project in southern Thailand over a 30-year period. We incorporated stakeholders' knowledge into the ABM on the basis of primary data collected during 2016-2018, including workshops with affected farmers to assess their interests and concerns, in-depth interviews with nearby-district farmers to assess farming behaviors, and expert opinion of policymakers to assess the relevant regulations and processes. In a case study for which the model was set up, the results predict that overall farmers would have more farm income if the dam would be built. We found that affected people require a standard of living similar to their previous livelihood as soon as possible after resettlement. However, the compensation for relocation offered to affected farmers may not be sufficient for sustainable resettlements. Facilitating compensation may increase the speed of implementing the project with better outcomes for everyone, including affected communities, whereas failure to reshape the current compensation policy leaves everyone more disadvantaged.

Based on:

Singto, C., de Vries, M., Hofstede, G.J., Fleskens, L., (2020). Ex ante impact assessment of reservoir construction projects for different stakeholders using agent-based modeling: Submitted to: Water Resources Management. 


\subsection{Introduction}

A development project can benefit some people while negatively impacting other groups of stakeholders. Typically, a majority of stakeholders support a project because they expect economic benefits. However, some affected stakeholders do not see an equal opportunity for economic benefit sharing and merely anticipate adverse impacts and uncertain longterm livelihood security, leading them to oppose the project. Conflicts among stakeholders often lead to a deadlock in finding acceptable solutions and preclude adaptations of plans to limit uncertainties. Land acquisitions are commonly implemented to support economic development projects, but mandated compensation is usually unreasonable, complex, implicit and insufficiently participatory for affected stakeholders (Ghatak \& Mookherjee, 2014). Affected people demand equal rights in relocation planning and frequently fight against existing land compensation laws and regulations (Morvaridi, 2004). Insight into the behavior of individuals or groups of affected people may assist policymakers in designing more acceptable and equitable compensation plans (Kermagoret et al., 2016). However, a challenge for obtaining such insight is that future changes in both individual and collective stakeholders' livelihoods need to be assessed. This assessment requires a practical ex ante assessment tool that can simulate impacts on different stakeholder groups to develop a better understanding of the impacts on affected stakeholders relative to beneficiaries and their sensitivity to varying levels of compensation.

In long-term assessments of water development projects, existing cost-benefit approaches do not differentiate impacts on different stakeholder groups, leading to difficulty in reducing inequality in compensation due to contentious planning, i.e., an undervaluation of the assets and a delay in compensation payments (Cernea, 2003). Instead of focusing on collective compensation in the cost-benefit approach, a market approach should be adopted to assess the individual willingness of affected people to accept the standard payment for resettlement in the planning process (Yu and Xu, 2016). Kunreuther and Easterling (1990) recommended that the individual behavior of affected people should be considered in the determination of compensation levels. Individual affected people will compare the level of compensation with expected benefits without the project; then, they decide to choose the option with greater utility, i.e., to accept the compensation offered or to resist the project (Kunreuther \& Easterling, 1996).

However, affected individuals have different backgrounds, willingness to accept, and resilient ability to overcome uncertainties. In this article we model these individuals as 'agents' in an agent-based model. Thus we often refer to affected farmers as 'agents'. Factors (in terms of characteristics of farmers or their farms) that make some affected people more resistant than others or that cause a high level of variability in the willingness to accept 
certain levels of compensation or risk taking should be duly considered. Popkin (1979; 5) argues that farmers compare alternatives and choose a "higher income and less variance" option for their long-term investment. This characteristic of agents is used in Rai (2007) in a study assessing the social inequality of compensation of Gandaki dam construction in Nepal.

Therefore, a long-term ex ante assessment of livelihood impacts comparing collective and individual benefits among affected and benefited agents should be made to identify a better policy of compensation to limit inequalities after relocation. Policymakers may deploy scenarios to envision impacts and adaptations to uncertainties of each option considered in decision-making processes. However, most studies limit themselves to collective benefits and impacts (Ghatak \& Mookherjee, 2014). Studies on land compensation to illustrate the uncertainties of affected agents individually are rare. While other models are only able to assess collective impacts, agent-based modeling (ABM) adds explanatory power by allowing to study both collective and individual benefits and impacts regarding behaviors, uncertainties and other critical indicators.

An agent-based model (also abbreviated ABM, plural ABMs) can illustrate the uncertainties of agents in the same system (Priya Datta et al., 2007) and can be deployed for ex ante impact assessment for various groups of stakeholders, including minority agents, in water resources planning (Berger et al., 2007). This capability helps policymakers understand how a policy alternative affects agents and their behaviors in conflict situations (Akhbari and Grigg, 2013). Moreover, presenting ABM results contributes to the acknowledgement of both positive and negative impacts. Therefore, we propose an ABM to assess ex ante effects of land compensation policy individually and collectively, for a better understanding of impacts on the whole system and to suggest suitable compensation policy for more equitable outcomes of water resource development projects.

In this study, an ABM for water resources planning in southern Thailand is developed and demonstrated. The aim of the model is to assess the impacts of land compensation policy in a basin development project. The main research question is to explore how dam construction and compensation policy affect farm income and the share of farmers accepting compensation payments. Mitigation approaches to prevent negative impacts for affected farmers can be proposed explicitly in an ABM (Berger et al., 2007). 


\subsection{Farmer behaviors in water resource development planning}

Farmers consider limitations and options when making a decision regarding new farming activities (Quang et al., 2014). A farmer selects the best crops and best practices to maximize yearly and future farm income depending on contextual factors and knowledge about aspects, such as crop yield and quality of land ( $\mathrm{Ng}$ et al., 2011). With their limitations, farmers may review their previous farm income and adapt their farm practices to reach their criteria (i.e., neighbors' farm income; Berger, 2001). For example, based on their historical perceptions, farmers may change crops or implement different practices, i.e., to make longterm investments in highly profitable crops or to make short-term investments to optimize crop yields under resource limitations. Their choices will also be based on expectations for the future (i.e., challenges related to weather, policies, new knowledge, and crop prices) (Becu et al., 2003; Schreinemachers \& Berger, 2011).

In addition to individual and collective income, other farmer behaviors have been found to influence decisions in response to water limitations (Schlüter \& Pahl-Wostl, 2007). An optimization decision concept is applied for individual objectives. The optimization approach entails that many agents can interact with neighbors and environments to adapt their decisions by regarding other stakeholders' objectives and by allowing stakeholders to cooperate with other stakeholders for their common benefits (Giuliani \& Castelletti, 2013). This optimization behavior can be applied to facilitate negotiations on conflicting interests among stakeholders; typically, such conflicts are about situations where if one agent wants to develop one objective, it will decrease the effectiveness of other stakeholders' objectives.

Governments often propose interventions that may affect other stakeholders' livelihoods. As one example, Galipeau et al. (2013) investigated the inequality among affected people and beneficiaries and compared differences between resettlers and non-resettlers (regarding farm income, land rights, crop selection and compensation to their livelihood). They found that the affected farmers lose their productive land after resettlement, affecting their standard of living. Consequently, interactions among stakeholders often change in reaction to interventions. The interactions of different groups of stakeholders, such as individual farmers and governmental institutions, differentially affect the environment in which they operate, depending on their responsibilities and interests (Bousquet and Le Page, 2004). Therefore, water resource planning requires careful investigation of stakeholders' behavior, especially in conflict situations (Berger, 2001).

Generally, water resource development conflicts occur when affected people reject moving because they do not receive enough compensation. A compensation policy may change affected farmers' livelihoods and farm income, and it should be sufficient for farmers' new 
investment (Ghatak \& Mookherjee, 2014). Qian (2015) studied the compensation policy for land acquisitions in Hangzhou, China, with key stakeholders, i.e., local government and affected farmers, and concluded that affected farmers face challenges of uncertainties related to maintaining their income after resettlement. In this case, monetary compensation is paid for values of property during the land acquisition process, but it is not enough to support their future livelihood or at least maintain their present income.

In a study by Lebel et al. (2014) on the Sirikit Dam in Thailand, built in 1957, the compensation plan was to support affected stakeholders for a short-term period after resettlement. This plan was drawn up without consulting the affected people. In this plan, different types of compensation, such as a pooled lottery allocating distant land and a few facilities, fixed cash compensation for the loss of trees, fixed cash for a household, and land compensation of a smaller size or lower quality, proved to be inadequate to reach the same standard of living as that expected without the dam. Moreover, this study suggests that compensation should address the delay of payment to more quickly resume the standard of living.

\subsection{Ex-ante assessment of farmer's behaviors by agent-based modeling}

A participatory approach to model design attempts to undertake participatory activities to bring together stakeholders (including affected stakeholders) to inform model development (Pahl-Wostl, 2002; Singto et al., 2020). The participatory development of scenario modeling approaches can be a powerful tool to propose solutions for decision-making (Sun and Muller, 2013). Computer models can contribute knowledge for making environmental policies, in which models can engage socioeconomic information to simulate how decisionmaking affects stakeholders and to predict their responses if changes occur (Fleskens and Hubacek, 2013). Correspondingly, a combination of stakeholders' perspectives and affected stakeholders' reactions can initiate constructing scenarios for future prediction and propose alternatives for decision-making (Fleskens and Stringer, 2014).

Simulating individual adoption behaviors under uncertain situations in scenarios helps policymakers improve policies (Berger \& Troost, 2014). ABM is a tool that can facilitate policymakers comprehend the impact of changes induced by policy interventions when farmers' decisions, which are the product of several interactions and limitations, are combined to simulate the collective impacts in the model (Berger 2001; Berger et al., 2006; Berger et al., 2007). Socioeconomic changes and stakeholders' perspectives can be put into the model to focus on decentralized water policy impacts (Becu et al., 2003). Moreover, ABM 
can simulate an environment and agents living in the environment as a collective system shaped by individual agent's decisions (Matthews et al., 2007). ABM can also be used to create a decision framework where several stakeholders are institutions rather than farmers (Giuliani \& Castelletti, 2013). Stakeholders can be agents and can react to changes in the environmental system following rules defined by the modelers, in which rules are informed from the real world (Akhbari and Grigg, 2013). ABM has, for example, been applied to investigate farmers' decisions with a cropping model to translating individual farmers' decisions into farm income and costs due to their cropping systems and farming practices (Ng et al., 2011).

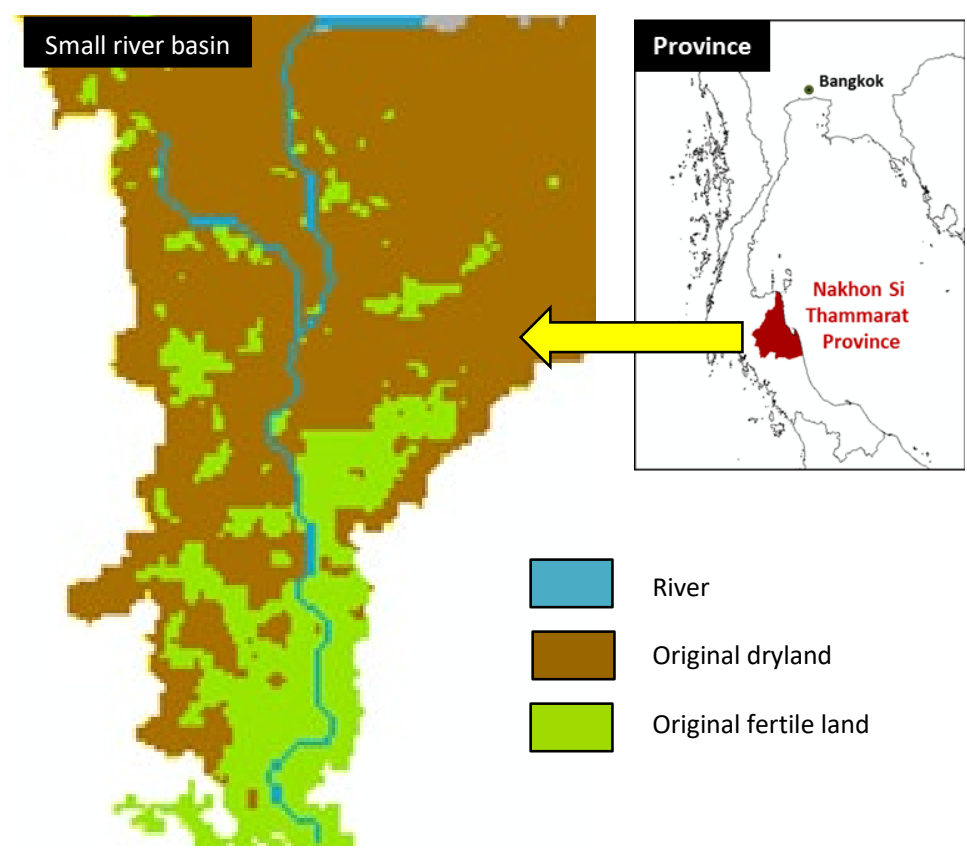

Figure 4.1 Setup of a typical $A B M$ environment for water resource development planning in southern Thailand.

To evaluate proposed options for acceptable outcomes in conflicts, ABM facilitates ex ante assessment to predict responses from stakeholder behavior in response to future interventions under the individual conditions of stakeholders (Le Pira et al, 2017). With these competencies, ABMs can be used in conjunction with other models to investigate ex ante assessments of individual farmers and farmland, including interactions among stakeholders in adopting policies and interactions between stakeholders and environments (Quang et al., 2014). Accordingly, studies have applied ABMs to enhance a conventional ex ante study for exploring changes in the socioeconomics of stakeholders in the same network. ABM helps ex ante to investigate farmers' behaviors under certain limitations and 
interactions among stakeholders when individual farmers aim to maximize farm income. This ability to apply resource limitations makes ABM superior to other modeling approaches in assessing farmer behavior and resource use (Schreinemachers et al., 2010). Therefore, $A B M$ provides high potential to enhance the understanding of the dynamics surrounding dam planning projects and their socioeconomic impacts in water conflict contexts.

\subsection{ABM development for ex-ante assessment}

\subsubsection{Purpose and setup}

We developed an ABM capable of simulating the impacts of the building of a dam, including the procedures for negotiating compensation, on farmer income and level of satisfaction. Behaviors of different types of farmers are simulated: with and without a dam planning process and with different amounts of compensation for affected farmers. Next to the level of compensation, one of the key factors affecting the satisfaction of affected people is the uncertainty experienced during delays in a dam project. Hence, we assessed the sensitivity of the ABM model to different periods of dam building caused by delays in the planning process.

The $A B M$ variables and procedures were defined using data available from official documents from relevant governmental organizations and were strengthened with expert and local knowledge to predict or forecast the future (Berger \& Troost, 2014). Several assumptions were made based on past events, empirical data, and the forecasted probability of future events. Socioeconomic data were based on the Wang Hip dam project EIA report (RID, 2016) and market crop prices (Office of Agricultural Economics, 2017). Local knowledge was mobilized during workshops and in-depth interviews conducted over the period 2016-2019 with policymakers and benefiting and affected farmers (Singto et al., 2018; Singto et al., 2020).

We implemented the ABM model in NetLogo 6.11. computer software. The model contains a number of stochastic elements: the farm size distributions, crops grown, and location of farmers, which are initialized in the set-up process. Therefore, the ABM should be repeatedly run to calculate an average to analyze trends in the results (Thiele et al., 2014). We ran simulations for 30 years and analyzed the average and distribution of probabilities of 200 model runs. The default simulation (10\%Y5) was run for a scenario where, annually, a $10 \%$ increase in offered compensation was offered up to a maximum of 5 years, when the dam would be constructed as accumulated patterns with scenarios exploring sensitivities to compensation and year of construction. The purpose of the demonstration was to evaluate 
the capabilities of the model and not to provide insight into an actual negotiation process, as no negotiations are actually taking place.

Three types of land were distinguished based on land cover (Globcover, 2009), topography (SRTM, 2018) and data on current and future irrigable land (RID, 2016):

1) Fertile land (green patches), consisting of land close to the river or land benefiting from irrigation (original and future irrigable land), with enough water to grow highprofit crops such as durian.

2) Dryland (brown patches), where most of the patches are far from the river and there is not enough water for growing high-profit crops (original rainfed land). If a dam is constructed, some dryland patches may change to irrigated fertile land (green patches).

3) River and inundated areas (blue patches) will increase depending on the amount of rainfall and inundated area.

The ABM applied the distribution (average and standard deviation) from 30 years of rainfall data based on 1977-2006, causing random drought events when rainfall was below the average (RID, 2016).

\subsubsection{Framework, agents, and behaviors}

The ABM model simulates farmers' reactions to changing environments and other stakeholders during the dam planning process and also after dam building during a total of 30 years. Figure 4.2 presents a flowchart of the main components of the model that are run at an annual time step:

1) Farmer behavior: farmers decide whether to maintain or plant new tree crops based on trends in market prices, the quality of land at the location of their plot, availability of water for irrigation, availability of funds for investment and level of certainty of land tenure. Farmers' choices are translated into annual farm income.

2) Satisfaction: satisfaction is determined based on a comparison of the farmers' incomes in relation to neighboring farmers within a search radius. If farmers experience land and water resource issues, this will impact their satisfaction levels, as will relocation in case they need to move to make room for reservoir construction.

3) Dam planning: the numbers of affected and non-affected stakeholders are updated, and a decision is made or postponed regarding dam construction. If the decision is made to construct a dam and in the years following dam construction, 
the negotiation on the compensation component becomes active. Otherwise, the next year starts with the determination of farmer behavior.

4) Negotiation on compensation: affected farmers can either accept this compensation (if they can buy a good, irrigable piece of land for the compensation) or request higher compensation. If they accept compensation, they will purchase new land and displace.

\section{Farmer behavior}

Farmers can grow three tree crops: para rubber (Hevea brasiliensis), oil palm (Elaeis guineensis) and durian (Durio zibethinus). Which crop they can grow depends on their land and water resources. Each crop comes with an investment cost, a nonproductive period during which the trees produce no return, and productive periods of a certain duration after which productivity drops. Original-dryland farmers involuntarily grow rubber trees in dryland conditions. Some fertile original-land farmers may switch to higher profit crops such as durian.

Farmers' switching of crops (or replanting) can occur after passing a threshold age of existing crops (ten years for oil palm and para rubber and twenty years for durian). Based on the current situation, we assumed that $50 \%$ of the farmers may potentially change crops, in which case $60 \%$ grow rubber, $30 \%$ grow oil palm, and $10 \%$ grow durian.

\section{Satisfaction}

Interviews with farmers informed the criteria of the level of satisfaction related to water scarcity, and limitations based on previous incomes, farming adaptation, and neighbors' income (Berger, 2001). Satisfaction scores changed if the elements of satisfaction change. Initial satisfaction was set at 0 . A drought reduces the satisfaction by 1 for farmers that are not within the irrigation distance of the river. Satisfaction increases by 1 for all farmers that are near the river. If there is above-average rainfall, satisfaction increases by 1 , and with normal rainfall, satisfaction remains the same. If the income of the farmer is lower than the average of all farmers within his neighboring radius, satisfaction reduces by 1 , while if it is higher than the average, satisfaction increases by 1 each year. When the dam is constructed, satisfaction of farmers that need to relocate decreases by 5 . 

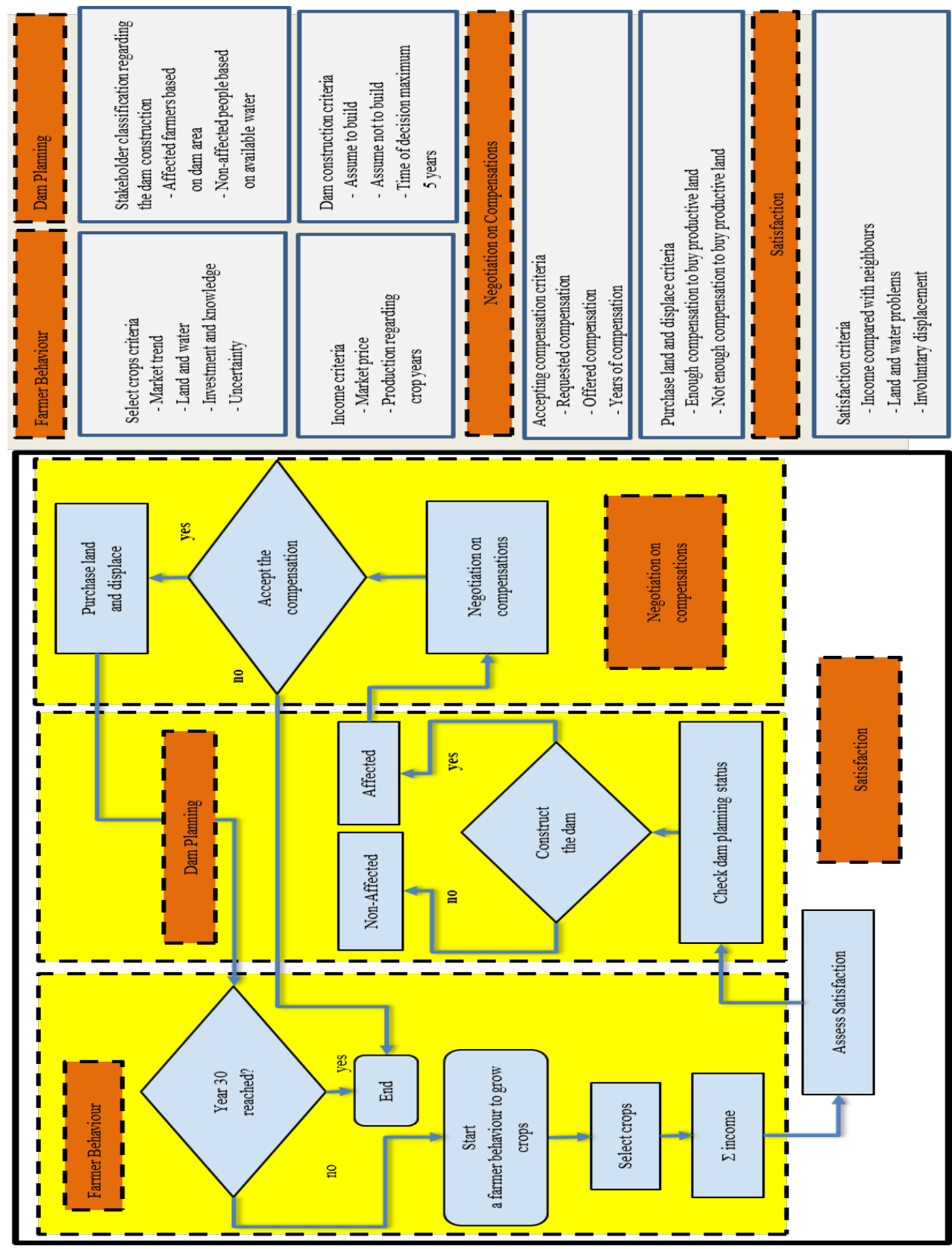

Figure 4.2 Flowchart of the ABM visualizing the processes modeled for one agent in one time step and criteria considered in four model compartments: farmer behavior, satisfaction, dam planning status, and negotiation on compensation. 


\section{Dam planning procedure}

A reservoir is modeled as a potential intervention. It is assumed that irrigation becomes possible by broadening the riparian zone within a reach of two cells from the river (i.e., these cells become productive land). In contrast, if there is no dam, each year, $5 \%$ of farmland far from the river is assumed to turn dry randomly due to increasing water usage for highly profitable crops. The chance of drought in this area was set at $50 \%$. Farmers living within a distance of 5 rai (patches) from the river could extract water from the river for irrigating their crops. The number of farmers was set to 1,000 farmers as default (made up by original dryland farmers $35 \%$, original fertile land farmers 33\%, farmers with land near the river $25 \%$, and affected farmers if the dam is built 7\%). We assumed that the reservoir would be built in the next five years.

\section{Compensation of affected stakeholders}

The official rate of compensation is dependent on land title. From interviews with RID officers, compensation amounts to 312,500 baht/hectare (approximately 32 baht/ US dollar) or 50,000 baht/rai when one hectare equals 6.25 rai (assessed price by Land Department) if villagers have land deeds and 40,000 baht/rai without deeds $(80-90 \%$ of the assessed price). However, the market price of land is generally much higher, approximately $250,000 \mathrm{baht} / \mathrm{rai}$, and if the affected residents would buy new farmland, they have to pay this market price. We allowed the land compensation rate to vary, using 150,000 baht per rai as the default. This amount was assumed to be enough to buy a dryland plot somewhere in the river basin. Compensation negotiations may take several years. Each year during the negotiation, the compensation level was assumed to increase by $10 \%$ (based on the interviews with the RID officer). Farmers keep receiving farm income from their land as long as relocation has not been performed. Upon relocation, affected farmers will change crops according to their expectations and limitations.

To validate the model, we discussed the results with RID participation officers who are responsible for the participation planning project in a focus group meeting on 13th November 2018 about the ability of the model to present and compare income and satisfaction of different types of farmers.

\subsection{Results}

\subsubsection{Environments in the next 30 years}

Presently, without reservoirs water availability limits farmers' choices. The without-dam scenario (Figure 4.3a) presents a change from productive land to dryland. Farmers living in 
dryland cannot change crops to more profitable crops. In addition, when productive land became dryland (see Section 3.b), the farmers possibly must shift from high to low profit crops due to the land productivity change.

With the changes introduced by building a dam (Figure $4.3 \mathrm{~b}$ ), the trends of land changes predict more irrigated land and less dryland. The farmers can change their crops in response to market prices and will choose to grow more profitable crops.

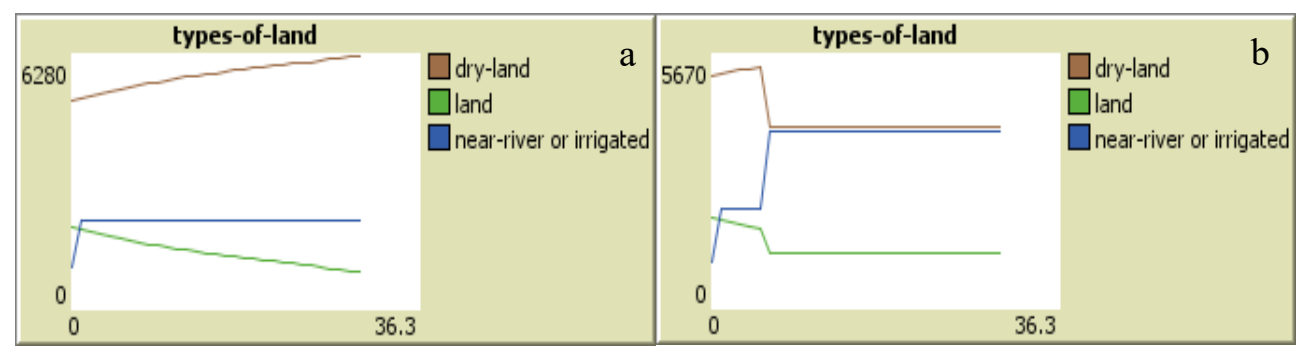

a. Without dam

b. With dam

Figure 4.3 Land change in the basin in the next 30 years without (a) and with dam construction (b).

\subsubsection{Individual affected farmer behavior}

ABMs are typically better at predicting farmer behavior at higher aggregation levels than at the individual level (Schreinemachers et al., 2010). Even so, they are good at describing the possible fates of individual agents. We randomly selected three individual affected farmers to illustrate their behavior for the first run of the ABM in the default scenario (10\%Y5). The three individual farmers (\#74, \#580, and \#666) accepted the proposed compensation in different years, faced different limitations to select crops, and showed a variable evolution of satisfaction due to the changes (Figure 4.4).

The above examples show that individual farmers' responses to crop price, water and land availability, and compensation are specific to each affected farmer. The speed of the decision to accept compensation tended to increase their future income and satisfaction. This result implies that combining the behaviors: a quick decision to move, investing right after receiving compensation, and ability to change crops, can mutually reinforce chances to improve income and satisfaction of affected people after displacement. 


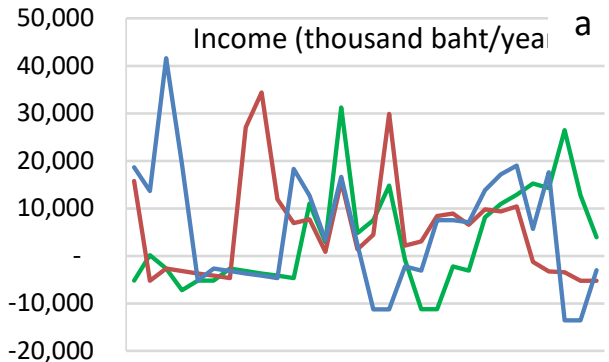

13557911131517192123252729

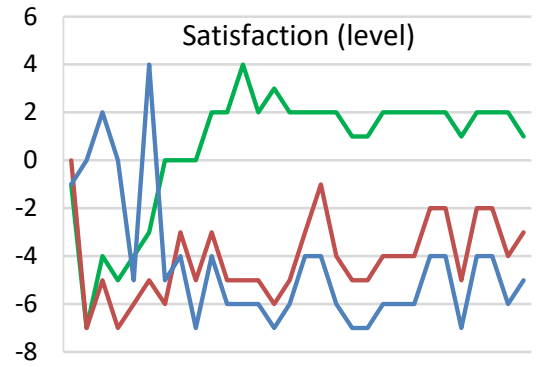

135779911131517192123252729

farmer 74 farmer $580 \_$farmer 666

\begin{tabular}{|c|c|c|c|c|c|c|}
\hline $\begin{array}{l}\text { Individual } \\
\text { Farmer }\end{array}$ & \#74 & & \#580 & & $\# 666$ & \\
\hline Year & Crop & Crop-age & Crop & Crop-age & Crop & Crop-age \\
\hline 0 & para & 24 & para & 22 & para & 15 \\
\hline 1 & para & 25 & para & 0 & para & 16 \\
\hline 2 & para & 26 & para & 1 & para & 17 \\
\hline 3 & para & 27 & para & 2 & para & 18 \\
\hline 4 & para & 28 & para & 3 & para & 0 \\
\hline 5 & para & 0 & para & 4 & para & 1 \\
\hline 6 & para & 1 & para & 5 & para & 2 \\
\hline 7 & para & 2 & para & 6 & para & 3 \\
\hline 8 & para & 3 & para & 7 & para & 4 \\
\hline 9 & para & 4 & para & 8 & para & 5 \\
\hline 10 & para & 5 & para & 9 & para & 6 \\
\hline 11 & para & 6 & para & 10 & para & 7 \\
\hline 12 & para & 7 & para & 11 & para & 8 \\
\hline 13 & para & 8 & para & 12 & para & 9 \\
\hline 14 & para & 9 & para & 13 & para & 10 \\
\hline 15 & para & 10 & para & 14 & para & 11 \\
\hline 16 & para & 11 & para & 15 & palm & 0 \\
\hline 17 & para & 12 & para & 16 & palm & 1 \\
\hline 18 & para & 13 & para & 17 & palm & 2 \\
\hline 19 & palm & 0 & para & 18 & palm & 3 \\
\hline 20 & palm & 1 & para & 19 & palm & 4 \\
\hline 21 & palm & 2 & para & 20 & palm & 5 \\
\hline 22 & palm & 3 & para & 21 & palm & 6 \\
\hline 23 & palm & 4 & para & 22 & palm & 7 \\
\hline 24 & palm & 5 & para & 23 & palm & 8 \\
\hline 25 & palm & 6 & para & 24 & palm & 9 \\
\hline 26 & palm & 7 & para & 25 & palm & 10 \\
\hline 27 & palm & 8 & para & 26 & palm & 11 \\
\hline 28 & palm & 9 & para & 27 & durian & 0 \\
\hline 29 & palm & 10 & para & 0 & durian & 1 \\
\hline 30 & palm & 11 & para & 1 & durian & 2 \\
\hline
\end{tabular}

Figure 4.4 Individual farming behavior of affected farmers: a) evolution of income; $b$ ) evolution of satisfaction level; c) evolution of crops grown and crop age. 


\subsubsection{The predicted farm income}

Figure 4.5a shows trends in income for each land type per rai in a default scenario without dam construction. Affected farmers perform similarly as farmers on original productive land. The affected farmers would have more chances to select higher profit crops and receive a good farm income due to living on productive land from which they do not need to be displaced.

Turning to the with-dam scenario (Figure 4.5b), farmers on productive land would have greater income. Dryland farmers continue to have the lowest income in the long run. The affected farmers would experience a period of low or even negative income during the years of resettlement but catch up with the average level of farmers towards the end of the simulation. However, their income might increase if irrigated area gradually expands after the construction of the dam (see Section 5.2).

Figure $4.5 \mathrm{c}$ shows that the average income after 30 years for dryland farmers and productive-land farmers would be higher with dam construction than without dam construction. Therefore, transforming drylands to irrigated land could assist dryland farmers in increasing their farm income. However, the potentially affected farmers may have problems finding new productive land and financing crop investment, which explains why they obtain less income than the productive-land farmers.

\subsubsection{Predicted satisfaction}

In the scenario without a dam, farmers living on drylands have the lowest (-2) satisfaction (Figure 4.6a). They are situated far from the river and cannot access water. This limitation causes lower incomes than the average and low opportunity to grow highly profitable crops. In contrast, the affected farmers would not need to be displaced, and living near the river on productive land would maintain their satisfaction level. Overall, their income would be higher than the average, but some of them might have lower incomes because of insufficient investment capacity for highly profitable crops.

In contrast, in the case in which the dam is constructed, affected farmers show an extreme decrease in satisfaction when the dam construction is started (satisfaction level drops to a low of -6 , Figure $4.6 \mathrm{~b}$ ). After displacement, the level of satisfaction of affected farmers steadily increases, but it takes more than a decade to recover and remains the lowest among other types of farmers. The scenario shows the lowest satisfaction of affected farmers, especially at the start of resettlement. Satisfaction increases over time due to less limitation 
in accessing water and growing more profitable crops. Interestingly, the increase in satisfaction would take longer than 10 years, and uncertainty over access to irrigated land and future income remains. Therefore, this scenario may cause resistance to dam construction.

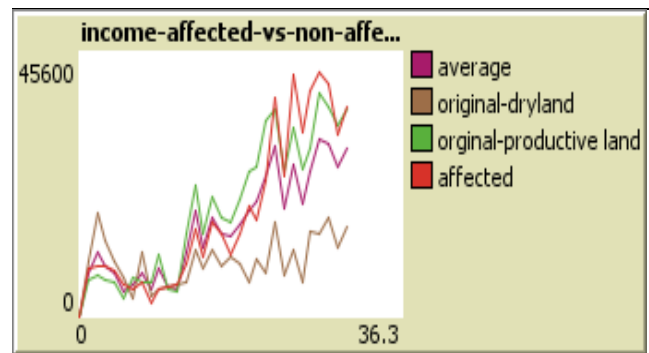

a. Without dam

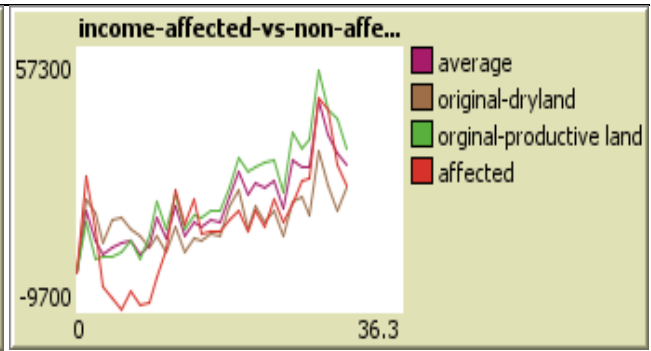

b. With dam

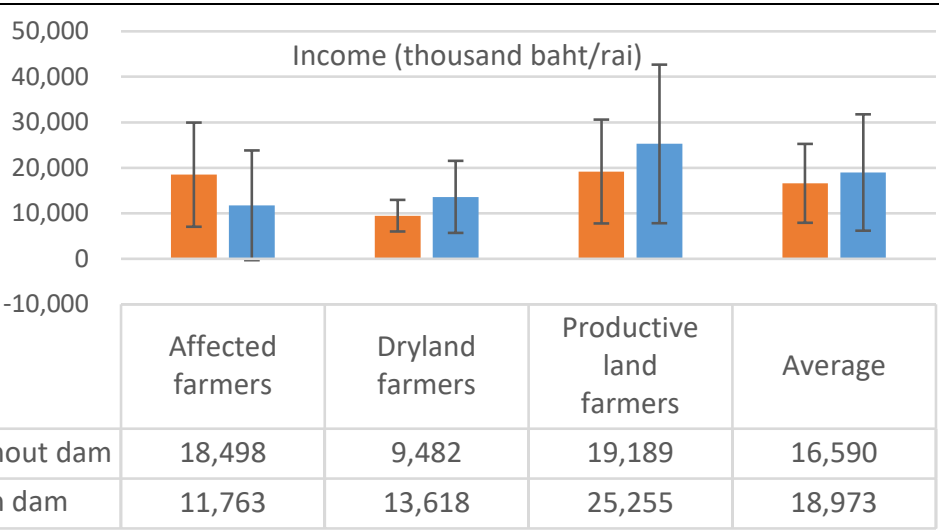

c. Average income of each type of farmer, without dam and with dam

Figure 4.5 Comparison of farm income of different types of farmers (default scenario).

Figure $4.6 \mathrm{c}$ shows the average satisfaction levels after 30 years for the two scenarios. Dryland farmers and productive-land farmers would be more satisfied with the dam than without the dam. Overall, the dam would increase accumulated satisfaction from 0.93 to 1.08 , whereas the affected farmers became more dissatisfied (1.67 to -1.15 ). 


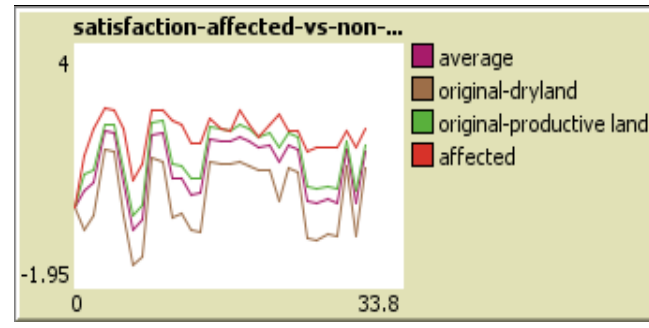

a. Without dam

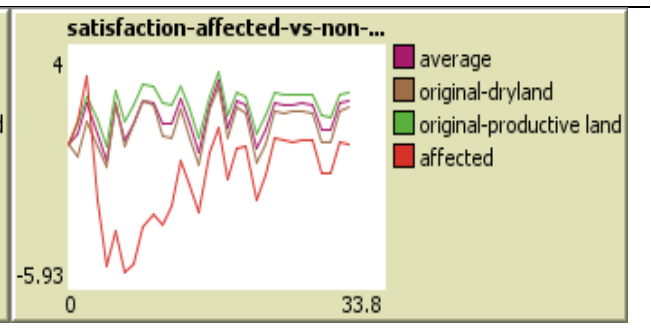

b. With dam

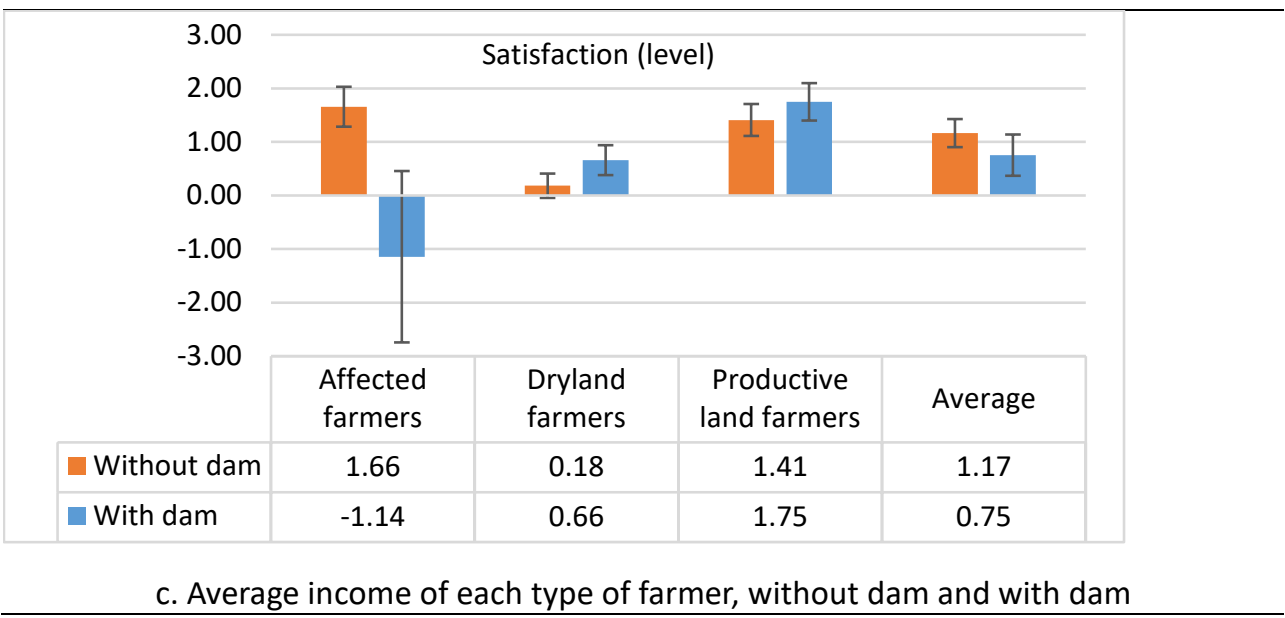

Figure 4.6 Comparison of farmer satisfaction with different types of farmers.

\subsubsection{Validation of the ABM with policy makers}

The policy-makers involved in the focus group discussion about the ABM results agreed that they received more knowledge of the impacts of the planned water resource development project for beneficiaries and affected farmers and that they now better understood the negative impacts on affected farmers. This new knowledge can possibly be used to consult and improve planning with the benefited stakeholders. However, due to the strong conflicts, they were skeptical that the knowledge from the model could be discussed in participatory meetings with both benefiting and affected farmers to consult and adjust planning for affected farmers. Satisfaction, moreover, was considered by the policy-makers as the most challenging variable to measure, and a higher overall satisfaction level as determined by the model does not guarantee that the dam would be constructed.

In summary, the advantage of this $A B M$ is that it can show the changes in accumulated income during the different years of dam implementation. The ABM helps to consider the 
impacts of the dam intervention. However, it is hard to apply the results to decide whether the dam should be constructed or not. Besides, it is also hard to refer to the results of the model to negotiate compensation of farmers. Finally, the use of the ABM to consult and codesign dam projects with stakeholders is challenging due to existing laws and regulations concerning dam construction and compensation.

\subsubsection{Sensitivity analysis of affected farmers}

A sensitivity analysis was performed to quantify the effect of different negotiation modalities, considering different incremental levels of compensation and lengths of the negotiation period in the following combinations:

- Default (10\%Y5): $+10 \%$ increase in compensation offered per year for 5 years

- Alternative $20 \% \mathrm{Y} 4:+20 \%$ increase in compensation offered per year for 4 years

- Alternative $30 \% \mathrm{Y} 3:+30 \%$ increase in compensation offered per year for 3 years

- Alternative $0 \% \mathrm{Y} 3:+0 \%$ increase in compensation offered per year for 3 years

The ABM was run 200 times for each scenario. The initial compensation price was kept equal in all scenarios based on a proposed land compensation price at 150,000 baht/rai plus compensation for mature trees on farmers' land (see Sections 5.1 and 5.2.) During the negotiation period, affected farmers continued to receive income from their farm production until they accepted compensation and moved to a new plot.

The effect of negotiation modalities on accumulated farm income is shown in Figure 4.7. Alternative $2(30 \% \mathrm{Y} 3)$ provides the highest income to affected farmers (16.00 million baht/rai). This modality also leads to the highest income for dryland farmers (13.87) and farmers overall (20.78). Clearly, the cumulative income of affected farmers is far more sensitive to the negotiation modalities than is that of non-affected farmers.

The negotiation modality of increasing compensation with $30 \%$ each year for 3 years $(30 \% \mathrm{Y} 3)$ also provides the highest average level of overall satisfaction, at 1.14 , higher than the default (10\%Y5), at 1.08 (Figure 4.8$)$. The $30 \%$ Y3 modality generates the highest level of satisfaction for affected farmers (-0.74). This option, however, does not provide the highest satisfaction to dryland farmers and productive land farmers for whom the $0 \% \mathrm{Y} 3$ modality is best. Nonetheless, differences are negligible for these categories of farmers, whereas affected farmers respond strongly to the modalities. 


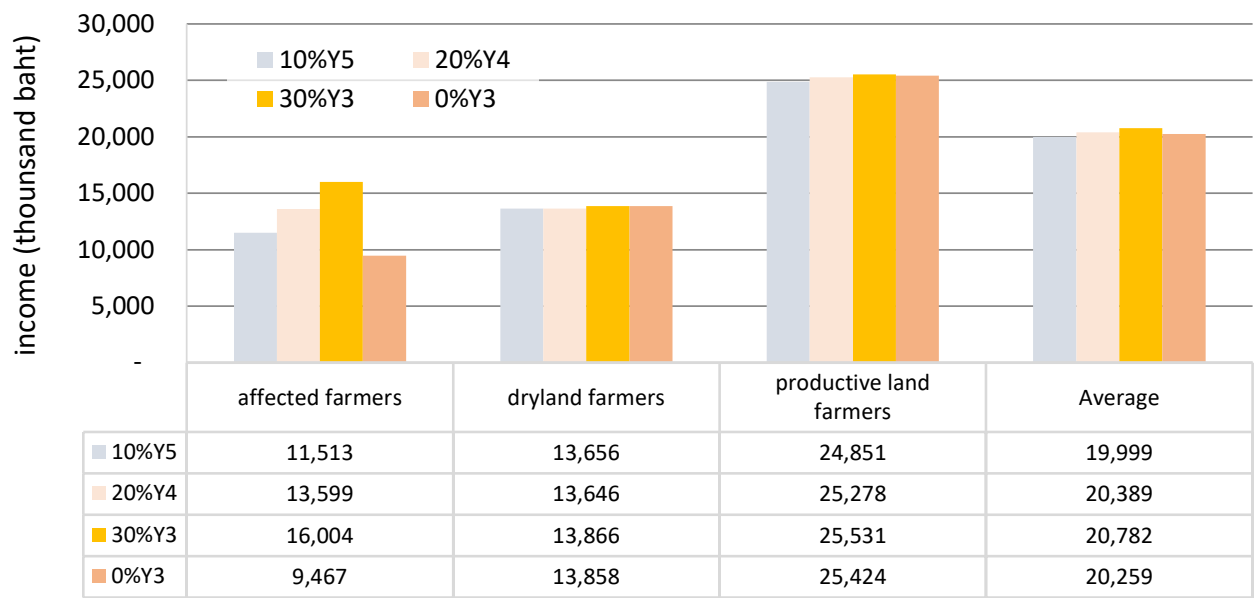

Figure 4.7 Average 30-year income of different types of farmers under four compensation scenarios.

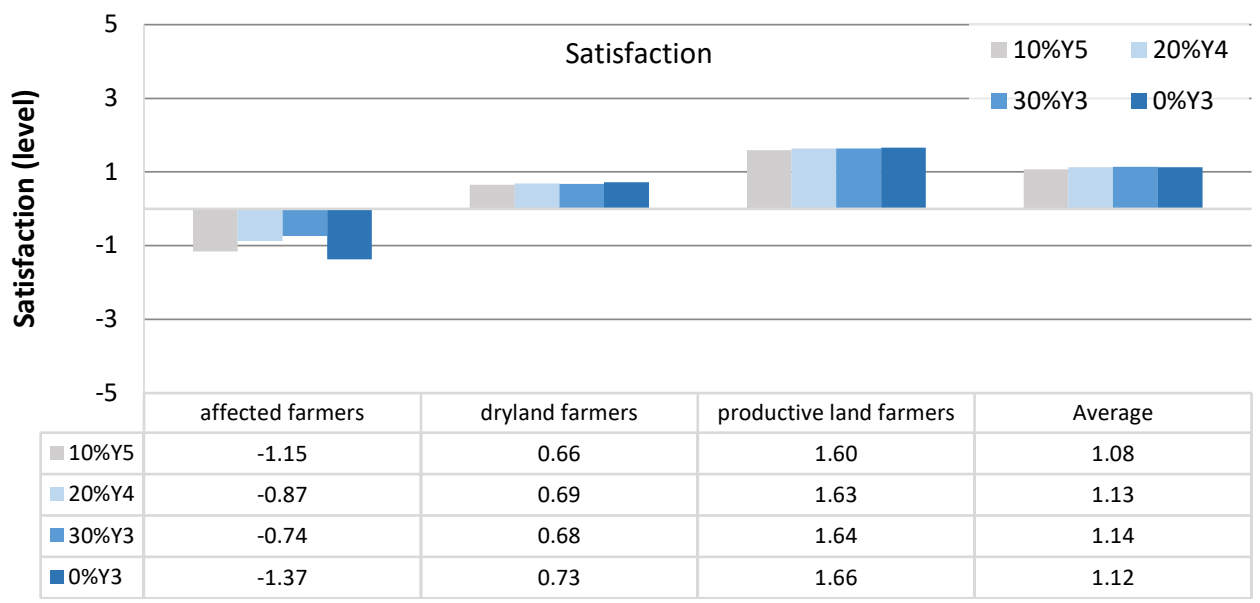

Figure 4.8 Average level of farmer satisfaction for different types of farmers under four compensation scenarios.

This sensitivity analysis indicates that increasing compensation and shortening the negotiation period enables the maximization of income for all types of farmers. Moreover, by increasing compensation levels, the speed of the negotiation process can be accelerated while positively impacting affected farmers' satisfaction scores. Without higher compensation, quick construction of a dam would be preferred by dryland and productive land farmers, but this would come at considerable further dissatisfaction of affected farmers. 


\subsection{Discussion}

Ex ante impact assessment of a medium-scale water resource development project using ABM shows that the dam project would provide collective economic benefits to farmers by allowing dryland farmers more opportunities to select diversified crops to increase their farm income. Thus, the ABM is helpful in assessing the economic and social implications for individual and collective farmers (Berger et al., 2006) on the basis of farmers' behaviors in relation to their resources (Schreinemachers et al., 2010) as a consequence of bringing change in environments of agricultural activities through the construction of reservoirs.

The understanding of the whole irrigation system can provide new knowledge and allow negotiation for mitigating negative impacts in water resource planning (Berger et al., 2007). It has been postulated that ABM can be used in a conflict situation (Akhbari and Grigg, 2013). This paper presented a case where an ABM was compiled with farmers' behaviors and the water resource planning policy of a river basin to comprehend the impacts of compensation on the affected farmers. This ex ante ABM research, therefore, can foster policy-makers to understand affected stakeholders' concerns of impacts for a dam project and predict more suitable decisions to reduce the likelihood of conflicts.

The perspectives of affected farmers involuntarily resettling to other areas were investigated. The mandatory laws and regulations compensated only for the damaged properties such as land, crops, and buildings. However, the displacement of affected farmers needs fair compensation for farmland acquisition and crop values. The compensation of land and crop values by government rules causes unfair benefits and dissatisfaction with the affected farmers. The findings show the collective outcomes of dam planning projects using a common cost-benefit approach. With the low amount of compensation, affected farmers lose the opportunity to receive the income they currently have and would likely be able to continue to enjoy if no dam is constructed, nor can they sustain a new settlement. Therefore, this study argues that the compensation valuation in existing cost-benefit analysis should be improved (Cernea, 2003; Yu and Xu, 2016).

In addition to considering collective outcomes, this study provides some examples of impacts on individual affected farmers facing different limitations. This factor responds to the point made by Cernea (2003), who stated that focusing on collective benefits usually implies no strong calculation of benefits for individual future farm income. Although ABMs are not necessarily good, nor intended, to simulate the effects for individual agents (Schreinemachers et al., 2010), the examples of individual affected farmers investigated contributed a similar result to Rai (2007), who found unequal compensation to individual farmers in a dam study. While Ghatak \& Mookherjee (2014) argue that compensation is 
acceptable when it supports investments by affected farmers, our individual farmer investigation shows that a low mandatory compensation policy would affect decisionmaking for long-term investment and restoration of income and satisfaction after displacement. As such, this study echoes Lebel et al. (2014), who concluded that low compensation levels brought lower income and low satisfaction to affected people and obstructed the dam policy. Insufficient compensation for a new investment in productive land caused less opportunity to select highly profitable crops and suffered from dryland or smaller land sizes.

In the sensitivity analysis, different periods of the start of dam construction also affected the delay in overall given compensation and new restoration of individual affected farmers' incomes. The individuals would still harvest from the previous farmland after they accepted the compensations until the dam construction started. Therefore, the delay of construction might increase the level of overall compensation plus farm income from their existing land. Even though it seems positive to delay the project, this would be an illusion for affected farmers. The delay of starting the construction would also delay the first farm income from new investment. In addition, the later acceptance of compensation would make them unable to afford the more expensive price of new land and obtain land in the first place, as less would be available. Therefore, the time of resettlement and compensation mechanism should be taken into consideration. The improvement of the compensation mechanism can help mitigate the resistance of protesters (Morvaridi, 2004).

Moreover, the investigation of long-term dam building and compensation outcomes is required because a better understanding of the adverse impacts on affected people facilitates a distribution of equality to affected farmers in early-stage planning (Lebel et al., 2014). Although ex ante assessment may not be practical for finding an optimal value of compensation in a situation if stakeholder elicitation is limited (Rakotonarivo et al, 2017), we argue that a suitable combination of earlier dam construction and increased compensation can support decision-making to decrease the inequality among farmers in water resource development. In line with Giuliani \& Castelletti (2013), several stakeholders can be engaged in ABM to support decision-making in a conflict situation. Therefore, this study shows that $A B M$ is an effective tool for the ex ante assessment of farmers' income and compensation for negative impacts using variations in negotiation periods for mitigating impacts and reducing inequality for affected people. 


\subsection{Conclusion}

A new approach to modeling water resource development conflicts is needed that is capable of simulating changes in environments, farm income, and satisfaction under the impact of dam construction and compensation policy. Therefore, an ABM is presented as a tool for the ex ante assessment of the impacts of interventions by simulating farmers' behaviors under resource limitations in real-world environments. Agents are benefiting farmers and affected farmers with conflicting interests in the dam planning process. Compensation is added as the crucial process to manage/resolve conflicts among stakeholders and policymakers in decision-making to implement the dam project. The farmer behavioral framework and methods are explained step by step, including data input. An ex ante assessment is presented for predicted farm income and satisfaction under scenarios with different durations of starting the construction of a dam and overall compensation level. The discussion focuses on the collective and individual impacts according to these different scenarios.

It is necessary to explore a practical technique that can combine multiple disciplines and stakeholder interests. In the participatory planning process, dialogues are not sufficient to present impacts on stakeholders. Policymakers need a clearer understanding of the implications of planned interventions on stakeholders' livelihoods. Affected stakeholders often request compensation for specific impacts they would suffer, which are pivotal criteria for their contribution to the project. Therefore, policymakers need a scenario analysis to illustrate the effects of policy alternatives.

In conflicts over a dam planning project, many arguments were discussed on the changes on affected farmers' livelihoods. A scenario study with the ABM that compares impacts on affected farmers with overall farmers in the next 30 years shows that the affected farmers would acknowledge the inequality of the compensation policy that they lose their land and income, whereas other farmers gain more benefits if the dam is built. Moreover, 30 years is regarded as a long period for affected stakeholders to restore their livelihood from replacement. Compensation is too low to buy new productive land to grow equally highly profitable crops as they could grow if no dam was constructed. The conditions of being able to buy only less productive farmland and experiencing less income during the new crop plantation for 3-7 years causes them to suffer for more than a decade, causing dissatisfaction. These conditions would fuel strong opposition against the dam.

This ex ante impact assessment implies that the dam would increase the collective farm income of farmers in the next 30 years. Most farmers will have more opportunities to select crops for drylands and benefit from more stable water availability for productive land. 
However, affected farmers with low compensation would suffer the opposite results. Opposition can be a practical way for affected farmers to gain more compensation. However, if the negotiation period is too long, the accumulated income would decrease, despite higher overall compensations due to the delay of new land investment. The ex ante impact assessment using agent-based modeling presented here shows just how much dissatisfaction could be avoided in this way. The government, therefore, should improve the assessment method to speed up the new land investment by using future income if there is no dam as the reference level for determining compensation instead of the estimation from the present value of existing land. ABM appears to be a useful tool to explore a multitude of future income scenarios, and the variations in outcomes for benefitting and affected farmers. 


\section{Compensation for dam building: Representation, languages of valorization and outcomes in Thailand}

Compensation of people affected by dam building can be unfair, leading to protests. Several international guidelines exist for compensation procedures that aim at equitable and reasonable compensation. Different criteria and procedures have been proposed for valuation of lost assets and income. We investigated nine dam building projects in Thailand, and evaluated the compensation process and outcomes against the guidelines of the World Commission on Dams and the World Bank. We studied the representation, recognition of languages of valorization in the compensation negotiation processes; and outcomes of the compensation. The results show deficient representation, insufficient attention to multiple languages of valorization, and mostly low compensations.

Based on:

Singto, C., Fleskens, L., Vos, J. (2020). Compensation for dam building: Representation, Languages of valorization and outcomes in Thailand. Submitted to: Impact Assessment and Project Appraisal. 


\subsection{Introduction}

All around the world dams are being constructed for hydropower generation, water storage and flood control. In many cases families have to be resettled because of the dam building. As in many cases those families do not have a voice in the project design and receive low compensation for their lost assets, they start to protest against the dam building. Determining the amount of compensation for people affected by dam building poses a huge challenge. The official rules for compensation often result in low compensation that does not compensate the lost property nor lost livelihoods of the affected people, resulting in increased poverty and sustained protests by the affected people (Hess and Fenrich, 2017; Picciotto, 2013; Shah et al., 2019; Thorkildsen, 2018).

In reaction to increasing critics related to the negative effects of large dams worldwide, the World Commission on Dams (WCD) performed a large review study on the effects of large dams. The seminal final report was published in 2000 and was the result of three years studying by a multi-disciplinary team of experts on large dam projects around the world commissioned by the World Bank (WB) and the World Conservation Union (IUCN). It identified many environmental, economic and social problems associated with large dams, including riverine communities being impacted by displacement without proper resettlement or compensation, lost cultural heritage and declining fish populations.

As part of the WCD evaluation, the socio-economic effects of resettlement of 50 large dam projects were assessed. Scudder and Gay (2006:26) concluded that "Actual or forecast outcomes improved or might have improved the living standards of a majority of resettles in only 9 percent of 44 cases while restoring or possibly restoring them in another 11 percent." This means that for the vast majority of cases ( 80 percent) the living standards of the majority worsened. Inadequate resettlement projects and insufficient compensation for people affected by dams have been widely reported also in more recent studies (see e.g., Blake, 2013; Cernea, 2008; Chalermsripinyorat, 2004; Hoogendam and Boelens, 2019; Kura et al., 2017; Missingham, 2003; Rousseau et al., 2017; Scudder, 2019; Sneddon and Fox, 2008; Yamsiri, 2014).

As main causes for the bad track record of resettlement projects associated with large dams the WCD identified four reasons (WCD, 2000: 191-192): "participation and transparency in planning processes for large dams was neither inclusive nor open, (...) where opportunities for the participation of affected people, and the undertaking of environmental and social impact assessment have been provided they often occur late in the process, are limited in scope, and even in the 1990s their influence in project selection remains marginal (...), little enforcement of existing regulations has contributed to the poor economic, social and 
environmental performance of many large dams (...) and in some countries, there is a lack of legal opportunities for affected groups to seek recourse, therefore lessening the accountability of the project developers."

Resettlement can be arranged if the land is compatible and the affected people agree. This land-for-land compensation often fails because of low productive land and inadequate service levels at the site of resettlement. Compensation at replacement costs for lost land also poses many problems: affected people might have informal or no land title deeds; too low valuation due too low registered prices; no land available to buy; land prices elsewhere are much higher; or later in time land prices increase (Hoogendam and Boelens, 2019; Nakayama et al., 1999; Picciotto, 2013).

Michael Cernea, former Senior Adviser for Social Policy and Sociology of the World Bank, concluded that compensations were generally too low, and could not prevent impoverishment of resettlers. He argues that resettlement and cash compensation should more than cover the lost property and livelihood opportunities of affected households. According to his experience, sufficient funds could easily be made available depending on political will of governments and project owners. Cernea advocates for benefit-sharing as an effective way of compensating affected people (Cernea, 2008). Alternatives for cash compensation could for instance be when affected people benefit from payments for upstream forest conservation to diminish sedimentation of the reservoir (Singer et al., 2014) or fishery from the reservoir (Nakayama et al., 1999).

This article scrutinizes compensation of people affected by dam building in Thailand. Over the past decades the government of Thailand (GoT) constructed multiple Water Reservoir Construction (WRC) projects. There are three categories of dams in Thailand (RID, 2010; 2018a):

(1)Large dams with a hydropower component are built and managed by the Electricity Generating Authority of Thailand (EGAT) and the Royal Irrigation Department (RID). A large dam has either a storage capacity of over $100 \mathrm{hm} 3$, or irrigates more than 12,800 ha, or the size of the reservoir is more than 1500 ha. An Environmental Impact Assessment (EIA) has to be conducted and approved for large dams.

(2)Medium dams, similar to large dams with no hydropower, are constructed and managed by the RID. Medium dams require a less stringent environmental assessment.

Small dams are dams that can be constructed in less than one year.

The presented research aims at better understanding the criteria of the valorization of land and income of affected people and the practices and outcomes of compensation for restoration. This better understanding will help to assess and improve the planning of 
restoration of livelihood in cases of involuntary resettlement. The research looks into the compensation practices of nine dam building projects in Thailand to scrutinize the representation of the affected people, the recognition of their languages of valorization, and the requested, offered and actually granted compensations. We use the World Commission on Dams (2000) and World Bank (2004) guidelines as reference for the evaluation of the compensation processes.

In the next sections we will first present the conceptual framework highlighting the links between representation, recognition, compensation and project approval and introduce the WCD and WB guidelines for involuntary resettlement and compensation. Then the process and outcomes of compensation in the nine dam projects will be analysed. After that we will discuss the outcomes and finally draw conclusions regarding the compensation processes.

\subsection{Conceptual framework}

To study the compensation of affected people we developed a general framework that looks how recognition of values and languages of valorization and representation in the decisionmaking process influence compensation of loss of livelihood of affected people and their acceptance and support of the project. Recognition, representation and (re)distribution can be regarded as strongly connected (Fraser, 1996, 2000, 2005; Schlosberg, 2004). Recognition is related to the cultural dimension of social struggles. The struggle for recognition is about getting respect for, and acceptance of, one's meanings, imaginaries, identities, ideas, values, norms, beliefs, moral and knowledges by others. These "others" primarily concern the decision makers, but also refer to society at large. The way people regard landscapes and ecosystems, and their relationship with society might be different for different groups in society. People express those worldviews in languages of valorisation (Martinez-Alier et al, 1998; Buchanan, 2013). From these different worldviews, combined with different (geographical, economical and institutional) positions, different groups in society derive different interests.

Figure 5.1 visualizes the relations between recognition of values, representation in decision making, compensation and acceptance of projects. Arrow I represents the mutual reinforcement of recognition and representation as outlined in the paragraph above (see also Hart et al., 2019). Arrow II indicates that compensation is more likely to be conform the demand of the affected people if their ideas, values and knowledge are recognized by the decision makers and if they are represented in the body that determines the compensation. 


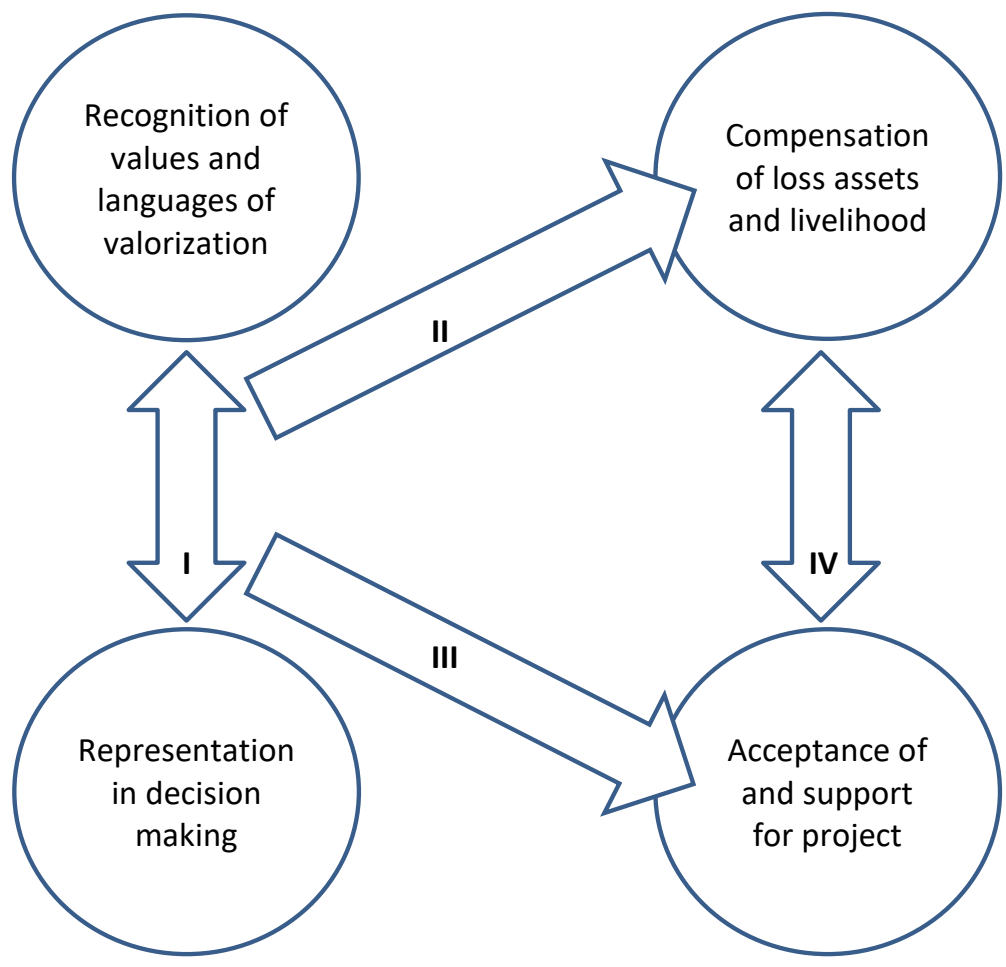

Figure 5.1 The relations between recognition, representation, compensation and acceptance (own elaboration).

To protect the rights of affected people it is important to recognize their values and make sure they have sufficient representation in decision making arenas. However, if the building of the dam is conditioned by the acceptance of the affected people, they obtain a de facto "veto right" that might bear the risk of cancelation of the project (Sneddon and Fox, 2008). This shows it is important to give all local communities - those that benefit as well as those that might get negatively affected - a significant decision-making power regarding the development of the area and not only consider the compensation of the directly affected people.

\subsection{The WCD and WB guidelines for involuntary resettlement and compensation}

The following features of involuntary resettlement and compensation procedures will be taken into account for the evaluation of the nine dam projects in Thailand. They are based on the guidelines from the World Commission on Dams (2000), and coincide with the 
guidelines provided by the World Bank Involuntary Resettlement Sourcebook (2004) and the World Bank Operational Manual (2005).

1. Representation of affected people in decision making (WCD Guideline 1 and 2; WB Sourcebook Chapter 6 and 7)

All stakeholders should be identified and should be able to participate in all cycles of the dam project. Constraints should be identified and resolved to establish a level playing field for stakeholder involvement, especially of minorities and deprived groups. Special attention should be paid to the representation of the stakeholders in the participation and decision making process. Stakeholders should agree on the process of decision making, dispute resolution and timeframe. The WB (2004:124) distinguishes four levels of participation of affected people: dissemination of information to the affected people; consultation about knowledge and options between the project implementer and affected people; collaboration in joint decision making through committees; and "extension of choice" transferring decision making power to affected people. Warner (2006) points out that for affected people the mere "participation" of any type holds the risk that this participation becomes to be seen as acceptance of the outcome of the participation process. Therefore, many affected people do not want to participate as they do not accept the dam project as legitimate and do not believe their voice will be taken into account.

2. Assessment of impacts for affected people (WCD Guidelines 1, 5, 17 and 18; WB Sourcebook Chapter 10)

It is essential to recognize all affected people (downstream and upstream of the dam, and those directly and indirectly affected by the dam and reservoir and other infrastructure), and their existing rights and uses of river water (including fishery) and the drowned land (including grazing, hunting and gathering of non-timber products from forests). Also informal usufruct from water and land resources should be acknowledged.

3. Recognition of multiple languages of valorisation (WCD Guideline 10; WB Sourcebook Chap 15)

Assessment of socio-economic impacts and negotiations about compensation are usually done in monetary terms. Different values and perceptions of stakeholders are mostly not taken into account in project planning (Antunes et al., 2009). However, the WCD recognises the importance of other languages of valorisation: "The methodologies and applications to value environmental and social impacts of dams can be used to ensure that impacts are internalised in the economic analysis where appropriate and possible. Where it is undesirable or not possible to express such impacts in economic terms, they should be considered separately as parameters in the multi-criteria analysis" (WCD, 2000:289; see also WB, 2004:51). 
4. Improve or restore livelihoods and living standards (WCD Guideline 19; WB Sourcebook Chapter 4)

The WB Operational Manual (2014:4, Table A1) states as objective of compensation: "To avoid or minimize involuntary resettlement and, where this is not feasible, to assist displaced persons in improving or at least restoring their livelihoods and standards of living in real terms relative to pre-displacement levels or to levels prevailing prior to the beginning of project implementation, whichever is higher." Benefit-sharing (WCD Guideline 20) with affected people is seen as an effective way to guarantee sufficient compensation. It can be project revenues-related (in a joint enterprise with affected people), project benefit-related (employment or service delivery) or resources-related (access to water) (see also the WB Sourcebook, 2004:340 and Cernea, 2008).

5. Monitoring and enforcement (WCD Guideline 21; WB Sourcebook Chapters 11 and 12) Implementation of plans for resettlement and compensation should be enforced and monitored. This will enhance the chance of a fruitful resettlement and fair compensation.

6. Possibility of appeal and resolution of potential conflicts or grievances (WCD Guidelines 22 and 23; WB Sourcebook Chapter 2)

Mechanisms should be in place for affected people to appeal against decisions. Furthermore, if conflicts arise a third party should be installed to mediate the interests, rules and practices of all involved stakeholders.

\subsection{Methodology}

Nine dam projects were selected based on geographical spreading across Thailand (see Figure 5.2) and available information on the compensation process. We performed a comparison of requested and offered compensation of Water Reservoir Construction (WRC) projects.

The selected dam projects span over a period of five decades (1968-2019). The Rules of the Office of the Prime Minister about public hearings 2548 (2005), and specially the Constitution 2550 (2007) Section 7 Paragraph 2 specify that all development projects have to arrange a participatory processes for affected people to speak out their voices about involuntary resettlements and compensation. As the 2007 Constitution marked a clear change towards a more participatory approach we take the year 2007 as a turning point. Therefore, we classified WRC projects into two periods, before the Constitution of 2007 and after 2007. 
To represent dams implemented before 2007, Sirinthorn, Pak Mun, Rasi Salai, and Khun Dan projects were chosen as information is available about the government and the affected people's perspectives, which allows to assess the outcomes of negotiation on compensation.

Looking at recent projects, after 2007, we selected projects (Prong Khun Petch, TapiPhumduang, Huay Sai Khaw, Wang Hip and Klong Klai) in planning or construction stage (see Figure 5.2). The basic information (Table 5.1) of each project was derived from Royal Irrigation Department reports (RID, 2010; 2018).

Information on the dam projects and compensation was obtained mainly from literature research. For this literature research, three sources were used: first, reports from The Cabinet Resolution of 2 May 1997 (The Meeting Results on Negotiation on the Issues of AOP) and five RID reports: (1) Manual for Water resources Development: Land acquisition for irrigation (2010), (2) Information Report on Irrigation Projects (2018), (3) the Post EIA report of the Khun Dan Dam (1997), (4) the report of studying environmental and social impacts of Prong Khun Petch (2010), and (5) the EIA report of Wang Hip (2015). Second, scientific literature on compensation processes and the specific dam projects was scrutinized. Third, grey literature including reports from NGOs and webpages was used to obtain additional information.

In the case of three ongoing dam projects (Huay Sai Khaw, Wang Hip and Klong Klai) field work was conducted by the first author. Several field visits, focus group discussions and workshops were organized in Wang Hip and Klong Klai by the first author between 2015 and 2019. In the Huay Sai Khaw project 14 affected people were interviewed about land compensation and participation issues in 2019. Two in-depth interviews were conducted with government officials: one working on land acquisition and implementation of the Huay Sai Khaw project and the other one an officer that was responsible for participation and land acquisition in several southern provinces.

To be able to compare the demanded, offered and paid cash compensations between very different geographic locations and time periods, for each project we compare the compensations per hectare with the nominal Gross Provincial Product (GPP) per capita (in current US\$) of the specific province in which the dam was built, in the year of the compensation. The GPP provides an indication of the average income per person in the province in a given year (Powell and Skarbek, 2006). It must be noted that the average income for a household depends on the number of members of a household. The total compensation depends on the size of the land of a household. The compensation/GPP ratio 
(the Comparative Index) offers an indication of the cash value attributed to land compared to the income in a region in a particular year. This index can be taken as a rough indication of the years an average household can live from the compensation, however many specific factors influence the income needed. The Office of the National Economic and Social Development Council (2017) provides the average GPP, The National Statistical Office (2014) provides the average number of members per household (2010), and the agricultural census (2013) the average landholding size per household (all data at the provincial level).

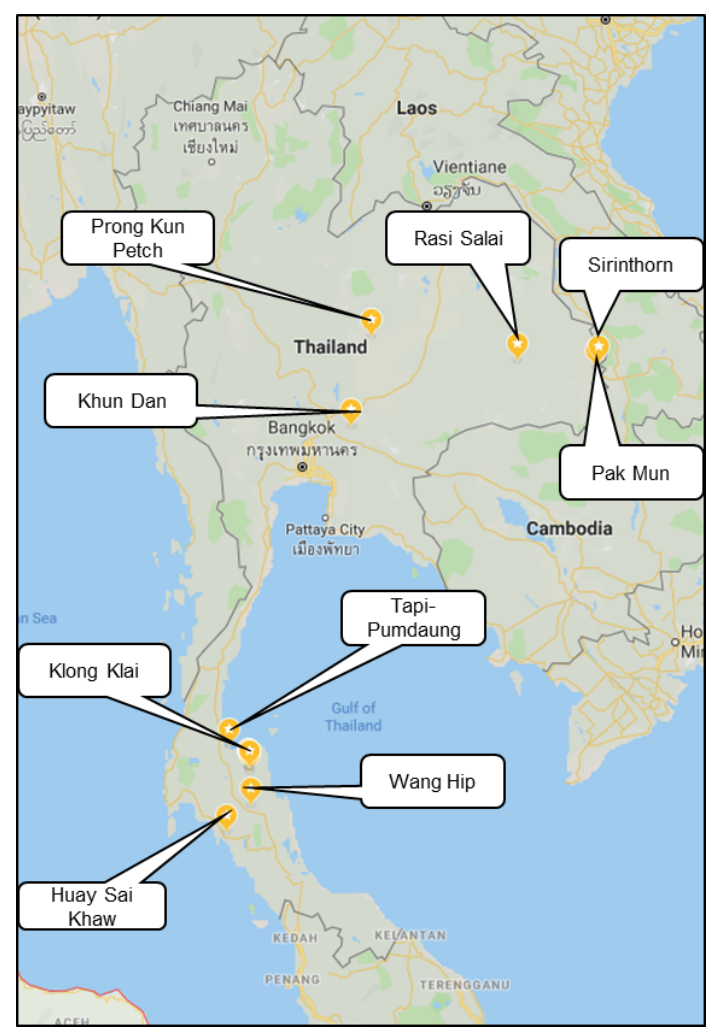

Figure 5.2 Cases of Water Resources Development projects in this article (Source: own elaboration). 
Table 5.1 Basic information of the studied cases (Source: own elaboration from The Cabinet Resolution of 2 May 1997: The Meeting Results on Negotiation on the Issues of AOP; RID report (2018), Singto, (2018).

\begin{tabular}{|c|c|c|c|c|c|c|c|}
\hline $\begin{array}{l}\text { WRC } \\
\text { Projects }\end{array}$ & $\begin{array}{l}\text { Main purpose of } \\
\text { dams }\end{array}$ & $\begin{array}{l}\text { Water } \\
\text { storage } \\
\text { capacit } \\
\text { y (Hm3) }\end{array}$ & $\begin{array}{l}\text { Area of } \\
\text { reservoi } \\
r \text { (ha) }\end{array}$ & $\begin{array}{l}\text { Irrigate } \\
\text { d area } \\
\text { (ha) }\end{array}$ & $\begin{array}{l}\text { Displaced } \\
\text { people }\end{array}$ & $\begin{array}{l}\text { Total } \\
\text { area } \\
\text { affecte } \\
\text { d (ha) }\end{array}$ & $\begin{array}{l}\text { Year of } \\
\text { establishmen } \\
t \text { of } \\
\text { compensatio } \\
n\end{array}$ \\
\hline \multicolumn{8}{|l|}{ Before 2007} \\
\hline $\begin{array}{l}\text { Sirinthorn } \\
\text { 1968-1971 }\end{array}$ & $\begin{array}{l}\text { Hydropower/reservoi } \\
r \text { for irrigation }\end{array}$ & $1,966.5$ & 28,800 & 24,352 & $\begin{array}{l}2,526 \\
\text { household } \\
\mathrm{s}\end{array}$ & 29,200 & 1997 \\
\hline $\begin{array}{l}\text { Pak Mun } \\
1990-1994\end{array}$ & $\begin{array}{l}\text { run of the river for } \\
\text { hydropower and } \\
\text { irrigation }\end{array}$ & 225.0 & 6,000 & 7,200 & $\begin{array}{l}903 \\
\text { household } \\
\mathrm{s}\end{array}$ & $\mathrm{n} / \mathrm{a}$ & 1997 \\
\hline $\begin{array}{l}\text { Rasi Salai } \\
\text { 1992-1998 }\end{array}$ & $\begin{array}{l}\text { Medium-scale } \\
\text { reservoir for } \\
\text { irrigation }\end{array}$ & 74.4 & 1,810 & 12,659 & $\begin{array}{l}2,681 \\
\text { people }\end{array}$ & 8,000 & 2019 \\
\hline $\begin{array}{l}\text { Khun Dan } \\
\text { 1997-2009 }\end{array}$ & $\begin{array}{l}\text { Large-scale reservoir } \\
\text { for irrigation }\end{array}$ & 292.5 & 243,300 & 29,600 & $\begin{array}{l}236 \\
\text { household } \\
\mathrm{s}\end{array}$ & 485 & 1997 \\
\hline \multicolumn{8}{|l|}{ After 2007} \\
\hline $\begin{array}{l}\text { Prong Khun } \\
\text { Petch } \\
2016-2019\end{array}$ & $\begin{array}{l}\text { Medium-scale } \\
\text { reservoir for } \\
\text { irrigation }\end{array}$ & 43.7 & 942 & 4,480 & $\begin{array}{l}352 \\
\text { people }\end{array}$ & 989 & 2011 \\
\hline $\begin{array}{l}\text { Tapi - } \\
\text { Phum Duan } \\
\text { g } \\
2009-2021\end{array}$ & $\begin{array}{l}\text { Medium-scale canals } \\
\text { for irrigation }\end{array}$ & - & - & 11,8367 & $\begin{array}{l}397 \\
\text { people }\end{array}$ & 576 & $\begin{array}{l}\text { Payment in } \\
\text { process }\end{array}$ \\
\hline $\begin{array}{l}\text { Huay Sai } \\
\text { Khaw } \\
2016-2019\end{array}$ & $\begin{array}{l}\text { Medium-scale } \\
\text { reservoir for } \\
\text { irrigation }\end{array}$ & 5.4 & 680 & 480 & 22 people & 159 & $\begin{array}{l}\text { Delayed } \\
\text { compensatio } \\
n\end{array}$ \\
\hline $\begin{array}{l}\text { Wang Hip } \\
2015-2021, \\
\text { not yet } \\
\text { started }\end{array}$ & $\begin{array}{l}\text { Medium-scale } \\
\text { reservoir for } \\
\text { irrigation }\end{array}$ & 20.1 & 5,000 & 2082 & 68 people & 151 & $\begin{array}{l}\text { Under strong } \\
\text { oppositions }\end{array}$ \\
\hline $\begin{array}{l}\text { Klong Klai } \\
\text { new } \\
\text { requested } \\
\text { in } 2015\end{array}$ & $\begin{array}{l}\text { Reservoir for } \\
\text { irrigation }\end{array}$ & $\mathrm{n} / \mathrm{a}$ & $\mathrm{n} / \mathrm{a}$ & $\mathrm{n} / \mathrm{a}$ & $\begin{array}{l}\text { Not yet } \\
\text { known }\end{array}$ & $\mathrm{n} / \mathrm{a}$ & $\begin{array}{l}\text { In planning } \\
\text { process }\end{array}$ \\
\hline
\end{tabular}

\subsection{Results}

\subsubsection{Land Expropriation Laws and Regulations in Thailand}

In Thailand offering land-for-land compensation is virtually impossible because all land suitable for agriculture is occupied by farmers, or situated in protected forest reserves. Therefore, cash-for-land is offered as compensation. 
The regulations on compensation changed between 1995 and 2002 - which can be regarded as a response to prolonged protests of people affected by dams (Missingham, 2003; Chalermsripinyorat, 2004). The NGO Assembly of the Poor (AOP) had an important role in the support of the local protests. The AOP was established in 1995 to protest against the Pak Mun dam, and then expanded to other dam projects in Thailand. AOP is a powerful network which functions as a national platform of local movements, that mobilizes negotiation power vis-a-vis government authorities. They are also supported by international environmental organizations. AOP has formulated alternative options for dam building such as the construction of small weirs in streams (Imhof et al., 2003).

As a reaction to these demands the Thai government implemented public hearings and transparency of information through Act 1997 (2540). The government also cancelled the Sai Buri dam project on 2 May 1997, and approved solutions formulated by AOP for three already constructed dam projects: Sirinthorn, Pak Mun, and Rasri Salai. Furthermore, the government ordered to suspend the activities of four unconstructed dam projects until new participatory studies would be concluded. Out of these four, only the Prong Khun Petch dam has been constructed until present (Missingham, 2003; Sneddon, 2003; Sneddon and Fox, 2008; Yamsiri, 2014).

The Act of Land Acquisition 1987 (2530) established the guidelines for determining compensation levels, i.e. compensation should be based on market prices for land, registered prices for land transactions, character and location, and reason of purchase (RID, 2010). Table 5.2 provides the centralized policy to determine price levels for compensation in case of involuntary resettlement. The Census Committee, chaired by the Provincial Governor, and appointed by the Ministry of Agriculture and Cooperatives, determines the amount of land held and the ownership in case of tittle deeds, and the land used in the case of informal use (without title deeds). The Land Acquisition Act distinguishes 3 methods to determine compensations, depending on the land tenure situation:

(1)Land with title, if landowners agree to sell: the deliberative method is applied. The Cabinet Resolution of 10 Oct 1957 (2500) establishes that first the corresponding department should negotiate a price with the affected people. If they disagree and the land is required, then the Act of Land Acquisition is applied. According to the Act of Land Acquisition of 1987 a Land Valuation Committee is established that determines the price. According to the Order of Ministry of Agriculture and Cooperatives of 7 Sep 2009 (2552) the Land Valuation Committee comprises of the District Governor as the chair and further includes the chief of land registration in the province from the Land Department, the president of local government council, and the chief of land acquisition of RID in the area. 
This price should not be higher than the latest transaction price as registered in the official land transfer register. The Committee proposes the price to RID for its approval.

(2)Land with title, if landowners disagree to sell: The Decree of Land Expropriation is applied with the same Land Valuation Committee. A land survey is issued and announced in places near the disputed land and the local government offices. The land survey is conducted to establish actual size, ownership and crops. The survey has to be completed within two years. If the landowners agree with the purchase, but disagree with the offered price, they may appeal to the Ministry of Agriculture and Cooperatives. This Ministry will assign five land experts to propose their comments to the Cabinet for making a decision. If the landowners refuse the offered price, they may start a lawsuit within a year after the Cabinet decision. (3)Land without title deeds: Cabinet Resolution 11 July 1989 (2532) is applied, whether or not the land users agree. This happens when RID is allowed by the other departments to use the land for WRC, but it finds later that the land is occupied and used by a person or more persons for a longer period, but without land title. The Cabinet Resolution aims to implement the project and compensate this group of people with a "relocation allowance", compensating lost income from land. The process is similar to the previous methods, except the chair of the Compensation Valuation Committee has to be the Provincial Governor instead of the District Governor. There are no concrete criteria for the relocation allowance, but this should be lower than the acquisition price of land with title, which means that theoretically the compensation can be very close to the land with title (but in practice is often half).

Lost perennial crops are also compensated, and this might be a substantial part of the total cash compensation (see Table 5.3). According to the cabinet resolution 11 July 1989 (2532), buildings and perennial crops must be compensated, excluding annual crops. The Census Committee propose the price for compensation from the census survey. The Agriculture Department established a crop valuation method with standard prices decreasing with the years after plantation of the perennial crop (reflecting the deprived future income) and number of trees per unit of land (RID, 2013).

According to the of the Ministry of Natural Resources and Environment (2012), all dam projects supplying an irrigated area of more than 12,800 ha $(80,000$ rai) require an Environmental Impact Assessment (EIA). In June 2013, the Administrative Court ruled necessary a public hearing and an EIA before signing any land purchase contract for all those projects. The EIA evaluates the benefits and impacts of the proposed project. The EIA has to be approved by the Ministry which should have consent of the president(s) of the subdistrict(s) affected by the dam building. The affected communities do not have a veto right. 


\begin{tabular}{|c|c|c|c|}
\hline & \multicolumn{2}{|l|}{ With title deed } & \multirow[t]{2}{*}{ Without title deed } \\
\hline & $\begin{array}{l}\text { Owner agrees with } \\
\text { compensation }\end{array}$ & $\begin{array}{l}\text { Owner disagrees with } \\
\text { compensation }\end{array}$ & \\
\hline $\begin{array}{l}\text { Land acquisition } \\
\text { method }\end{array}$ & $\begin{array}{l}\text { compromising } \\
\text { land acquisition method } \\
\text { paying for titled land }\end{array}$ & $\begin{array}{l}\text { Decree of Land } \\
\text { Expropriation } \\
\text { land acquisition method } \\
\text { paying for titled land }\end{array}$ & $\begin{array}{l}\text { Cabinet resolution } 11 \text { July } \\
2532 \text { (1989) } \\
\text { Relocation allowance paying } \\
\text { for occupied land }\end{array}$ \\
\hline $\begin{array}{l}\text { Assign a } \\
\text { transparent } \\
\text { committee under } \\
\text { different laws }\end{array}$ & $\begin{array}{l}\text { Compensation valuation is } \\
\text { calculated according to the } \\
\text { Land Acquisition Act } 2530 \\
\text { (1987) } \\
\text { Land Value Committee is } \\
\text { assigned by the Agricultural } \\
\text { Minister, the District } \\
\text { Governor is the chair of the } \\
\text { Committee. }\end{array}$ & $\begin{array}{l}\text { Compensation valuation is } \\
\text { calculated following the } \\
\text { Decree section } 9 \text { paragraph } \\
4 \\
\text { Land Valuation Committee is } \\
\text { assigned by the Agricultural } \\
\text { Minister, the District } \\
\text { Governor is the chair of the } \\
\text { Committee. }\end{array}$ & $\begin{array}{l}\text { The price is evaluated } \\
\text { regarding Cabinet } \\
\text { Resolution, then the } \\
\text { affected people can appeal } \\
\text { against the set } \\
\text { compensation. } \\
\text { Land Valuation Committee } \\
\text { appointed by cabinet } \\
\text { resolution, the Provincial } \\
\text { Governor is the chair of the } \\
\text { Committee. }\end{array}$ \\
\hline $\begin{array}{l}\text { Approve } \\
\text { compensation } \\
\text { prices }\end{array}$ & $\begin{array}{l}\text { Check, prioritize and } \\
\text { approve the compensation } \\
\text { by RID }\end{array}$ & $\begin{array}{l}\text { Check, prioritize and } \\
\text { approve the compensation } \\
\text { list by RID } \\
\text { If still disagree, the Cabinet } \\
\text { can approve } \\
\text { Yet refused, appealing to the } \\
\text { court is the final decision of } \\
\text { the price }\end{array}$ & $\begin{array}{l}\text { The Committee assigned by } \\
\text { Cabinet resolution decides } \\
\text { on the offer by the } \\
\text { committee. }\end{array}$ \\
\hline
\end{tabular}

For a better understanding of the actual cash compensation, we looked at the recent dam project Huay Sai Khaw in Krabi province (Table 5.3). The amounts were approved to be paid in 2018-2019. The value of the land was determined by considering three characteristics of the land: land quality and crops, previous land investments, and land location. The affected people themselves claimed market prices for their land, which were much higher than the offered prices. The project did offer slightly higher prices for land closer to roads. However, with the resulting compensations, the affected people could not buy new land. Only smaller plots of land or faraway and unproductive land were affordable for the resettlers.

Affected people can appeal against the determination of the value of their land with a committee consider the appealed compensation if the land has title deeds. If this committee agrees with a higher market value for crops and land the project can pay these higher prices.

Affected people can appeal against the determination of the value of their land with a special committee if the land has title deeds. If this committee agrees with a higher market value for crops and land the project can pay these higher prices. 
Table 5.3 Example of land valuation for cash compensation in Huay Sai Khaw case (source: RID. 2019a).

\begin{tabular}{|c|c|c|c|c|c|c|}
\hline & & $\begin{array}{l}\text { Land } \\
\text { compensation } \\
\text { (US\$/ha) }\end{array}$ & $\begin{array}{l}\text { Number of } \\
\text { palm trees } \\
\text { (trees/ha) }\end{array}$ & $\begin{array}{l}\text { Crop } \\
\text { compensation } \\
\text { (US\$/palm } \\
\text { tree) }\end{array}$ & $\begin{array}{l}\text { Total crop } \\
\text { compensation } \\
\text { (US\$/ha) }\end{array}$ & $\begin{array}{l}\text { Total } \\
\text { compensation } \\
\text { (US\$/ha) }\end{array}$ \\
\hline \multirow{2}{*}{$\begin{array}{l}\text { Offered } \\
\text { compensation }\end{array}$} & $\begin{array}{l}\text { With title } \\
\text { deed }\end{array}$ & 14,570 & 156 & 146 & 22,767 & 37,338 \\
\hline & $\begin{array}{l}\text { Without } \\
\text { title deed }\end{array}$ & 7,285 & 156 & 146 & 22,767 & 30,052 \\
\hline \multirow{2}{*}{$\begin{array}{l}\text { Demanded } \\
\text { compensation }\end{array}$} & $\begin{array}{l}\text { With title } \\
\text { deed }\end{array}$ & 36,831 & 156 & 189 & 29,596 & 66,022 \\
\hline & $\begin{array}{l}\text { Without } \\
\text { title deed }\end{array}$ & 14,733 & 156 & 189 & 29,596 & 44,167 \\
\hline
\end{tabular}

\subsubsection{Description of the compensation processes and outcomes of nine dam projects}

\subsubsection{Dams built before the year 2007}

\section{Sirinthorn Dam}

The Sirinthorn (or Sirindhorn) Dam in the Lam Dom Noi River near the border with Laos was finished in 1971 and serves for hydropower and irrigation. The dam has a modest height of 42 meters, but its reservoir has a considerable $280 \mathrm{~km}^{2}$ of extension. The dam affected 2,526 people that lost their homes and a total of 6,880 ha of agricultural land was inundated. They also lost livelihood from fishing, hunting and gathering non-timber forest products. The affected households were resettled in a so-called Nikhom, a resettlement village. There was no EIA report (because an EIA only became obligatory from 1992 onward). Consequently, there was no representation of the affected people in the planning process. Before the construction, 2.4 ha of fertile land per household was promised for the resettlement. However, the soils at the resettlement site proved to be very infertile. The resettlers also received a cash compensation of US\$ 560 per household (Blake, 2013).

The affected people could not sustain themselves and started to demand better compensation. In 1995 they joined the protests of the Assembly of the Poor. The affected people and the NGO succeeded in having half of the members of the committee to establish the compensation to be approved by AOP. This committee requested 2.4 ha/household or 6,425 US\$/household for the compensation. The government approved this cash compensation on 29 April 1997, and compensation was paid (The Secretariat of the Cabinet, 1997). However, in 1998, the displaced people requested more compensation, because they realized - after they got paid - that they had demanded too low compensation for the land 
and livelihood they lost. The government refused to re-consider the compensation as the payment had already been made.

\section{Pak Mun Dam}

The Pak Mun Dam project was initiated in 1990 and finished in 1994. The main purpose of the dam in the Mun river is the generation of hydropower. The $255 \mathrm{hm}^{3}$ of water storage in the reservoir behind the dam would also provide water for 7,200 ha of irrigated land. When the gates are closed the reservoir inundates some 6,000 ha (Nippanon et al., 2000; WCD, 2000). Originally, in 1985, the number of households to be compensated was determined at 248. However, re-assessment of the census in 1994 identified 903 households. Moreover, fishers claimed the dam had destroyed the river flow system and fishery. As stipulated in the Cabinet Resolution of 2 May 1997, the Impact Mitigation Committee of the Pak Mun Dam re-studied these impacts, and finally compensation was paid to more than four thousand households of fishers. The affected people claimed 3.2 ha or 10,000 US\$/household to compensate for the lost livelihood of fishers. In 1997, the government approved to pay to 3,084 affected households either 2.4 ha/household or 7,025 US\$/household if no land was available and 1,200 US\$/household/year for loss of income during the three-year construction period (The Secretariat of the Cabinet, 1997).

In May 2000 some three thousand fishers occupied the dam site with support of the AOP and backed by the study of the WCD. They requested to open the gates for five years to restore the fish ecosystem (Glassman, 2002; Missingham, 2003). As a result, the government opened the dam gates four months per year (Jul-Oct) for fish to migrate. After these five years the gated were closed permanently (Yamsiri, 2014). Recent research has shown that after initial increase because of the opening of the gates, after the permanent closure, fish stocks declined, also in the upstream tributaries of the Mun River (Baird et al., 2020).

The language of valorisation of the fishers expressed the value of the river in many aspects, not only the fish that sustained their livelihoods, but also the spiritual importance of the river. The inhabitants used to practice religious ceremonies in the Mun's rapids annually. This was not taken into account by the project (Yamsiri, 2014).

\section{Rasi Salai Dam}

The Rasi Salai Dam is a 17 meters high dam with 7 gates built in the middle part of the Mun River. It was constructed between 1992 and 1998 by EGAT with assistance from the WB. No EIA was executed, and the affected people and potential beneficiaries were not consulted. The capacity of the dam is $74 \mathrm{hm}^{3}$, and the created reservoir (when the gates are closed) flooded 8,000 ha of farmland and $\mathrm{Pa}$ Bun Pa Than, or seasonally flooded forest. Apart from the reservoir also rice farmland outside the reservoir was flooded, impeding rice cultivation 
(Sretthachau et al., 2000). The forest wetland is a crucial habitat and spawning ground for migratory fish in the Mekong river system, and the wetland area is also used to cultivate rice, breed cattle, fish and gather non-timber forest products (vegetables, herbs, mushrooms, salt, and fuelwood) (Kiguchi, 2016). The project aimed to irrigate 12,660 ha of land, but a geological salt deposit in the subsoil turned the water in the reservoir too saline. The project originally recognized that the reservoir would displace 2,681 people.

During the construction period, the affected people, organized in a local organization called "Tam Forest Conservation Group" and the AOP demonstrated before the Parliament and requested a new census to determine the exact number of people affected. The NGOs claimed a total of 15,000 people were affected (Imhof et al., 2003). They claimed the census committee should comprise for fifty percent of representatives of the affected people to guarantee fair compensation. As a result, the government ordered a new census and land survey in April 1996. The demand of the affected people was to pay $12,500 \mathrm{US} \$ / \mathrm{ha}$ and additionally a compensation for lost occupation of 9,500 US\$/year for four years of construction. The majority of the people did not have official land titles.

The struggle for compensation led to many political confrontations between factions in the affected villages. After many years, the government decided to pay 8,000 US\$/ha for 1,156 affected people. Later, an additional 1,525 affected people were paid, based on the new census. The compensation process lasted some 30 years, and new requests of affected people continued. The RID paid the last compensations in 2019.

The local inhabitants requested the gates of the dam to be opened permanently as the water was too saline to be used for irrigation and high water levels jeopardized the rice cultivation (Matthews, 2011). Several protests were organized by the villagers and in 2000 the government decided to open the gates for four month each year (Kiguchi, 2016).

Resettled inhabitants were discontent with the project. They were not consulted on the design nor implementation of the project. The compensation process was very slow and caused a lot of political struggle. Many direct, indirect and cultural damages were not taken into account. Furthermore, the project did not deliver on its promise to provide irrigation water, but instead partly damaged the rice fields and natural forest wetland that provided food. The local culture of exchanging fish for rice was severely affected (Shannon, 2005). People used to have several ceremonies throughout the year, like the heet sip song ceremony binding different villages. These are now not much attended as the exchange of products does no longer take place (Mack, 2018). Losing land made most people emigrate to Bangkok for new occupations, and when an economic crisis occurred in 1997 they had no land to return to. 


\section{Khun Dan Dam}

The Khun Dan Prakamchorn dam is the biggest concrete dam in Thailand: with a height of $92 \mathrm{~m}$, a length of $2,720 \mathrm{~m}$. The dam is only a two-hour drive from Bangkok, and the forested scenery and white water rivers attract many tourists, including for rafting. The project was started in 1997 and finished in 2009. The dam's purpose is irrigation and flood control. An EIA was performed before the start of the construction. Its water storage capacity is 224 $\mathrm{hm}^{3}$. The reservoir covers 494 ha and irrigates an area of 29,600 ha. The project required the resettlement of 236 households (27 of them without land titles) (RID, 2001). The government could not arrange new land for all. Therefore, cash compensation was applied to most of the affected people, and all paid before the construction at 50,290 US\$/ha. This relative high amount paid per hectare can be explained by the high land prices in this region, related to the attractive location of the land for tourism development.

If no land was available for resettlement, cash compensation was paid for land with a title deed. For 17 affected people without title deeds, the government arranged that they could rent 0.8 ha in a temple compound at three kilometres distance, at low cost. This served to build houses and practice subsistence agriculture, but was not enough to generate income. A pilot Post-EIA report showed that displaced people who did not earn enough amounted to $34.6 \%$ (RID, 2001). In this project long-term planning and long-term assessment got more attention than in other dam construction projects. Training about service provision and tourism were offered, such as for tour guides or business owners that could run stores or rafting tours.

\subsubsection{Dam projects after 2007}

\section{Prong Khun Petch Dam}

The Prong Khun Petch dam project is a medium-scale reservoir for irrigation purpose which has been under construction since 2016 . The dam should be finished in 2020 . The storage capacity of the reservoir will be $43.7 \mathrm{hm}^{3}$, covering 942 ha to serve 4,480 ha of irrigated area. The project affected 69 households, or 352 people. The dam was approved in 1989. An EIA was not needed due to its small size. Instead, a less stringent environmental and social impacts study was completed in 2010 by Kasetsart University under monitoring of the RID. The compensation was ordered to be paid in 1989 at 1,460 US\$/ha. As of 2019 some had been paid, and some projects were still in process.

Several NGOs requested to study the environmental impact more in depth and the construction to be stopped. Consequently, the government ordered to suspend the project in April 1996. However, some 500 farmers mobilized in favour of the project and demanded 
the continuation of the project in August 1996. During a public hearing in February 1997 some 22,200 people from the five involved districts almost unanimously expressed their support of the project (only 4 people voted against the dam) (RID, 2003; 2011).

Nevertheless, the government ordered to halt the project, together with other dam projects, on 29 April 1997. In reaction, the pro-project protests continued: more than 3,000 people gathered on April 1998; about 2,000 people blocked the main road in January 1999, and in June 1999 some 1,200 people mobilized to request the continuation of the dam construction (RID, 2011).

Meanwhile, also the people that opposed the project, supported by the NGOs, demonstrated to stop the project. Finally, on 20 September 2005, the government allowed to continue the project after a study on environmental and social impacts. This study was done in $\mathbf{2 0 0 7}$ with participation of the communities. Affected people that had received the compensation of 1,460 US\$/ha before the project was stopped in 1992, protested because affected people who received compensation in 2011 received 10,249 US\$/ha. In April 2011, the government endorsed the equal compensation for both groups (RID, 2011). The government approved the continuation of the project in 2016.

\section{Tapi - PumDuang Irrigation System}

The Tapi-Pumduang irrigation system project was approved in 2009. Currently, it is still under construction. It will provide irrigation water to 11,840 ha. No ElA study was necessary because of the relative small size. The project will affect 397 farmers owning a total of 576 ha. After the project approval, the project was met with strong resistance. The affected people claimed to be excluded from the meetings. Around 200 people demonstrated in several places. Nevertheless, the decree of land expropriation was issued in April 2011. Reports in the local media showed different numbers of affected people and area of land acquisition. Uncertainty also arose on the presumed land use change from paddy rice to less water consuming crops as para rubber and oil palm. Compensation of 14,600 US\$/ha with title deeds was offered where the affected people requested 91,240 US\$/ha. The government re-approved the project in 2017 with more participation of the villages (RID, 2019a).

\section{Huay Sai Khaw Dam}

The Huay Sai Khaw project is a medium-scale reservoir for irrigation which construction started in 2016 and planned to finish in 2019. The designed water storage capacity is 5.4 
$\mathrm{hm}^{3}$, and the reservoir will cover $680 \mathrm{ha}$. Some people lost parts of their land, and 22 people had to be displaced. The project, initially initiated in 1978, and officially requested in 1992, aimed to support irrigated land for 7,368 ha for 398 households. The pre-feasibility study was conducted from 1998 to 2001 (RID, 2019b).

Several points were raised by affected people during the interviews performed in the area. One main issue was that the local people had known for years about the execution of the dam, but did not know when construction would start. With the expropriation process underway farmers stopped fertilizing their land, but the construction was only started 15 years after the pre-feasibility study was completed. This affected negatively their production. Many of the affected people indicated that they did not attend the meetings on the process of establishing compensation. The officers did not explain much about compensation but focused on project information, and when they participated they did not share their opinion about the compensation. They rather discussed the compensation outside of the meetings.

As is shown in Table 5.3, land with title deed was offered 37,338 US\$/ha, and land without title deed 30,052 US\$/ha. The payment of the compensation showed many delays due to the bureaucratic fiscal budget system. The payment started in 2017, however, as of 2019 the 22 displaced people had not been paid fully yet. The affected people's requested amounts were almost twice as high, and additionally land prices had increased considerably in the region as result of the increased demand for land. This made it completely impossible to buy the same area of land as lost to the reservoir.

\section{Wang Hip}

The Wang Hip medium-scale dam building project was initiated in 1990. Its main intended purpose was irrigation of 2082 ha, supplementing provision of drinking water for the town of Thung Song (27 thousand inhabitants), and flood control (RID, 2016a: 2017). The construction was planned to start in 2015 and the project would be concluded in 2021. Its water storage capacity would be $20 \mathrm{hm}^{3}$ and the reservoir would cover $81.6 \mathrm{ha}$. It would need to acquire 150.8 ha of land officially owned by 68 affected people. The EIA was started in 2009 and was approved in 2015.

However, the affected people protested fiercely against the construction of the dam. During interviews and focus group discussions during 2016-2017 the affected people demanded clarity about the exact location of the reservoir and expressed disagreement with the necessity of the dam. They regarded the benefits of the project to be unrealistic and overestimated, and the negative effects for the environment and their community to be underestimated. The affected people expressed their love for the river and the landscape. 
As in many other conflicting dam projects, they wrapped big trees in orange and yellow textiles (resembling Buddhist monks) as form of protest. They expressed their discontent because they were not consulted in the EIA process (Singto et al., 2018).

During the EIA process the compensation for land was established at US\$ 41,000 per ha based on the official procedure that uses the officially registered land transaction price and compensation of the lost crops. However, this land price is much lower than the real market price, and the affected people claim their crops, including para-rubber, are worth much more. The affected people demanded US\$90,000 per ha (RID, 2016b), which the RID could not pay. The affected families refrained from participating in the talks about compensation because they did not trust the government. Furthermore, a large part of the rubber tree plantation was situated in a protected forest and not taken into account for compensation.

\section{Klong Klai}

The Klong Klai water resources project was first proposed in 1996 as part of the Southern Seaboard Development Project. The proposed medium-scale dam would have a water storage capacity of $62 \mathrm{hm}^{3}$, provide water for industry development, and affect 95 ha belonging to 64 households. The affected people opposed strongly to the proposed dam project, mainly because the project would benefit the industry rather than agriculture, leading to the cancellation of the proposed project design in 2008. In 2015 some farmers requested RID to develop a new design for a dam to provide water for agriculture, control riverbank erosion, and control flooding in the downstream part of the catchment. The project was started with the newly introduced "Community-Based Irrigation" (CBI) approach, with representatives of the communities participating in the design (RID, 2017; Singto et al., 2018).

The first option discussed with the village representatives was the originally planned dam in Krung Ching. Although now the water would not be for industry development, the village V6 resisted this plan as they feared their land would not be compensated because many did not have land title deeds, or land would not be sufficiently compensated for the current high income from durian fruit production. The second option would be to locate the dam at another location in the watershed. Some villagers would prefer the dam to be built inside a forest reserve, which is not allowed. Currently the process is underway to find another location for the dam. The problem of the location and proper compensation recognizing all interest proves to be very difficult. Balanced representation of different groups in the design process, trust, and access to information are needed to come to fruitful negotiation, but have been insufficiently present until the end of the field research in 2018, despite the participatory $\mathrm{CBI}$ approach. 


\subsection{Discussion}

In this section we will discuss and compare the nine cases according to the six features of involuntary resettlement as presented in the Section 3: (1) Representation of affected people, (2) Assessment of impacts, (3) Recognition of multiple languages of valorisation, (4) Compensation, (5) Monitoring and enforcement, and (6) Appeal.

\subsubsection{Representation of affected people}

According to the WB and WCD guidelines, affected people should be able to participate in all four levels: be informed, be consulted, by collaboration, and by joint decision-making. In Thailand, the 2007 Constitution stipulates that affected people must be heard. Laws and regulations stipulate various mechanisms for participation: through EIAs, through public hearings, and through representation in the Land Valuation and Compensation Committees. Consultation in the overall project objectives and design is recently introduced through the Community-Based Irrigation (CBI) approach.

The pre-2007 cases (Sirinthorn, Pak Mun, Rasi Salai and Khun Dan) show little participation of affected people in the project. In the first three cases the issue of lost fishery and other non-agricultural benefits from the submerged places caused most contestation. In the Khun Dan case the compensation per hectare was high, but resettled people were forced to find income from tourism.

The post 2007 cases (Prong Khun Petch, Tapi-Phumduang, Huay Sai Khaw, Wang Hip and Klong Klai) show different forms of participation of the affected people. In the case of projects with prior ElA studies the affected people were informed and consulted. However, in most cases information provision to - and representation of affected people in the Land Valuation and Compensation Committees - was deficient. Although community-based design can be useful in resolving conflicting interests related to dam building (Del Bene et al., 2018), in the Klong Klai case, the newly introduced CBI did not yet lead to joint design of the WRC project because of mistrust and conflicting interests of the villages.

\subsubsection{Assessment of impacts on affected people}


When assessing the impacts of dams it is important to take into account all affected people and their direct and indirect uses of the river and drowned land, according to both WCD and WB. In Thailand the assessment of impacts can be part of the EIA or public hearing.

From the pre-2007 cases it becomes clear that the Thai law had great difficulty in recognizing the impact on fishers. Also, the impact on hunting, grazing and gathering of non-forest products were mostly ignored. This makes that large differences exist in the number of people that claim to be impacted, and the actual number of people recognized as affected. For the government it is hard to determine non-land based deprived people as it risks attracting and rewarding non-grounded claims by outsiders. This problem could be tackled by working closely together with the local communities that know and have registered the people using the affected resources. Another major problem for the compensation is the fact that many affected people do not have title deeds of the land they cultivate. This is tackled by granting them a relocation allowance, but at lower rates as compared to the land with title deeds.

In the post-2007 cases we selected these issues continued. In the Huay Sai Khaw Dam project the long period (15 years) between the initial project meetings and the start of the construction created much uncertainty and not-compensated loss of income. In the Prong Khun Petch and Tapi-Phumduang projects, the affected people accused the government of not wanting to conduct an EIA while this was demanded. In Wang Hip, the EIA was not executed well as part of the affected people was not consulted. Enríquez-de-Salamanca (2018) argued that the possible bias in the EIA can be reduced by balancing well the political power of the stakeholders in the assessment process.

\subsubsection{Recognition of multiple languages of valorisation}

The WCD Guideline 10 and WB Sourcebook Chapter 15 stress the importance of recognition of other than economic values. The compensation process in Thailand focusses on monetary compensation. The language of valorization of the government is on the market value of the land and buildings, as officially registered, and the cash value of the perennial crops on that land. The villagers also use the economic values to express the value of their land (although they claim higher prices), but also deploy other languages of valorization. In the case of Wang Hip for example, affected people stressed the ecosystem and natural values of the river. In many cases the inhabitants attribute spiritual and cultural values to the river and forests (see the two dams in the Mun river), and attribute high value to the security of landbased or fishery-based livelihoods. In the case of Rasi Salai the social cohesion related to the exchange of products was lost. 
In negotiations about the compensation, demands from affected people might not directly relate to the value of their property or livelihood. They express their disagreement with the project rather than disagreement with the compensation as such. They might oppose the dam construction for various, very different reasons, related to mistrust in the government; disagreement with the public purpose of the dam, the technical design of the project, or with the destruction of the natural habitat and aquatic and forest ecosystem. In this sense the opposition and protests of affected people are not always to demand better compensation.

\subsubsection{Compensation and restoration or improvement of livelihoods}

Both WCD and WB stress the importance of a compensation that improves the livelihoods of the affected people, which could preferably take the form of benefit-sharing to restore livelihoods (Cernea, 2008). In Thailand the compensation is based on the Land Acquisition Act of 1987. In the regulation the land price is the market price, as registered in the official register of land transactions. It takes into account not only the land with officially registered title deeds, but untitled land also. In Thailand benefit-sharing is not practiced as way to compensate affected people.

Table 5.4 provides an overview of the economic values demanded by the affected people and the compensations approved by the government. Table 5.4 shows that these approved prices were lower than requested, except for the Sirinthorn dam. The requested prices referred to the market value, where the approved prices reflect the registered prices from the Land Department. We compared the offered compensation with the GPP. Strikingly, this "Comparative Index" decreased if we compare the before and after 2007 projects (especially if we do not consider the Khun Dan case, with its exceptionally high land price). The index decreases from 10 (for the pre-2007 projects, excluding the Khun Dan case) to 8 (post 2007 projects). This would indicate that approved prices per hectare decreased over time as compared to average income in the region of the dam project. 
Table 5.4 Demanded and offered land compensation compared with GPP per capita

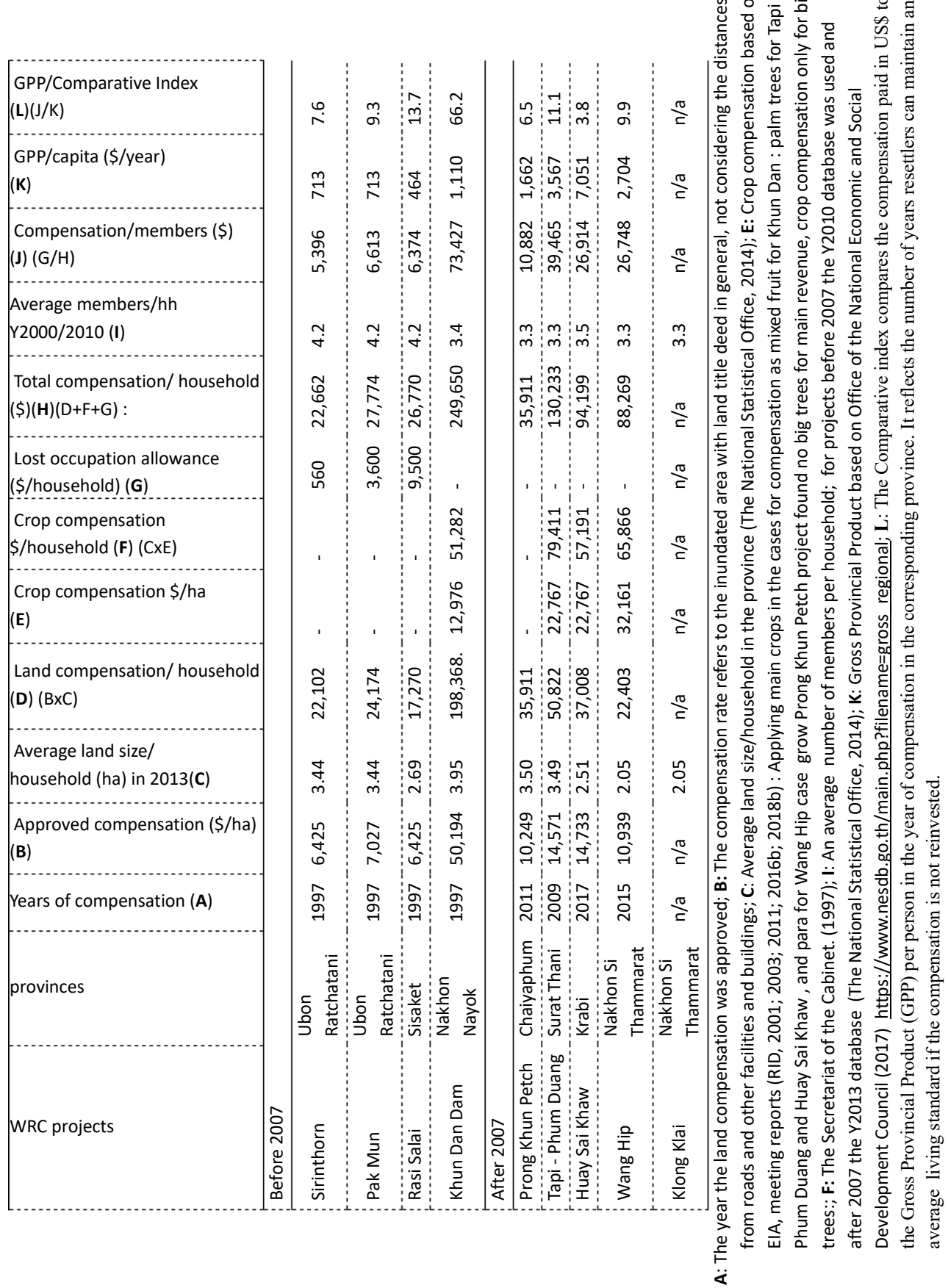


In absolute terms it becomes quite clear that families cannot live long from the cash compensation they receive for their land. An example calculation for the Wang Hip project to illustrate this: assuming a household has 3.3 members and 2.05 hectares of land their cash compensation would be $2.05 \times$ (US\$10,939 for land + US\$32,161 for crop) = US\$88,269. The household would need some 3.3 x 2,704 US\$/year/person, or 8,923 US\$. The Comparative Index is 9.9, implying the family could only live some ten years from their compensation. This finding is in line with Vanclay (2017) and Cernea (2008) that although improvements are made in consultation of affected people in dam planning processes, there are high risks of impoverishment of affected people.

\subsubsection{Monitoring and enforcement}

According to WCD Guideline 21, implementation of compensation agreements should be monitored and enforced. In Thailand EGAT and RID are responsible for executing the payment to affected people. In the studied cases, approved payment schemes were executed but sometimes took many years, which affects the affected people negatively.

\subsubsection{Appeal}

The WB and WCD emphasise the importance of mechanisms of appeal against decisions on compensation. In Thailand this is regulated through an appeal to the Ministry of Agriculture and Cooperatives that assigns an expert committee or a law suit (RID, 2010). In the studied projects several cases were brought to court, but usually with little effect as to the increase of the offered compensation at collective level. At individual level court case might be successful, but no information was available to check this.

Apart from the formal way to appeal many protests were organised by affected people at the dam building sites and in front of the Parliament building in Bangkok. These protests were mostly ineffective in the sense that they did not result in higher compensations as in cases of Sirinthorn and Rasi Salai Dams.

\subsection{Conclusion}

The compensation of affected people of nine dam construction projects in Thailand was scrutinized against the guidelines of WB and WCD. The findings show that before the 2007 Constitution the representation of affected people had been limited (for example no EIA 
was needed). Strong opposition of affected people against the dam projects, such as in the cases of Rasi Salai and Pak Mun dams, made the government open the gates five years for four months to restore fish stocks. In some cases, the cash compensation was increased because of the protests.

The comparative analysis relating compensation for a household member with GPP per capita revealed that in most cases the cash compensation was not sufficient to buy back new land. After the law of participation was enforced by the Constitution 2007, the compensation decreases as compared to the GPP per capita. The Comparative Index decreased from an average of 10 to 8 . Increased representation is expected to increase recognition and compensation. However, our case show that after the 2007 Constitution with more representation, on average, the compensations relative to the GPP decreased. An explanation for this might be that the affected people did not participate in the early planning processes. It must be remarked that this conclusion is based on only a small sample of 7 dam projects, so more research should be done to be able to draw conclusions on the effect of the 2007 Constitution on the levels of compensation.

Thai government plans to build many more dams in the years to come, therefore it is important to consider more effective representation of affected people in decision making and recognition of their language of valorisation to guarantee fair compensation. Compensation should be on the agenda in the early planning stages and village communities should be involved in land surveys and census committees to determine who is affected. Also non-land-based income and non-economic values should be taken into account. The government should shift from present formally registered market values to deprived future income as a baseline to compensate. This shift of objective may increase compensations substantially, and consequently also increase costs of investment. An alternative might be to offer benefit-sharing from the projects revenues. 


\section{Synthesis}




\subsection{Problem, Objective and Research questions}

In 2015 the United Nations unanimously adopted a Sustainable Development Agenda containing 17 Sustainable Development Goals (SDGs.) SDG 16 is Peace, Justice and Strong institutions, with Target 16.7 to "Ensure responsive, inclusive, participatory and representative decision-making at all levels" as being an essential element for sustainable development. One of many stadia where this comes into play is in the provision of water involving construction of dams and reservoirs. Governments and their institutions play a key role in responding to a rising demand for water, especially in water scarce peri-urban areas (Roth et al., 2019) and more urgently now due to climate change (for Thailand see: Kaewthong and Ditthakit, 2018). Participation in discussions concerning Water Reservoir Construction (WRC) projects is important as trade-offs between people's livelihoods, ecological values and economic development raise conflicts among stakeholders, i.e. government and affected people. Thailand is all too familiar with this situation.

Participation can be at different levels, from informing, consulting, and co-designing, to empowering involvement (Reed, 2008; WB, 2004). Lack of effective participation can and has resulted in conflicts, protests and cancellation and abandonment of WRC projects, leaving many potential beneficiaries unserved. The challenge is to discover how to realize SDG Target 16.7, in this instance in Thailand.

\section{The research problem}

The research problem addressed in this thesis is the lack of understanding of the effects of particular forms of participation on knowledge co-creation, decision making, trust, and project outcomes. This is an important topic to investigate because different forms of stakeholder participation have very different outcomes for the stakeholders. The different levels of participation facilitate particular forms of knowledge co-creation, different degrees of involvement in decision-making, and building of different levels of mutual trust (O'Faircheallaigh, 2010; Bryson et al., 2013).

In Thailand the Royal Irrigation Department (RID) is responsible for the design and implementation of medium-sized water reservoirs. As in the case of large dams, mediumsized dam projects also receive much opposition from the local communities that are affected negatively by such projects. People involuntarily displaced due to land acquisition valorise (and complain about the loss of) community livelihood, income from land-based activities and occupations, also pointing to poor restoration of livelihood, and inequity in benefit sharing (Vanclay, 2017). 
Since the Participation Act of 2003, the RID has conducted participation processes in many projects, but opposition against many projects has continued to persist. In 2015 a new, more participatory approach was introduced: Community-Based Irrigation (CBI). The idea was that more effective participation could overcome opposition, and more sustainable and equitable projects could be built based on balancing of interest, trust, and co-creation of knowledge.

In Thailand, affected people often refuse to participate in planning arenas arranged by government officials. The involved parties have high levels of mistrust regarding the intensions of others. There is little research on actual practices of participation in WRC projects in Thailand and their effects. This thesis research has sought to make first steps in filling this void and exploring possibilities for introducing new approaches for participatory planning. Potential practices and tools are proposed to improve participatory processes, encourage co-designed options, limit uncertainties from proposed WRC projects, and introduce greater recognition of affected communities. Applications of the potential practices and tools aim to mitigate negative impacts, reduce conflicts between government and affected communities, and encourage social learning leading to more inclusive designs and equity in the outcomes of the WRC projects.

\section{Objectives}

More strongly engaging stakeholders in determining alternative water resource interventions should be institutionalized. A Participatory Integrated Assessment (PIA) approach was studied in Thailand to investigate whether it can support more sustainable development of medium-scale water reservoir construction (WRC) projects.

The main objective of the study was to evaluate participatory processes in water resource development projects. The aim was to see whether and how the project outcomes incorporated the values and perspectives of affected stakeholders, and how that could be improved. To accomplish this, this thesis research had four sub-objectives. First, to develop a framework for assessment of participatory processes. Second, to study how stakeholders can elicit their perspectives through participatory modelling. Third, to investigate ex-ante outcomes of proposed dams by integrating equity considerations and criteria relating to stakeholders' perspectives in agent-based modelling. And fourth, to create a framework and set of variables using language of valorisation from affected people's interests and knowledge to mitigate conflicts and reach agreeable outcomes.

The main research question was:

How can Participatory Integrated Assessment (PIA) improve process outcomes of water resource projects in Thailand? 
The four related sub-questions were:

SRQ1:How are stakeholders engaged in water reservoir construction projects and how do their inter-relations influence project outcomes?

SRQ2:What role can participatory modelling play in eliciting and reconciling stakeholder perspectives on water resource planning?

SRQ3: What are the impacts of WRC on affected stakeholders and what are possible solutions for negotiating better outcomes?

SRQ4:How can different language of valorisation in dam planning conflicts be recognized as relevant criteria in a WRC planning framework to enhance participation and compensation to affected people?

\subsection{Review of main findings of the research}

This thesis scrutinised the participatory process and outcomes of medium-scaled dam projects in Thailand. The main research question was: How can Participatory Integrated Assessment (PIA) improve process outcomes of water resource projects in Thailand? Discussion of the findings and conclusions regarding this main question are presented later in this chapter. A brief overview of the findings of the sub-research questions are presented here.

\section{Assessing participation in water resource development}

The first research question was "How can Participatory Integrated Assessment (PIA) improve process outcomes of water resource projects in Thailand?" Drawing on theoretical principles of participation, including empowerment, equity, trust, and learning as well as the micropolitics of power and representation, two contrasting water reservoir construction projects were analysed. One was a top-down planning project (Wang Hip), the other a project implemented with the new Community-Based Irrigation (CBI) approach based on bottomup stakeholder consultations (Klong Klai).

Not surprisingly, lack of representation was found to hamper the fostering of trust in affected people and led to the exclusion of some affected people in knowledge sharing and decision making. In the top-down case affected people were ignored in the design process when important decisions (may) have been made concerning engineering options and economic developments (claimed by the affected people) before they were consulted during the planning stage. Interestingly, even in the bottom-up case where there was opportunity for representation, it became clear that fostering of trust can be difficult. 
In the top-down project (Wang Hip), the agenda setting at the negotiation table was clear: the government made the decision on the project goals, design, budget and implementation. Water supply for agriculture was set as the first priority, with industry and flood control for the town also considered high priority objectives. As noted by Jimenez (2016), an authoritative agenda may be practical for fast and manageable success, but negotiating on a pre-set agenda leaves little room for adjustment. In this case the limited information sharing with stakeholders about the project and the top-down decision-making deepened the conflict and opposition.

In the bottom-up project (Klong Klai), relations between stakeholders were already troubled due to a previous (cancelled) project proposal for constructing a dam. Consequently, the participatory platform was viewed as a tool to put the building of the dam back on the agenda, reflecting the continued mistrust by the opponents of the previous project. Implementation of participation faced difficulties as meetings were met with great resistance by some affected people which was manifested by them not participating. So, although designed to increase participation and reduce opposition, the CBI process proved deficient in practice. Knowledge was not explicitly shared in the planning process. Therefore, social learning clearly did not happen.

While in the top-down project the focus was on informing and negotiating compensation, the bottom-up approach expected to discuss acceptable solutions. Although some acceptable options were raised by the community, the agenda was not clear or trusted by the participants. Thus, the process was hijacked and paralyzed by the lingering effects of the former process and planned project. Additionally, different languages of valorisation were not appreciated in the negotiation process which further reduced trust. Among other things, this led to the insight that mediation is vital for successful participation and plays a crucial role in building an atmosphere of trust, relationships, acceptable agreements, and future collaborations.

In conclusion, participation was difficult to arrange in a situation where there was existing conflict, but it was still necessary to implement for more sustainability. The CBI approach may render projects less efficient in term of time, budget, and lower overall benefits. However, it may also reduce conflict, which would be a long term benefit. Better design of the processes would help discovery of more acceptable outcomes. Applying the framework of Reed (2008), which emphasizes that participation has to have a focus on empowerment, equity, trust, and learning, the $\mathrm{CBI}$ process revealed representation issues in the empowerment of $\mathrm{CBI}$ members who should be held more accountable by their communities, even though they were assigned by community leaders who the stakeholders trust to solve their problems. Moreover, lack of trust affected learning among stakeholders. 
Increasing participation calls for a standardized approach to more effectively organize representation, assign accountability, and uphold the quality of facilitation in the participatory process.

Participatory modelling for understanding affected people's perspectives and concerns, and to explore and co-design options for water resources interventions

The second research question addressed was "What role can participatory modelling play in eliciting and reconciling stakeholder perspectives on water resource planning?" A Bayesian Belief Network (BBN) modelling framework was developed to explore stakeholders' views on water resource management issues and interventions. The initial framework began with variables and links between variables and was reviewed through a participatory planning process taking stakeholders' interests and concerns into account. Conditional Probability Tables (CPTs) were built using information elicited from stakeholders, which helped to understand their perspectives. Community perspectives and expert knowledge were combined in BBN workshops to co-create system understanding. Negative perspectives that 'the dam would damage affected people's livelihoods' and that 'livelihoods could barely be restored with low compensation' were included as critical issues that required consideration in early project planning.

Application in the two case study projects (Klong Klai and Wang Hip), made it clear that the participatory BBN development was more practical for stakeholder consultation in bottomup projects, whereas application in a top-down context, in which a decision was already made, was more challenging.

In the top-down planning case (Wang Hip), affected stakeholders insisted on fixed perspectives and expressed strong resistance to the dam. The difficulty of negotiation was evident in the probability of events in the CPTs. In this case, co-design or consultation could not be organized. The BBN was only practical for informing and presenting variables and their relations, and investigating affected stakeholders' perspectives. Participants did not believe in links between the dam and benefits of the dam. Effective and systematic participation before making a decision can enhance the acceptance, if the participation is used to inform options to manage uncertainty and restore livelihoods. However, it also became clear that compensation is not likely to promote acceptance if the compensation rates are low and do not consider long-term impacts. To address these concerns, options for resettlement planning and benefit-sharing need to be identified and considered fair.

In the case where a bottom-up approach was used (Klong Klai), the BBN development process was more practical for stakeholder consultation and co-design. The participatory meetings that were organized for two years before the BBN workshops had built trust 
between communities. The BBN workshops facilitated policy-makers' understanding of participants' perspectives in relation to intervention options in the early stages of planning. Additionally, participants could more easily understand variables and interactions as well as other stakeholders' interests through the links and likelihood indications in the CPTs. This allowed negotiation for benefit sharing. The dam location and inundated area were issues raised by the community, and discussions emerged on land exchanges among (potentially) benefited and affected people. Some critical variables, i.e. compensation and displacement, were omitted from the discussions to avoid conflict in the early planning stages. Uncertainty about farm income after displacement also emerged as a pivotal concern requiring further analysis.

Through sensitivity analysis, it was proven that participation in early planning garnered higher acceptance from the community. The BBN development process was intuitive for the participants, although it needs several iterations before participants understand how CPTs function. The BBN workshop asserted critical variables of displacement and compensation in the co-creation process, when participants trusted the process and had a clear agenda. It is of course important that data for each state of variables and criteria should be adjusted when more concrete data are available Interestingly, increasing compensation may not increase the level of acceptance if the decision has already been made. Therefore, the agenda of compensation should not be ignored in this first stage. Benefit-sharing may be discussed to create potential options at first.

Ex-ante impact assessment of reservoir construction projects for different stakeholders using Agent-Based Modelling

The third research question was "What are the impacts of WRC on affected stakeholders and what are possible solutions for negotiating better outcomes?" An agent-based model was developed to explore the impacts of WRC under various scenarios. Agent-Based Modelling $(A B M)$ is a practical tool for ex-ante assessment as it enables the combining of various environmental and socio-economic conditions with farmers' behaviour to simulate the outcomes of proposed options. The results, while not all surprising, indicate that $A B M$ is a useful approach for getting a more detailed picture of impacts on different stakeholders.

Without a dam, dryland provides the lowest farm income. Farmers cannot change crops due to water limitations. Satisfaction is limited. With a dam, accumulated income increases for all farmers except affected farmers, who must find new productive land and invest in new tree crops which is difficult due to low compensation. More water storage also stabilizes water supply to the farmers living near the river and downstream. 
However, while many parties benefit, the negatively affected people cannot maintain their livelihood and income in the short term, due to involuntary displacement related to construction of the dam. While compensation is requested for farmland and crops, the findings revealed that official rules on compensation seemed unfair to affected farmers, with an income loss of almost fifty percent. Extreme decreases in satisfaction of affected stakeholders were observed, caused by uncertainty over their livelihood at the start of resettlement. It can take ten years before satisfaction levels recover. Although relocation decreased satisfaction greatly, investigations revealed that shortening the period of uncertainty by speeding up the negotiation process about compensation helped displaced people to relocate to better quality land and invest in new crops.

The ex-ante assessment of dam planning by applying $A B M$ is helpful for identifying and giving attention to specific groups of stakeholders who experience different opportunities and limitations from a project. Inequitable compensation cannot restore income and sustain livelihoods lost by negatively affected parties. With conventional cost-benefit analysis, the focus is on collective assessment rather than classified groups of stakeholders. The ABM approach allows iterative experimentation with, and gradual improvement of, criteria for compensation, e.g., sharing of benefits, using negotiation to reduce the inequality gap. This is helpful for clarifying opportunities for long term livelihood restoration early-on in the planning process.

\section{Framework for dam building compensation}

The fourth and final research question was: "How can different language of valorisation in dam planning conflicts be recognized as relevant criteria in a WRC planning framework to enhance participation and compensation to affected people?" This research question is linked to the key objective of proposing a framework for consideration of affected people and critical criteria, language, processes, and practices. It also aimed to assess past performance of compensation of affected communities in water reservoir construction projects in Thailand.

The framework applied considered 1) Representation of affected people in decision making, 2) Assessment of impacts for affected people, 3) Recognition of multiple languages of valorisation, 4) Improvement or restoration of livelihoods and living standards, 5) Monitoring and enforcement, and 6) Possibility of appeal and resolution of potential conflicts or grievances. Moreover, cash compensation was benchmarked using Gross Provincial Product (GPP) in the year of compensation to calculate a comparative index.

Nine dam construction projects in Thailand were evaluated based on the framework. A comparative analysis was made of projects initiated before and after the constitutional 
change in 2007 promoting participation laws in the country. Compensation for lost assets is based on the Acquisition Act of 1987 that suggests three methods to determine compensations. All led to low compensation and often conflicts and fierce opposition to the projects.

The findings of this research show that the participation approach and compensation practices used in Thailand did not lead to livelihoods being restored to at least the same level as before displacement. In the nine projects studied, because of the official compensation rules applied, compensation was significantly below what would be required to restore livelihoods. Among the projects dating from before 2007, participation by affected people mostly started after the projects were opposed. In projects initiated after 2007, participation was performed through Environmental Impact Assessment (EIA) or environment assessments; yet, these projects mostly informed rather than consulted on compensation. The compensation applied the replacement cost method to value lost assets, limiting options for livelihood restoration due to low compensation values for land without title and uncertainty regarding project implementation.

Additionally, the languages of valorisation used by affected people mainly focused on ecosystem and natural values with the intention of opposing dams on that basis, but also included income from fishery that was not considered in the compensation regulations that only focus on land-based income. Although compensation should be directly negotiated in early planning, it is usually negotiated only after the dam construction has been approved. When negotiation on compensation is not on the agenda destruction of environment is used as an argument to oppose dam projects instead.

\subsection{Limitations and challenges of the research methodologies}

Before discussing the answer to the primary research question and the implications of this research project for dam construction policy, it is important to mention several limitation and challenges of the field research, which have some impact on the applicability of the general conclusions to all dam projects in Thailand. Five main difficulties were: the extended duration of the project cycle; restricted access to project documentation; limited availability of input data for modelling; the relation between the researcher as a functionary of RID and affected communities and NGOs; and the limited number of cases studied.

The length of the project planning and design process in both Klong Klai and Wang Hip extended well beyond the field research period. This meant that neither the final design, nor the implementation, let alone the completion of the construction could be researched. The projects had also started before the start of the field work, although the project histories 
could be reconstructed through interviews and project documents. To assess the effects of the dam construction projects the compensation outcomes of six completed projects were studied.

In several cases it was proved to be difficult to obtain documents related to ongoing or finished dam projects. This difficulty was because not all details of the design and negotiation processes are documented or archived. This was overcome by additional literature research, including the use of news media and NGO internet sites, and interviews.

For the construction of the BBN and ABM models, various data were required. These data proved to be available to only a limited extent. Workarounds to cover this gap involved filling in missing data with local and expert knowledge, and the use of sensitivity analysis to understand which parameters had the largest impact on model outcomes. The use of the BBN models to understand stakeholders' perceptions of how the system functions and expected impacts did result in models that helped decision-makers understand the key factors affecting local stakeholders' perceptions. However, collecting data before and during the design phase of projects, and having data available on changes that occurred after WRC project implementation in comparable contexts would have helped to improve the models.

Regarding the relationship between the researcher and local communities, the researcher being attached to RID, the same organisation that was executing the dam projects, was both an advantage and a disadvantage. As an insider to the organisation he could obtain information directly from colleagues, and access RID documents and project documentation. However, in the face of the many conflicts with affected communities, the position as a functionary of RID posed some limitations during the field work. Mistrust made arranging and conducting interviews with representatives of affected or opposing villages difficult at first. However, after initial hesitation good work relations were established with most village leaders. Contacts at a local university and students in the study areas helped with coordinating community meetings and building mutual understanding with community leaders and (potentially) affected families. Trust was also gained with many village dwellers opposed to dam projects by repeatedly engaging in informal chats, listening carefully to their arguments and grievances, and organising focus groups on several occasions during the field research period that extended in total more than three years. While this provided useful findings on its own, it did delay and limit some of the fieldwork.

Finally, this research conducted only two in-depth case studies. Although the main procedures of participation and negotiation in terms of laws and regulations are similar to other projects in Thailand, specific circumstances, history, landscapes and livelihoods vary for different dam projects across the country. In this sense, the specific findings from the 
two dam projects cannot be considered representative of all water resource projects in Thailand.

\subsection{Scientific significance}

The environmental and social impact of dam projects has raised considerable academic interest, both in terms of ex-post assessments (e.g. Kirchherr et al., 2016; Sivongxay et al., 2017; Bertoni et al., 2019) and ex-ante studies attempting to find ways to reduce negative impacts (e.g. Kirchherr et al., 2018; Lanzanova et al., 2019; Yigzaw et al., 2019). This thesis has contributed to this literature by making, for the first time, an in-depth study of the CBI design process introduced by RID in Thailand in 2015. This design process, which focuses on medium-scale WRC projects, is intended to reduce negative impacts of dam construction. The process is important, as simply a smaller size project is no guarantee of higher sustainability and less social and environmental impact (Fung et al., 2019). This PhD study has both contributed to assessment of the $\mathrm{CBI}$ process and developed new tools to support the process. Through this innovative action research approach, the study has also been able to uncover some preconditions that are necessary for bottom-up processes to lead to effective participation.

The $\mathrm{CBI}$ design, and the role the study has played within it, are typical PIA approaches. PIA has been commended as a process that enables effective participation by focusing on sharing of knowledge and co-learning (Mayoux and Chambers, 2005; Ridder and Pahl-Wostl, 2005; Sinclair et al., 2013; Schindler et al., 2015). However, its practical implementation - in a socio-political context where stakeholders have little trust in the government and its intentions with the $\mathrm{CBI}$ process - is fraught with challenges. This PhD project provides new insight into overcoming these challenges. Skilful facilitation is required to build trust with apprehensive stakeholders, through convincing them that there is no fixed agenda and that options and concerns of all stakeholders will be considered in co-designed intervention options. This research also revealed a lack of trust among different local stakeholder groups. Operationalising the PIA process on the premise of stakeholders autonomously putting their ideas and concerns forward is likely to lead to gaps in agendas and unspoken discussion points. Facilitators need to be alert for these omissions and take an active attitude toward putting these sensitive points on the agenda, i.e. their role goes beyond good facilitation skills as defined by Reed (2008). Also issues of representation of stakeholders in the design process, including processes of communication, negotiation and accountability relations between the representatives and their constituencies are important. The findings of this thesis confirm in the real world situation of Thailand that the participation process can only be fruitful if participants have a voice in the decision making about the design and are not 
merely providers and recipients of information (Reed et al., 2018; Van Asselt and RijkensKlomp, 2002).

Another challenge for PIA is that, although its intention is to pre-empt adverse project impacts and disadvantaged outcomes for social groups, engaging (potentially) affected people in participatory processes can be difficult as they (for various reasons) do not want to participate in the project, nor negotiate compensation. Hence, the PIA cannot presuppose willingness to share knowledge and engagement with the participatory design process. This project has shown that, to overcome this deadlock, micro-political analysis is helpful to see different positions within stakeholder groups, and pinpoint likely difficulties in the participatory design process (Rasch and Köhne, 2016). This lengthens the process, but increases the ability to elicit viewpoints of different groups.

One of the key contributions of this thesis research project is that it shows that participatory modelling exercises using BBNs and $A B M$ are useful in different settings and stages within the overall PIA. Such models enable the combination of qualitative and quantitative information in a PIA process which is sensitive to relationships among stakeholder groups, considers suitable institutions, and embraces uncertainty (Salter et al., 2010). Most existing literature on the participatory deployment of such tools focuses only on their use in joint, plenary assessment of scenario outputs (Henriksen et al., 2012; Portoghese et al., 2013; Cai and Xiong, 2017). When this is not opposed by stakeholders, they can be effective tools for social learning and identifying alternative solutions. However, as Morrissey et al. (2012), have posited, the isolated development of models with specific groups of stakeholders can inform also learning, for example through compiling and integrating variables deemed important by such groups into indicators for sustainability assessment. This thesis confirms this, further showing how flexible these tools can be for different group categories and different stages of the process.

Compensation negotiations take several years, during which opportunity costs, lack of benefits and loss of chances occur and need to be taken into account. The PIA approach generates dynamic understanding about complicated socio-environmental concerns, and collaboration in knowledge generation and social learning in a participatory process engaging stakeholders. This improved PIA approach not only enables stakeholders to offer changes, but can also improve the reliability of participation and methodology for looking at relevant concerns.

Overall, this thesis project has advanced our comprehension of how scientific theories, models, and frameworks can be dynamically combined and used to improve outcomes of participation and bring greater sustainability to water resource projects and other similar 
kinds of projects in Thailand and beyond. To communicate these important developments and make them accessible, results of this research have been disseminated in publications, presentations in local and international conferences, and workshop arrangements for stakeholders of the case studies.

\subsection{Towards a more participatory and integrated planning of WRC projects in Thailand}

Participation was first embedded in the constitution of Thailand in 1997 with the aim that project developers would consult citizens, inform the general public about expected benefits and adjust processes before projects started. The revised constitution of 2007 stipulates that an EIA is required for WRC projects. While informing and consultation are compulsory under these laws, in practice the public hearings are a platform for quarrels between government officers and local communities rather than a crucial step in constructive consultations. The analyses conducted during this research found insufficient provision of information, unequal power and non-systematic negotiation processes in the practices of the nine existing dam projects and the ongoing projects in Wang Hip and Klong Klai. Clearly, despite the laws to increase participation, current practices are not effective.

Concerning the CBI participatory process for WRC projects introduced in 2015, the findings of this research indicate that participation needs to involve stakeholders in the design process to help assigning responsibility to representatives and address inputs from consultations. In the design phase it should be clarified which institutions will be responsible for addressing suggestions and concerns stakeholders share in the co-designs. Compensation is a legal element to RID but non-economic perspectives and diverse languages of valorisation are difficult to deal with under the existing rules and regulations. Additionally, the elaboration of a restoration plan is an optional element to RID and related governmental organizations involved in WRC projects to mitigate relocation issues and support resettlement of affected stakeholders. While the $\mathrm{CBI}$ process has been a step forward, there are key elements still needing improvement.

Inequity and feeling ignored in participation are motives for affected stakeholders to oppose dam construction and urge the government to cancel dam projects as reported in Chapter 5. The Assembly of the Poor (AOP), the strongest NGO in Thailand was established in 1995 as a powerful advocacy network. The first actions of the AOP resulted in the cancelation of a planned dam project, approval of AOP requested changes for three already constructed dams, and suspension of four planned but not yet constructed projects in 1997. In addition, the government ordered the projects to implement public hearings before they could obtain 
approval. Continuing with contested projects leads to stronger conflicts, such as not allowing officials to work in the area and mobilizing people to protest in the cities. Sustained opposition especially manifests where stakeholders feel that compensation has been unfair. Low levels of compensation mean that affected people are at risk of impoverishment. Making things worse, the government tends to pay little attention to benefit-sharing and offers no long-term planning. Clearly, efforts to increase equity and recognition of affected stakeholders is a core issue for Thailand to build greater acceptance of water resource projects.

For policy makers to address the above issues, it is necessary to solve three key problems: 1) failure to consider the interests of affected stakeholders; 2) inequitable compensation; and 3) limited opportunities for benefit-sharing. Better participation using PIA as a guideline will help to accomplish this and support the acceptance and sustainability of WRC projects in multiple ways.

Regarding consideration of the interests of affected stakeholders, this PhD research has revealed six key requirements for accomplishing this. A first requirement is to build trust. Taking the findings in Chapter 2 into account, using a micro-political lens to understand stakeholders' positions can help. Second, institutionalizing participation by setting a clear agenda, for example by defining tangible objectives for stakeholder engagement in the CBI process, and providing skilful facilitation will help people become more accustomed to the process. Local (elected) and regional (assigned) community leaders could be tasked to ensure accountable representation. Third, based on the findings reported in Chapter 3 and 4 , stakeholders should be encouraged to share their knowledge and participate in codesigning options by contributing ideas. When sensitive issues are not raised, facilitators must bring them up to benefit long-term outcomes for affected people, and the whole project. Fourth, engagement should start early on in the planning phase, with stakeholders being allowed and encouraged to share their concerns and propose mitigation options, and, subsequently, be part of the negotiations to arrive at acceptable solutions. Fifth, based on the findings contained in Chapter 5, using the PIA framework can establish an opportunity to improve resettlement planning for affected people by bringing up the topic of compensation early on in the planning process. The PIA process addresses representation of affected people, assessments of impacts

on affected people, recognition of multiple languages of valorisation, and compensation and restoration or improvement of livelihoods. Sixth, more effective representation and recognition of stakeholders' languages of valorisation will greatly increase the fairness of compensation for affected stakeholders. Policy should also pay attention to broader values and perceptions, not only cash compensation. While such an approach would require the 
government to delegate some decision powers and invest more time and resources in the project planning stage. The return on that investment will be more accepted and sustainable projects in the end.

Further this thesis proved that creative methods to elicit stakeholders' views and support co-design of project interventions can play a catalysing role in embedding participation in the $\mathrm{CBI}$ approach. Based on the experiences in the pilots (Chapters 3 and 4), the study shows the usefulness of the application of BBN and ABM modelling tools as vehicles to foster participation. Affected stakeholders can share their knowledge, interests, and values in constructing networks and conditional probability tables, promoting sharing and learning about variables and relations. At a minimum, this can help decision makers get a better understanding of affected stakeholders' expected impacts from the project, while it holds promise as a mechanism for co-designing options and compensation. In the latter case, BBNs could help build trust among stakeholders too. ABM can take the assessment one step further by simulating individual behaviors taking into account interactions and future impacts under uncertainty of project implementation. This can create better understanding of how WRC projects may affect the incomes of different stakeholders and their level of satisfaction, and enable studies of options to enhance the restoration of their livelihoods and levels of satisfaction. It is important however to remember that external factors will always play a role, and that while a particular exercise may provide clear conclusions, those are likely not the only issues that need to be resolved.

In order for criteria on compensation to be more equitable, the government has to improve the mechanisms to calculate the compensations. Currently, land acquisition is based on official title deeds and registered transactions which usually are much below the market value. This thesis proposes four actions to change and improve the current mechanisms and, thereby, provide more equitable compensation. First, projects should not solely use a costbenefit analysis of collective benefits, but focus instead on individual assessments among affected groups of stakeholders to better understand impacts on them. Second, a different method to determine fairer compensation should be used, specifically suggested is an equity approach to valuing assets. In this approach, the new income level of affected people after resettlement is compared with that of: i) unaffected people (requires an ex-post study); and ii) the forecasted income had they not been dislocated (requiring an ex-ante method comparing two income projections, with and without resettlement) (Nieman \& Shapiro, 2008). The equity approach aims for compensation equal to a situation of no involuntary resettlement. However, this approach requires higher government investment and causes a longer return of investment period (usually 50 years). Third, the government should also take lost income into account because affected people need time to find new land and invest in resettlement. Fourth, the compensation following an equity approach should extend to 
those affected stakeholders who do not hold title deeds, or whose livelihoods do not depend on land. These vulnerable stakeholders suffer the greatest loss from the existing policies, which has led them to protest and ask for compensation after project implementation. Focusing on such groups, understanding their current livelihoods, concerns, interests and language of valorisation, and propose compensation for rights to access resources and benefit sharing could promote their participation in decision-making as well as restore their livelihoods and income. Without increasing compensation equity, the opposition to water resource projects will not be overcome.

Regarding opportunities for benefit sharing: benefit-sharing with affected people may encourage voluntary relocation, or at least help speed up restoration of income after resettlement. Benefit-sharing mechanisms could change the status of affected stakeholders to beneficiaries, enlarging their willingness to co-design projects. One of the clear insights from applying the $A B M$ was that acceleration of the project will reduce the period that stakeholders have to live with uncertainty, and shorten the required restoration period for affected people. The challenge is how to promote this criteria or concept in the negotiation process and effect the required institutional changes in processes and laws to accommodate it. When done successfully, benefit-sharing could be a guiding principle protecting against pitfalls in participation, enabling a decentralized approach supporting self-organization in consultation and co-design. That in turn would greatly contribute to the goal of more acceptable, equitable and sustainable water resource projects in Thailand.

\subsection{Recommendations for further research}

Based on the findings of this PhD project, several issues can be pointed out that merit further research. Climate change and societal developments will intensify the search for water security, and in turn also increase the number of conflicts over water and land. This makes more studies on practices of participatory design highly relevant. As the present study was the first in-depth assessment of the Community-Based Irrigation (CBI) design process, introduced by the Thai government in 2015, it would be very interesting to extend this research to other projects that used the $\mathrm{CBI}$ process. This will help increase understanding of the mechanisms and sub-processes at play and identify factors that lead to successful participatory planning as well as challenges.

The experiences of using BBNs and ABMs as participatory tools also warrant more research. It would be interesting to see how these modelling tools could include and empower stakeholders that have normally little voice in water resource planning projects. The translation of local knowledge and values into the models poses challenges, which can be 
studied in future pilots. Interactions between stakeholders could be expanded in the models, and the altering patterns of water demands under climate change and social developments could be included in model simulations as well.

The study on the compensation for affected families in nine dam projects in Thailand left several questions. Scrutinizing compensation of affected families with a larger sample of dam projects in Thailand could make a statistical factor analysis possible. It would be interesting to investigate the different positions of affected families in the negotiation process on compensation with the micro-politics approach and how this influences the compensation outcomes. This could include a longitudinal study on the long-term effects of the resettlement on affected families.

\subsection{Conclusions}

This PhD project was focused on the effectiveness of Participatory Integrated Assessment (PIA) processes in the context of water resource projects in Thailand. In an ideal PIA process, policymakers can prioritize choices developed from interaction with stakeholders in order to find acceptable policy interventions and outcomes that lead to greater effectiveness, equity, and restoration. In theory, the PIA can support the possibility for stakeholders (residents and farmers) to further their interests through interaction with other stakeholders, especially through participatory processes that enable sharing of preferences, values, knowledge, and concerns. In conflict situations, which often occur around dam projects in Thailand, such processes often fail to take interests and values from affected stakeholders into consideration. Therefore, this $\mathrm{PhD}$ research was concerned with improving the participatory planning of WRC projects through the application of different frameworks and tools addressing the above concerns.

Given the complexity of water resource planning it is necessary to have a practical approach that can combine multiple disciplines and stakeholders' interests, and yet allows easy comprehension and communication of impacts. In participatory processes, dialogue is not sufficient to present impacts to stakeholders. The approach should, hence, build in tools that are easy to understand and user-friendly for participants to have a clearer understanding of project impacts on their lives, and to propose options they see as more equitable options. Affected stakeholders often request certainty about benefits they would receive, which are pivotal criteria for their support of the project.

Deployment of participatory micro-politics, BBN, ABM, and valorisation frameworks and methodologies can facilitate better decision-making and initiate social learning in contested 
projects. Engaging stakeholders in a participatory design process of complex socioenvironmental projects can foster sustainability through combining values, interests, objectives and impacts. New modelling approaches developed in this thesis to simulate the impacts of a dam on affected people contribute to better understanding, especially of stakeholders who require deeper consideration than provided in general collective assessments. The lessons from model simulations can be useful for policy-makers in designing more customized compensation for affected stakeholders in order to obtain more sustainable resettlements. Sensitivity analysis also helps to find solutions to mitigate specific issues that are prone to cause conflicts. The whole participatory modelling process enhances trust.

While participatory modelling shows promise, exchange of information and interests with affected people should be systematically embedded in consultation platforms to ensure accountable representation. Too often, affected people have been excluded from the project design phase or facilitation was deficient, causing them to lack trust in the process. Therefore, institutionalizing the participation process would ensure more accountable representation of all parties and increase the opportunities to negotiate. It would allow affected people to participate early in the process, recognize their interests and knowledge, allow them to set the agenda, and to establish effective representation.

A clear agenda and transparent information exchange will reduce uncertainty and gain trust. This is by no means easy, as the dominant language of argument, type of knowledge recognized, and ineffective rules with so many stakeholders, create a context where to date problems have not been solved. Instead, lack of trust, environmental degradation, loss of livelihood, and inequality continue to be main concerns. New approaches to determining compensation, especially but not only regarding land valorisation, are needed to further increase trust, and have been suggested in this thesis.

This PhD research has developed and proven some new approaches for a Participatory Integrated Assessment of water reservoir projects in Thailand learning from current practices, and using the new knowledge for improving participation of vulnerable affected people. The new knowledge derived from the research provides policy makers in water resource governance awareness about the importance of participation of the affected groups, and the need for engaging them from the start of the planning process. Application of new participatory modelling tools shows practical approaches to articulate local knowledge and interests from stakeholders and possibly mitigate negative impacts. This can support social learning and building trust in situations of conflict between government and communities. In assessing the performance of the PIA process, further elaboration is still needed on how to best measure these indicators and how they can be most effectively used 
by policy-makers. Transferability of the PIA approach to other reservoir construction projects needs to be assessed in the future as well.

To answer the main research question of this PhD project, "How can Participatory Integrated Assessment (PIA) improve process outcomes of water resource projects in Thailand?", this study shows that PIA, incorporating the recommendations from this thesis, can improve water resource projects process outcomes by: 1) allowing representation of different interests and values from different groups of stakeholders, including those with low political power, and building trust in the process; 2 ) setting a clear agenda to consult and negotiate for project design; 3) eliciting more knowledge for better understanding concerning the complex socio-environmental dynamics surrounding WRC projects and facilitation of collaborative co-design of project interventions; 4) providing understanding early on of how affected people are impacted by WRC projects for long-term planning of project interventions, and bringing up negotiations about compensation; and 5) informing valorisation and compensation practices in project planning to mitigate negative social and environmental impacts. Participatory modelling supports the achievement of these results, and benefit-sharing as a strategy can help garner increased support of local communities for WRC projects. This importance responds to sustainable development goal with Target 16.7; in order to ensure participatory decision-making for water resource projects benefiting collectively to overall people, but not ignoring vulnerable families. Dams can bring important benefits, dams can bring huge negative effects - Effective PIA helps to balance interests of different stakeholders in the design process. 


\section{Literature cited}

Akhbari, M., \& Grigg, N. S. (2013). A framework for an agent-based model to manage water resources conflicts. Water resources management, 27(11), 4039-4052. Antunes, P., Kallis, G., Videira, N., \& Santos, R. (2009). Participation and evaluation for sustainable river basin governance. In: Elsevier.

Arnstein, S. R. (1969). A ladder of citizen participation. Journal of the American Institute of planners, 35(4), 216-224.

Awakul, P., \& Ogunlana, S. O. (2002). The effect of attitudinal differences on interface conflicts in large scale construction projects: a case study. Construction Management \& Economics, 20(4), 365-377.

Baillergeau, E., \& Duyvendak, J. W. (2016). Experiential knowledge as a resource for coping with uncertainty: evidence and examples from the Netherlands. Health, Risk \& Society, 18(7-8), 407-426.

Baird, I. G., Manorom, K., Phenow, A., \& Gaja-Svasti, S. (2020). What about the tributaries of the tributaries? Fish migrations, fisheries, dams and fishers' knowledge in NorthEastern Thailand. International Journal of Water Resources Development, 36(1), 170199.

Bal, M., Bryde, D., Fearon, D., \& Ochieng, E. (2013). Stakeholder engagement: Achieving sustainability in the construction sector. Sustainability, 5(2), 695-710.

Barnes, M., Knops, A., Newman, J., \& Sullivan, H. (2004). Recent research: The micro-politics of deliberation: Case studies in public participation.

BayesFusion, L. L. C. (2017). GeNle Modeler-User Manual. BayesFusion, LLC, 524.

Becu, N., Perez, P., Walker, A., Barreteau, O., \& Le Page, C. (2003). Agent based simulation of a small catchment water management in northern Thailand: description of the CATCHSCAPE model. Ecological Modelling, 170(2-3), 319-331.

Berger, T. (2001). Agent-based spatial models applied to agriculture: a simulation tool for technology diffusion, resource use changes and policy analysis. Agricultural economics, 25(2-3), 245-260.

Berger, T., Birner, R., Mccarthy, N., DíAz, J., \& Wittmer, H. (2007). Capturing the complexity of water uses and water users within a multi-agent framework. Water resources management, 21(1), 129-148.

Berger, T., Schreinemachers, P., \& Woelcke, J. (2006). Multi-agent simulation for the targeting of development policies in less-favored areas. Agricultural Systems, 88(1), 2843.

Berger, T., \& Troost, C. (2014). Agent-based modelling of climate adaptation and mitigation options in agriculture. Journal of Agricultural Economics, 65(2), 323-348. 
Bertone, E., Sahin, O., Richards, R., \& Roiko, A. (2016). Extreme events, water quality and health: A participatory Bayesian risk assessment tool for managers of reservoirs. Journal of Cleaner Production, 135, 657-667.

Bertoni, F., Castelletti, A., Giuliani, M., \& Reed, P. M. (2019). Discovering Dependencies, Trade-offs, and Robustness in Joint Dam Design and Operation: An Ex-post Assessment of the Kariba Dam. Earth's Future, 7(12), 1367-1390.

Blake, D. (2013). Sirindhorn Dam Affected Communities Still Seeking Justice and Compensation, International Rivers, retrieved from:

https://www.internationalrivers.org/blogs/294/sirindhorn-dam-affected-communitiesstill-seeking-justice-and-compensation

Bots, P. W., \& van Daalen, C. E. (2008). Participatory model construction and model use in natural resource management: a framework for reflection. Systemic Practice and Action Research, 21(6), 389.

Bouejla, A., Chaze, X., Guarnieri, F., \& Napoli, A. (2014). A Bayesian network to manage risks of maritime piracy against offshore oil fields. Safety Science, 68, 222-230.

Bourne, L., \& Walker, D. H. (2005). Visualising and mapping stakeholder influence. Management decision, 43: 649-60.

Bousquet, F., \& Le Page, C. (2004). Multi-agent simulations and ecosystem management: a review. Ecological Modelling, 176(3-4), 313-332.

Bromley, J., Jackson, N. A., Clymer, O., Giacomello, A. M., \& Jensen, F. V. (2005). The use of Hugin $^{\circledR}$ to develop Bayesian networks as an aid to integrated water resource planning. Environmental Modelling \& Software, 20(2), 231-242.

Bruce, C., \& Madani, K. (2015). Successful collaborative negotiation over water policy: substance versus process. Journal of Water Resources Planning and Management, 141(9), 04015009.

Bryson, J. M., Quick, K. S., Slotterback, C. S., \& Crosby, B. C. (2013). Designing public participation processes. Public administration review, 73(1), 23-34.

Bui, T. M. H., Schreinemachers, P., \& Berger, T. (2013). Hydropower development in Vietnam: Involuntary resettlement and factors enabling rehabilitation. Land Use Policy, 31, 536544.

Buchanan, K. S. (2013). Contested discourses, knowledge, and socio-environmental conflict in Ecuador. Environmental science \& policy, 30, 19-25.

Cai, J., \& Xiong, H. (2017). An agent-based simulation of cooperation in the use of irrigation systems. Complex Adaptive Systems Modeling, 5(1), 9.

Cain, J. (2001). Planning improvements in natural resource management. guidelines for using bayesian networks to support the planning and management of development programmes in the water sector and beyond: Centre for Ecology and Hydrology. 
Carmona, G., Varela-Ortega, C., \& Bromley, J. (2011). The use of participatory objectoriented Bayesian networks and agro-economic models for groundwater management in Spain. Water Resources Management, 25(5), 1509-1524.

Carmona, G., Varela-Ortega, C., \& Bromley, J. (2013). Participatory modelling to support decision making in water management under uncertainty: two comparative case studies in the Guadiana river basin, Spain. Journal of environmental management, 128, 400-412.

Castelletti, A., \& Soncini-Sessa, R. (2007). Bayesian Networks and participatory modelling in water resource management. Environmental Modelling \& Software, 22(8), 1075-1088.

Cernea, M. M. (2000). Risks, safeguards and reconstruction: A model for population displacement and resettlement. Economic and Political Weekly, 3659-3678.

Cernea, M. M. (2003). For a new economics of resettlement: a sociological critique of the compensation principle. International social science journal, 55(175), 37-45.

Cernea, M. M. (2008). Compensation and benefit sharing: Why resettlement policies and practices must be reformed. Water Science and Engineering, 1(1), 89-120.

Chalermsripinyorat, R. (2004). Politics of Representation: A case of Thailand's assembly of the poor. Critical Asian Studies, 36(4), 541-566.

Chen, S. H., \& Pollino, C. A. (2012). Good practice in Bayesian network modelling. Environmental Modelling \& Software, 37, 134-145.

Costa, A., Caldas, J. C., Coelho, R., Ferreiro, M. D. F., \& Gonçalves, V. (2016). The building of a dam: Value conflicts in public decision-making. Environmental Values, 25(2), 215-234.

Crow-Miller, B., Webber, M., \& Molle, F. (2017). The (re) turn to infrastructure for water management? Water Alternatives, 10(2): 195-207.

Del Bene, D., Scheidel, A., \& Temper, L. (2018). More dams, more violence? A global analysis on resistances and repression around conflictive dams through co-produced knowledge. Sustainability science, 13(3), 617-633.

Deinet, S., Scott-Gatty, K., Rotton, H., Twardek, W. M., Marconi, V., McRae, L., Baumgartner, L. J., Brink, K., Claussen, J. E., Cooke, S. J., Darwall, W., Eriksson, B. K., Garcia de Leaniz, C., Hogan, Z., Royte, J., Silva, L. G. M., Thieme, M. L., Tickner, D., Waldman, J., Wanningen, H., Weyl, O. L. F., Berkhuysen, A. (2020) The Living Planet Index (LPI) for migratory freshwater fish - Technical Report. World Fish Migration Foundation, The Netherlands

Devitt, P., \& Hitchcock, R. K. (2010). Who drives resettlement? The case of Lesotho's Mohale Dam.

Duarte-Abadía, B., Boelens, R., \& Roa-Avendaño, T. (2015). Hydropower, encroachment and the re-patterning of hydrosocial territory: The case of Hidrosogamoso in

Dubash, N. K. (2009). Global norms through global deliberation? Reflections on the World Commission on Dams. Global Governance: A Review of Multilateralism and International Organizations, 15(2), 219-238. 
Earthscan.Shah, E., Vos, J., Veldwisch, G. J., Boelens, R., \& Duarte-Abadía, B. (2019). Environmental justice movements in globalising networks: a critical discussion on social resistance against large dams. The Journal of Peasant Studies, 1-25.

Enríquez-de-Salamanca, Á. (2018). Stakeholders' manipulation of environmental impact assessment. Environmental Impact Assessment Review, 68, 10-18.

Etxano, I., Garmendia, E., Pascual, U., Hoyos, D., Díez, M. Á., Cadiñanos, J. A., \& Lozano, P. J. (2015). A participatory integrated assessment approach for Natura 2000 network sites. Environment and Planning C: Government and Policy, 33(5), 1207-1232.

Farmani, R., Henriksen, H. J., \& Savic, D. (2009). An evolutionary Bayesian belief network methodology for optimum management of groundwater contamination. Environmental Modelling \& Software, 24(3), 303-310.

Faysse, N., Sellika, I. E., Rinaudo, J. D., \& Errahj, M. (2018). Participatory scenario planning for sustainable irrigated agriculture when actors seldom communicate: an experiment in Morocco. International Journal of Water Resources Development, 34(6), 982-1000.

Ferreira, S., \& Gallagher, L. (2010). Protest responses and community attitudes toward accepting compensation to host waste disposal infrastructure. Land Use Policy, 27(2), 638-652.

Fleskens, L., \& Hubacek, K. (2013). Modelling land management for ecosystem services. In: Springer.

Fleskens, L., \& Stringer, L. C. (2014). Land management and policy responses to mitigate desertification and land degradation. Land Degradation and Development, 25(1), 1-4.

Flores, M. J., Nicholson, A. E., Brunskill, A., Korb, K. B., \& Mascaro, S. (2011). Incorporating expert knowledge when learning Bayesian network structure: a medical case study. Artificial intelligence in medicine, 53(3), 181-204.

Fraser, N. (1996). Social justice in the age of identity politics: Redistribution, recognition, and participation. The Tanner Lectures on Human Values. Paper presented at the Conferencia dictada en Stanford University, April.

Fraser, N. (2000). Rethinking recognition. New left review, 3, 107.

Fraser, N. (2006). Mapping the feminist imagination: From redistribution to recognition to representation. In Die Neuverhandlung sozialer Gerechtigkeit (pp. 37-51): Springer.

Fung, Z., Pomun, T., Charles, K. J., \& Kirchherr, J. (2019). Mapping the social impacts of small dams: The case of Thailand's Ing River basin. Ambio, 48(2), 180-191.

Furlong, C., De Silva, S., Guthrie, L., \& Considine, R. (2016). Developing a water infrastructure planning framework for the complex modern planning environment. Utilities Policy, 38, 1-10.

Galipeau, B. A., Ingman, M., \& Tilt, B. (2013). Dam-induced displacement and agricultural livelihoods in China's Mekong Basin. Human Ecology, 41(3), 437-446. 
Gaventa, J., \& Valderrama, C. (1999). Participation, citizenship and local governancebackground paper for workshop: strengthening participation in local governance. Brighton, UK.

Gelcich, S., Edwards-Jones, G., Kaiser, M. J., \& Castilla, J. C. (2006). Co-management policy can reduce resilience in traditionally managed marine ecosystems. Ecosystems, 9(6), 951-966.

Ghatak, M., \& Mookherjee, D. (2014). Land acquisition for industrialization and compensation of displaced farmers. Journal of Development Economics, 110, 303-312.

Giuliani, M., \& Castelletti, A. (2013). Assessing the value of cooperation and information exchange in large water resources systems by agent-based optimization. Water Resources Research, 49(7), 3912-3926.

Glassman, J. (2002). From Seattle (and Ubon) to Bangkok: the scales of resistance to corporate globalization. Environment and Planning D: Society and Space, 20(5), 513-533.

Gregory, A. (2000). Problematizing participation: A critical review of approaches to participation in evaluation theory. Evaluation, 6(2), 179-199.

Grey, D., \& Sadoff, C. W. (2007). Sink or swim? Water security for growth and development. Water policy, 9(6), 545-571.

Grimble, R., \& Wellard, K. (1997). Stakeholder methodologies in natural resource management: a review of principles, contexts, experiences and opportunities. Agricultural systems, 55(2), 173-193.

Gualini, E., \& Majoor, S. (2007). Innovative practices in large urban development projects: Conflicting frames in the quest for "new urbanity". Planning Theory \& Practice, 8(3), $297-$ 318.

Hall, D. M., Gilbertz, S. J., Anderson, M. B., \& Ward, L. C. (2016). Beyond "buy-in": designing citizen participation in water planning as research. Journal of cleaner production, 133, 725-734.

Hare, M. (2011). Forms of participatory modelling and its potential for widespread adoption in the water sector. Environmental Policy and Governance, 21(6), 386-402.

Hare, M., \& Pahl-Wostl, C. (2002). Stakeholder categorisation in participatory integrated assessment processes. Integrated Assessment, 3(1), 50-62.

Hart, B., O'Donnell, E., \& Horne, A. (2019). Sustainable water resources development in northern Australia: the need for coordination, integration and representation. International Journal of Water Resources Development, 1-23, online first.

Haselip, J. (2011, November). Transparency, consultation and conflict: Assessing the microlevel risks surrounding the drive to develop Peru's Amazonian oil and gas resources. In Natural Resources Forum (Vol. 35, No. 4, pp. 283-292). Oxford, UK: Blackwell Publishing Ltd.

Henriksen, H. J., \& Barlebo, H. C. (2008). Reflections on the use of Bayesian belief networks for adaptive management. Journal of environmental management, 88(4), 1025-1036. 
Henriksen, H. J., Rasmussen, P., Brandt, G., Von Buelow, D., \& Jensen, F. V. (2007). Public participation modelling using Bayesian networks in management of groundwater contamination. Environmental Modelling \& Software, 22(8), 1101-1113.

Henriksen, H. J., Zorrilla-Miras, P., de la Hera, A., \& Brugnach, M. (2012). Use of Bayesian belief networks for dealing with ambiguity in integrated groundwater management. Integrated environmental assessment and management, 8(3), 430-444.

Hess, C. E. E., \& Fenrich, E. (2017). Socio-environmental conflicts on hydropower: The São Luiz do Tapajós project in Brazil. Environmental science \& policy, 73, 20-28.

Hoogendam, P., \& Boelens, R. (2019). Dams and Damages. Conflicting epistemological frameworks and interests concerning "compensation" for the Misicuni project's socioenvironmental impacts in Cochabamba, Bolivia. Water, 11(3), 408.

Horowitz, L. S. (2011). Interpreting industry's impacts: micropolitical ecologies of divergent community responses. Development and Change, 42(6), 1379-1391.

Hoshino, E., van Putten, I., Girsang, W., Resosudarmo, B. P., \& Yamazaki, S. (2016). A Bayesian belief network model for community-based coastal resource management in the Kei Islands, Indonesia. Ecology and society, 21(2).

Hubacek, K., \& Reed, M. (2009). Lessons learned from a computer-assisted participatory planning and management process in the Peak District National Park, England. In Adaptive Environmental Management (pp. 189-202). Springer, Dordrecht.

Imhof, A., Wong, S., \& Schneider, C. (2003). International rivers people water life. International Rivers Organization. 1847 Berkeley Way, Berkeley CA 94703, USA. https://www.isranews.org > isranews-pr-news > download

Jacob, T., \& Bernard, C. (2013). Exploring the politics of local participation in rural development projects: small dams rehabilitation project in Zimbabwe. Russian Journal of Agricultural and Socio-Economic Sciences, 14(2).

Jeronimo, R. P., Rap, E., \& Vos, J. (2015). The politics of land use planning: Gold mining in Cajamarca, Peru. Land Use Policy, 49, 104-117.

Jiménez, M. R. M. (2016). Dialogue-confrontation of knowledge and cultural negotiation: a Southern production on axes of a popular education pedagogy. Educar em Revista, (61), 37-54.Julian, D. A., Reischl, T. M., Carrick, R. V., \& Katrenich, C. (1997). Citizen participation-lessons from a local United Way planning process. Journal of the American planning association, 63(3), 345-355.

Kaewthong, N., \& Ditthakit, P. (2018). Effects of climate change on agriculture water demand in lower Pak Phanang river basin, southern part of Thailand. In MATEC Web of Conferences (Vol. 192, p. 03043). EDP Sciences.

Käkönen, M., \& Hirsch, P. (2009). The anti-politics of Mekong knowledge production. Contested waterscapes in the Mekong region: Hydropower, livelihoods and governance, 333-365. 
Kesby, M. (2005). Retheorizing empowerment-through-participation as a performance in space: Beyond tyranny to transformation. Signs: Journal of women in Culture and Society, 30(4), 2037-2065.

Keshtkar, A., Salajegheh, A., Sadoddin, A., \& Allan, M. G. (2013). Application of Bayesian networks for sustainability assessment in catchment modeling and management (Case study: The Hablehrood river catchment). Ecological modelling, 268, 48-54.

Kermagoret, C., Levrel, H., Carlier, A., \& Dachary-Bernard, J. (2016). Individual preferences regarding environmental offset and welfare compensation: a choice experiment application to an offshore wind farm project. Ecological Economics, 129, 230-240.

Kiguchi, Y. (2016). Impacts of Dam Construction on the Mekong: The experience of the Mun River. Mekong Watch.

Kirchherr, J. (2018). Strategies of successful anti-dam movements: Evidence from Myanmar and Thailand. Society \& natural resources, 31(2), 166-182.

Kirchherr, J., Pohlner, H., \& Charles, K. J. (2016). Cleaning up the big muddy: A meta-synthesis of the research on the social impact of dams. Environmental Impact Assessment Review, 60, 115-125.

Kirchherr, J., Pomun, T., \& Walton, M. J. (2018). Mapping the social impacts of 'Damocles projects': the case of Thailand's (as yet Unbuilt) Kaeng Suea ten dam. Journal of International Development, 30(3), 474-492.

Kishor Mahato, B., \& Ogunlana, S. O. (2011). Conflict dynamics in a dam construction project: a case study. Built Environment Project and Asset Management, 1(2), 176-194.

Kjærulff, U., \& van der Gaag, L. C. (2000, June). Making sensitivity analysis computationally efficient. In Proceedings of the Sixteenth conference on Uncertainty in artificial intelligence (pp. 317-325). Morgan Kaufmann Publishers Inc..

Kuenzer, C., Campbell, I., Roch, M., Leinenkugel, P., Tuan, V. Q., \& Dech, S. (2013). Understanding the impact of hydropower developments in the context of upstreamdownstream relations in the Mekong river basin. Sustainability science, 8(4), 565-584.

Kunreuther, H., \& Easterling, D. (1990). Are risk-benefit tradeoffs possible in siting hazardous facilities? The American Economic Review, 80(2), 252-256.

Kunreuther, H., \& Easterling, D. (1996). The role of compensation in siting hazardous facilities. Journal of policy analysis and management, 15(4), 601-622.

Kura, Y., Joffre, O., Laplante, B., \& Sengvilaykham, B. (2017). Coping with resettlement: A livelihood adaptation analysis in the Mekong River basin. Land Use Policy, 60, 139-149.

Kurukulasuriya, P., \& Rosenthal, S. (2013). Climate change and agriculture: A review of impacts and adaptations.

Landuyt, D., Broekx, S., D'hondt, R., Engelen, G., Aertsens, J., \& Goethals, P. L. (2013). A review of Bayesian belief networks in ecosystem service modelling. Environmental Modelling \& Software, 46, 1-11. 
Lanzanova, D., Whitney, C., Shepherd, K., \& Luedeling, E. (2019). Improving development efficiency through decision analysis: reservoir protection in Burkina Faso. Environmental modelling \& software, 115, 164-175.

Lawler, J. J., Lewis, D. J., Nelson, E., Plantinga, A. J., Polasky, S., Withey, J. C., Helmers, D.P., Martinuzzi, S., Pennington, D., and Radeloff, V. C. (2014). Projected land-use change impacts on ecosystem services in the United States. Proceedings of the National Academy of Sciences, 111(20), 7492-7497.

Le Pira, M., Marcucci, E., Gatta, V., Inturri, G., Ignaccolo, M., \& Pluchino, A. (2017). Integrating discrete choice models and agent-based models for ex-ante evaluation of stakeholder policy acceptability in urban freight transport. Research in transportation economics, 64, 13-25.

Lebel, L., Lebel, P., Chitmanat, C., \& Sriyasak, P. (2014). Benefit sharing from hydropower watersheds: Rationales, practices, and potential. Water resources and rural development, 4, 12-28.

Levontin, P., Kulmala, S., Haapasaari, P., \& Kuikka, S. (2011). Integration of biological, economic, and sociological knowledge by Bayesian belief networks: the interdisciplinary evaluation of potential management plans for Baltic salmon. ICES Journal of Marine Science, 68(3), 632-638.

Lohmann, L., \& Tongdeelert, C. (1991). The Muang Faai irrigation system of northern Thailand. Ecologist, 21(2), 101-101.

Lynam, T., De Jong, W., Sheil, D., Kusumanto, T., \& Evans, K. (2007). A review of tools for incorporating community knowledge, preferences, and values into decision making in natural resources management. Ecology and society, 12(1).

Mack, L. (2018). Rasi Salai Dam violates people's cultural rights. The Isaan Record, retrieved from: https://isaanrecord.com/2018/12/13/rasi-salai-dam-violates-peoples-culturalrights/

Magsi, H., \& Torre, A. (2014). Proximity analysis of inefficient practices and socio-spatial negligence: Evidence, evaluations and recommendations drawn from the construction of Chotiari reservoir in Pakistan. Land Use Policy, 36, 567-576.

Mahato, B.K., \& Ogunlana, S. O. (2011). Conflict dynamics in a dam construction project: a case study. Built Environment Project and Asset Management, 1(2), 176-194.

Mamitimin, Y., Feike, T., \& Doluschitz, R. (2015). Bayesian network modeling to improve water pricing practices in northwest China. Water, 7(10), 5617-5637.

Manowong, E., \& Ogunlana, S. O. (2006). Public hearings in Thailand's infrastructure projects: effective participations?. Engineering, Construction and Architectural Management.

Marcot, B. G., Steventon, J. D., Sutherland, G. D., \& McCann, R. K. (2006). Guidelines for developing and updating Bayesian belief networks applied to ecological modeling and conservation. Canadian Journal of Forest Research, 36(12), 3063-3074. 
Martinez-Alier, J. (2003). The Environmentalism of the poor: a study of ecological conflicts and valuation. Edward Elgar Publishing.

Martinez-Alier, J., Munda, G., \& O'Neill, J. (1998). Weak comparability of values as a foundation for ecological economics. Ecological Economics, 26(3), 277-286.

Matthews, N. (2011). Drowning under Progress: Water, Culture, and Development in the Greater Mekong Subregion. In Water, Cultural Diversity, and Global Environmental Change (pp. 349-366): Springer.

Matthews, R. B., Gilbert, N. G., Roach, A., Polhill, J. G., \& Gotts, N. M. (2007). Agent-based land-use models: a review of applications. Landscape Ecology, 22(10), 1447-1459.

Mayoux, L., \& Chambers, R. (2005). Reversing the paradigm: quantification, participatory methods and pro-poor impact assessment. Journal of international development, 17(2), 271-298.

McCartney, M. P. (2007). Decision support systems for large dam planning and operation in Africa (Vol. 119). IWMI.

Mkrtchyan, L., Podofillini, L., \& Dang, V. N. (2015). Bayesian belief networks for human reliability analysis: A review of applications and gaps. Reliability engineering \& system safety, 139, 1-16.

Ministry of Natural Resources and Environment Notification, (2012). Ministry of Natural Resources and Environment Notification. Type and Sizes of Projects or Activities Required Environmental Impact Assessment, Criteria, Procedures and Guidelines. Royal Gazette Volume 127, Part 97, dated 20th June B.E. 2555 (2012).

Missingham, B. (2003). Forging solidarity and identity in the assembly of the poor: From local struggles to a national social movement in Thailand. Asian Studies Review, 27(3), 317-340.

Morinville, C., \& Harris, L. M. (2014). Participation, politics, and panaceas: exploring the possibilities and limits of participatory urban water governance in Accra, Ghana. Ecology and Society, 19(3).

Morrissey, J., Iyer-Raniga, U., McLaughlin, P., \& Mills, A. (2012). A strategic project appraisal framework for ecologically sustainable urban infrastructure. Environmental Impact Assessment Review, 33(1), 55-65.

Morvaridi, B. (2004). Resettlement, rights to development and the Ilisu Dam, Turkey. Development and Change, 35(4), 719-741.

Mundial, B. (2004). Involuntary Resettlement Sourcebook. Planning and Implementation in Development Projects. Washington DC: World Bank.

Nakayama, M., Gunawan, B., Yoshida, T., \& Asaeda, T. (1999). Resettlement issues of Cirata Dam project: a post-project review. International Journal of Water Resources Development, 15(4), 443-458.

Narayanan, V. K., \& Fahey, L. (1982). The micro-politics of strategy formulation. Academy of Management Review, 7(1), 25-34. 
National Statistical Office (2014). Key Indicators of Thai Population. http://www.nso.go.th/sites/2014/nsopublic (accessed 3 October, 2019).

National Statistical Office (2014). 2013 AGRICULTURAL CENSUS http://www.nso.go.th/ sites/2014/Pages/Agri/2556/report-full.aspx (accessed 3 October, 2019).

Ng, T. L., Eheart, J. W., Cai, X., \& Braden, J. B. (2011). An agent-based model of farmer decision-making and water quality impacts at the watershed scale under markets for carbon allowances and a second-generation biofuel crop. Water Resources Research, 47(9).

Niemann, P., \& Shapiro, P. (2008). Efficiency and fairness: Compensation for takings. International Review of Law and Economics, 28(3), 157-165.

Nippanon, J., Schouten, R., Sripapatrprasite, P., Vaddhanaphuti, C., Vidthayanon, C., Wirojanagud, W., \& Watana, E. (2000). Pak Mun dam, Mekong river basin, Thailand. A WCD Case Study prepared as an input to the World Commission on Dams. Cape Town, World Commission on Dams.

OAE (2016). Agricultural Statistics in Crop Year 2015/2016; Office of Agricultural Economics, Ed.; Ministry of Agriculture and Cooperatives: Bangkok, Thailand.

O'Faircheallaigh, C. (2010). Public participation and environmental impact assessment: Purposes, implications, and lessons for public policy making. Environmental impact assessment review, 30(1), 19-27.

Office of Agricultural Economics (2017). Price and Production Index. Thailand Foreign Agricultural Trade Statistics 2017. Office of Agricultural Economics.

Office of the National Economic and Social Development Council. (2017). (Gross Regional and Provincial Product Chain Volume Measures 2017 Edition) http://www.nesdb.go.th/main.php?filename=gross_regional (accessed 3 October, 2019).

Pahl-Wostl, C. (2002). Towards sustainability in the water sector-The importance of human actors and processes of social learning. Aquatic sciences, 64(4), 394-411.

Phan, T. D., Smart, J. C., Capon, S. J., Hadwen, W. L., \& Sahin, O. (2016). Applications of Bayesian belief networks in water resource management: a systematic review. Environmental Modelling \& Software, 85, 98-111.

Picciotto, R. (2013). Involuntary resettlement in infrastructure projects: A development perspective. Paper presented at the Infrastructure and land policies: Proceedings of the 2012 Land Policy Conference, Puritan Press Inc, Hollis, NH.

Pollino, C. A., Woodberry, O., Nicholson, A., Korb, K., \& Hart, B. T. (2007). Parameterisation and evaluation of a Bayesian network for use in an ecological risk assessment. Environmental Modelling \& Software, 22(8), 1140-1152.

Popkin, S. L., \& Popkin, S. L. (1979). The rational peasant: The political economy of rural society in Vietnam: Univ of California Press. 
Powell, B., \& Skarbek, D. (2006). Sweatshops and third world living standards: Are the jobs worth the sweat? Journal of Labor Research, 27(2), 263-274.

Priya Datta, P., Christopher, M., \& Allen, P. (2007). Agent-based modelling of complex production/distribution systems to improve resilience. International Journal of Logistics Research and Applications, 10(3), 187-203.

Qian, Z. (2015). Land acquisition compensation in post-reform China: Evolution, structure and challenges in Hangzhou. Land Use Policy, 46, 250-257.

Quang, D. V., Schreinemachers, P., \& Berger, T. (2014). Ex-ante assessment of soil conservation methods in the uplands of Vietnam: An agent-based modeling approach. Agricultural Systems, 123, 108-119.

Rai, K. (2007). The dynamics of social inequality in the Kali Gandaki 'A'dam project in Nepal: The politics of patronage. Hydro Nepal: Journal of Water, Energy and Environment, 1, 2228.

Rakotonarivo, O. S., Jacobsen, J. B., Larsen, H. O., Jones, J. P., Nielsen, M. R., Ramamonjisoa, B. S., Mandimbiniaina, R.H., Hockley, N. (2017). Qualitative and quantitative evidence on the true local welfare costs of forest conservation in Madagascar: are discrete choice experiments a valid ex ante tool? World Development, 94, 478-491.

Rasch, E. D., \& Köhne, M. (2016). Micropolitics in resistance: The micropolitics of large-scale natural resource extraction in South East Asia. Society \& natural resources, 29(4), 479492.

Reed, M. S. (2008). Stakeholder participation for environmental management: a literature review. Biological conservation, 141(10), 2417-2431.

Reed, M. S., Vella, S., Challies, E., de Vente, J., Frewer, L., Hohenwallner-Ries, D., Huber, T., Neumann, R.K., Oughton, E.A., Sidoli del Ceno, J., van Delden, H. (2018). A theory of participation: what makes stakeholder and public engagement in environmental management work?. Restoration Ecology, 26, S7-S17.

Ribot, J. C. (2002). African decentralization: local actors, powers and accountability. Geneva: UNRISD.

Ricart, S., \& Clarimont, S. (2017). Qualifying irrigation system sustainability and governance by means of stakeholder perceptions: the Neste Canal (France). International Journal of Water Resources Development, 33(6), 935-954.

Ricart, S., Ribas, A., \& Pavón, D. (2016). Qualifying irrigation system sustainability by means of stakeholder perceptions and concerns: lessons from the $\mathrm{S}$ egarra- $\mathrm{G}$ arrigues $\mathrm{C}$ anal, $\mathrm{S}$ pain. In Natural Resources Forum (Vol. 40, No. 1-2, pp. 77-90). Oxford, UK: Blackwell Publishing Ltd.

RID (2001). Post EIA report of the Khun Dan Dam. The Royal Irrigation Department.

RID (2003). Project Information Report of Prong Khun Petch Dam. (RID Office of Project Management), Ed.; Royal Irrigation Department: Bangkok, Thailand, 2003. 
RID (2008). "Manual of Medium-scale Water resources Construction." In, edited by Royal Irrigation Department Office of Medium-scale WaterResouces Development, 418. Bangkok, Thailand.

RID (2010). Manual for Water resources Development: Land acquisition for irrigation (pp. 12). Bangkok, Thailand: Royal Irrigation Department.

RID (2011). The Report of Studying Environmental and Social Impacts of Prong Khun Petch,. (RID Office of Project Management), Ed.; Royal Irrigation Department: Bangkok, Thailand, 2011.

RID (2013). List of moving free and crops affected by irrigation projects. Bureau of Legal Affairs and Land. Royal Irrigation Department.

RID (2015). "Application Report in 2015 of Royal Irrigation Department." In.

RID (2016a). Environmental Impact Assessment EIA Report; Wang Hip project, Nakhon Si Thammarat Province t; (RID Office of Project Management), Ed.; Royal Irrigation Department: Bangkok, Thailand, 2016.

RID (2016b). Meeting Report of Mitigation to affected people in Wang Hip project on 20Jan-2016. Public Participatory Promotion Division. Royal Irrigation Department.

RID (2017). Community-Based Irrigation Report of Water resources Development project of Tha Sala and Nop Pitam districts in Nakhon Si Thammarat. Public Participatory Promotion Division. Royal Irrigation Department.

RID (2018a). Information Report of Irrigation Projects (pp. 21-22). Bangkok, Thailand: Royal Irrigation Department.

RID (2018b). Environmental Impact Assessment EIA Report; Huai Kra Lang project, Chaiyaphum Province t; (RID Office of Project Management), Ed.; Royal Irrigation Department: Bangkok, Thailand, 2018.

RID (2018c). Information of Irrigation Projects. Royal Irrigation Department: Bangkok, Thailand.

RID (2018d), Participatory water resource planning at watershed level: Klong Klai sub-basin 20015-2017 in Nop Pitam and Tha Sala Districts, Nakhon Si Tamarat Province, Thailand., Royal Irrigation Department.

RID (2019a). Tapi - PumDuang Irrigation System Report. Bureau of Large Scale Water resources Development. Royal Irrigation Department.

RID (2019b). Land acquisition report of Huay Sai Khaw Reservoir. Bureau of Legal Affairs and Land. Royal Irrigation Department.

Ridder, D., \& Pahl-Wostl, C. (2005). Participatory Integrated Assessment in local level planning. Regional Environmental Change, 5(4), 188-196.

Riethof, M. (2017). The international human rights discourse as a strategic focus in socioenvironmental conflicts: the case of hydro-electric dams in Brazil. The International Journal of Human Rights, 21(4), 482-499. 
Roncoli, C., Dowd-Uribe, B., Orlove, B., West, C. T., \& Sanon, M. (2016, February). Who counts, what counts: representation and accountability in water governance in the $U$ pper C omoé sub-basin, B urkina F aso. In Natural Resources Forum (Vol. 40, No. 1-2, pp. 6-20). Oxford, UK: Blackwell Publishing Ltd.

Roozbahani, A., Ebrahimi, E., \& Banihabib, M. E. (2018). A framework for ground water management based on bayesian network and MCDM techniques. Water Resources Management, 32(15), 4985-5005.

Roth, D., Khan, M. S. A., Jahan, I., Rahman, R., Narain, V., Singh, A. K., Priya, M., Sen, S., Shrestha, A., Yakami, S. (2019). Climates of urbanization: local experiences of water security, conflict and cooperation in peri-urban South-Asia. Climate Policy, 19(sup1), S78S93

Rothman, F., \& Oliver, P. (1999). From local to global: The anti-dam movement in southern Brazil, 1979-1992. Mobilization: An International Quarterly, 4(1), 41-57.

Rousseau, J.-F., Orange, D., Habich-Sobiegalla, S., \& Van Thiet, N. (2017). Socialist hydropower governances compared: dams and resettlement as experienced by Dai and Thai societies from the Sino-Vietnamese borderlands. Regional environmental change, 17(8), 2409-2419.

Ruiz-Villaverde, A., \& García-Rubio, M. A. (2017). Public participation in European water management: from theory to practice. Water Resources Management, 31(8), 24792495.

Salter, J., Robinson, J., \& Wiek, A. (2010). Participatory methods of integrated assessmenta review. Wiley Interdisciplinary Reviews: Climate Change, 1(5), 697-717.

Sayatham, M., \& Suhardiman, D. (2015). Hydropower resettlement and livelihood adaptation: The Nam Mang 3 project in Laos. Water resources and rural development, 5, 17-30.

Schindler, J., Graef, F., \& König, H. J. (2015). Methods to assess farming sustainability in developing countries. A review. Agronomy for sustainable development, 35(3), 10431057.

Schlosberg, D. (2004). Reconceiving environmental justice: global movements and political theories. Environmental politics, 13(3), 517-540.

Schlüter, M., \& Pahl-Wostl, C. (2007). Mechanisms of resilience in common-pool resource management systems: an agent-based model of water use in a river basin. Ecology and Society, 12(2).

Schreinemachers, P., \& Berger, T. (2011). An agent-based simulation model of humanenvironment interactions in agricultural systems. Environmental Modelling \& Software, 26(7), 845-859.

Schreinemachers, P., Potchanasin, C., Berger, T., \& Roygrong, S. (2010). Agent-based modeling for ex ante assessment of tree crop innovations: Litchis in northern Thailand. Agricultural economics, 41(6), 519-536. 
Schulz, C., \& Adams, W. M. (2019). Debating dams: The World Commission on Dams 20 years on. Wiley Interdisciplinary Reviews: Water, 6(5), e1396.

Scudder, T. (2019). A retrospective analysis of Laos's Nam Theun 2 Dam. International Journal of Water Resources Development, 1-20. Online first.

Scudder, T., and Gay, J. (2006). "A Comparative Survey of Dam-Induced Resettlement in 50 Cases." In The Future of Large Dams: Dealing with Social, Environmental. Institutional and Political Costs, edited by Scudder, Thayer, 56-86. London:

Shah, E., Vos, J., Veldwisch, G. J., Boelens, R., \& Duarte-Abadía, B. (2019). Environmental justice movements in globalising networks: a critical discussion on social resistance against large dams. The Journal of Peasant Studies, 1-25.

Shannon, K. L. (2005). The social and environmental impacts of the Hua Na dam and KhongChi-Mun project: The necessity for more research and public participation. Presentation at Water for Mainland Southeast Asia, 30.

Shinn, J. E., King, B., Young, K. R., \& Crews, K. A. (2014). Variable adaptations: Micro-politics of environmental displacement in the Okavango Delta, Botswana. Geoforum, 57, 21-29.

Sinclair, A. J., Kumnerdpet, W., \& Moyer, J. M. (2013). Learning sustainable water practices through participatory irrigation management in Thailand. Natural Resources Forum 37(1), 55-66.

Singer, J., Pham, H. T., \& Hoang, H. (2014). Broadening stakeholder participation to improve outcomes for dam-forced resettlement in Vietnam. Water resources and rural development, 4, 85-103.

Singto, C., Fleskens, L., \& Vos, J. (2018). Institutionalizing participation in water resource development: Bottom-up and top-down practices in southern Thailand. Water, 10(6), 781.

Singto, C., Fleskens, L., Vos, J., \& Quinn, C. (2020). Applying Bayesian belief networks (BBNs) with stakeholders to explore and codesign options for water resource interventions. Sustainable Water Resources Management, 6(2), 1-17.

Sivongxay, A., Greiner, R., \& Garnett, S. T. (2017). Livelihood impacts of hydropower projects on downstream communities in central Laos and mitigation measures. Water resources and rural development, 9, 46-55.

Smith, P. D., \& McDonough, M. H. (2001). Beyond public participation: Fairness in natural resource decision making. Society \& Natural Resources, 14(3), 239-249.

Sneddon, C., \& Fox, C. (2008). Struggles over dams as struggles for justice: The World Commission on Dams (WCD) and anti-dam campaigns in Thailand and Mozambique. Society and Natural Resources, 21(7), 625-640.

Sretthachau, C., Nungern, K., \& Olsson, A. (2000). Social impacts of the Rasi Salai Dam, Thailand: Loss of livelihood security and social conflict: World Commission on Dams.

SRTM. (2018). Shuttle Radar Topography Mission 1 Arc-Second Global (Digital Object Identifier (DOI) number: /10.5066/F7PR7TFT. 
Stringer, L. C., Dougill, A. J., Fraser, E., Hubacek, K., Prell, C., \& Reed, M. S. (2006). Unpacking "participation" in the adaptive management of social-ecological systems: a critical review. Ecology and society, 11(2).

Stringer, L. C., Fleskens, L., Reed, M. S., de Vente, J., \& Zengin, M. (2014). Participatory evaluation of monitoring and modeling of sustainable land management technologies in areas prone to land degradation. Environmental management, 54(5), 1022-1042.

Sule, I., Khan, F., Butt, S., \& Yang, M. (2018). Kick control reliability analysis of managed pressure drilling operation. Journal of Loss Prevention in the Process Industries, 52, 720.

Sun, Z., \& Müller, D. (2013). A framework for modeling payments for ecosystem services with agent-based models, Bayesian belief networks and opinion dynamics models. Environmental Modelling \& Software, 45, 15-28.

Swain, A. (2004). Political structure and dam conflicts: comparing cases in Southeast Asia.

The Secretariat of the Cabinet. (1997). The Cabinet Resolution of 2 May 1997:The Meeting Results on Negotiation on the Issues of Assembly of the Poor.

Thiele, J. C., Kurth, W., \& Grimm, V. (2014). Facilitating parameter estimation and sensitivity analysis of agent-based models: A cookbook using NetLogo and R. Journal of Artificial Societies and Social Simulation, 17(3), 11.

Thorkildsen, K. (2018). 'Land yes, dam no!' Justice-seeking strategies by the anti-dam movement in the Ribeira Valley, Brazil. The Journal of Peasant Studies, 45(2), 347-367.

Ticehurst, J. L., Newham, L. T., Rissik, D., Letcher, R. A., \& Jakeman, A. J. (2007). A Bayesian network approach for assessing the sustainability of coastal lakes in New South Wales, Australia. Environmental Modelling \& Software, 22(8), 1129-1139.

Tilly, C. (2003). The politics of collective violence. Cambridge University Press.

Tilt, B., \& Gerkey, D. (2016). Dams and population displacement on China's Upper Mekong River: Implications for social capital and social-ecological resilience. Global Environmental Change, 36, 153-162.

Tongdeelert, C. and Lohmann, L. (1991). The Muang Faai irrigation system of northern Thailand. Ecologist, 21(2), 101-101.

van Asselt, M. B. A., \& Rijkens-Klomp, N. (2002). A look in the mirror: reflection on participation in integrated assessment from a methodological perspective. Global Environmental Change, 12(3), 167-184.

Vanclay, F. (2017). Project-induced displacement and resettlement: from impoverishment risks to an opportunity for development? Impact Assessment and Project Appraisal, 35(1), 3-21.

Van de Kerkhof, M., \& Linnerooth-Bayer, J. (2001). A survey on the methodology of participatory integrated assessment. IIASA Interim Report. Laxenburg, Austria, IIASA.

Van den Bos, K., Wilke, H. A., \& Lind, E. A. (1998). When do we need procedural fairness? The role of trust in authority. Journal of Personality and social Psychology, 75(6), 1449. 
Warner, J. F. (2006). More sustainable participation? Multi-stakeholder platforms for integrated catchment management. Water resources development, 22(1), 15-35.

Warner, J. F. (2007). The nature of the beast: towards a comparative MSP typology, in: Warner, J. (Ed.) Multi-stakeholder platforms for integrated water management. Ashgate Publishing, Ltd., pp. 1-20.

WCD, World Commission on Dams (2000). Case Study Thailand: Pak Mun Dam and Mekong/Mun River Basins http://geocompendium.grid.unep.ch/reference_scheme/ final_version/GEO/Geo-2-054.htm

Woodhill, J. (2010). Sustainability, social learning and the democratic imperative: Lessons from the Australian Landcare movement. In Social learning systems and communities of practice (pp. 57-72). Springer, London.

Xue, J., Gui, D., Lei, J., Zeng, F., Mao, D., \& Zhang, Z. (2017). Model development of a participatory Bayesian network for coupling ecosystem services into integrated water resources management. Journal of Hydrology, 554, 50-65.

Yamsiri, T. (2014). Water management in Thailand: dams and the voice of the affected and displaced people. In The Stae of Environmental Migration (pp. 253-251).

Yigzaw, N., Mburu, J., Ackello-Ogutu, C., Whitney, C., \& Luedeling, E. (2019). Stochastic impact evaluation of an irrigation development intervention in Northern Ethiopia. Science of The Total Environment, 685, 1209-1220.

Yu, B., \& Xu, L. (2016). Review of ecological compensation in hydropower development.

Renewable and Sustainable Energy Reviews, 55, 729-738.

Zhen, N., Barnett, J., \& Webber, M. (2020). Is Trust Always a Precondition for Effective Water Resource Management?. Water Resources Management, 1-14.

Zorrilla, P., Carmona, G., De la Hera, Á., Varela-Ortega, C., Martínez-Santos, P., Bromley, J., \& Henriksen, H. J. (2010). Evaluation of Bayesian networks in participatory water resources management, Upper Guadiana Basin, Spain. Ecology and society, 15(3). 


\section{English summary}

This thesis treats the participatory process and outcomes of medium-scaled dam projects in Thailand. The aim was to assess whether and how outcomes incorporated the values and perspectives of affected stakeholders, and how that could be improved. To accomplish this, this thesis research had four sub-objectives. First, to develop a framework for assessment of participatory processes. Second, to study how stakeholders can elicit their perspectives through participatory modelling. Third, to investigate ex-ante outcomes of proposed dams by integrating equity considerations and criteria relating to stakeholders' perspectives in agent-based modelling. And fourth, to create a framework and set of variables using language of valorisation from affected people's interests and knowledge to mitigate conflicts and reach agreeable outcomes. The main research question was: How can Participatory Integrated Assessment (PIA) improve process outcomes of water resource projects in Thailand?

\section{Assessing participation in water resource development}

The first research question was "How are stakeholders engaged in water reservoir construction projects and how do their inter-relations influence project outcomes?" Drawing on theoretical principles of participation, including empowerment, equity, trust, and learning as well as the micro-politics of power and representation, two contrasting water reservoir construction projects were analysed. One was a top-down planning project (Wang Hip), the other a project implemented with the new Community-Based Irrigation (CBI) approach based on bottom-up stakeholder consultations (Klong Klai).

Not surprisingly, lack of representation was found to hamper the fostering of trust in affected people and led to the exclusion of some affected people in knowledge sharing and decision making. In the top-down case affected people were ignored in the design process when important decisions (may) have been made concerning engineering options and economic developments (claimed by the affected people) before they were consulted during the planning stage. Interestingly, even in the bottom-up case where there was opportunity for representation, it became clear that fostering of trust can be difficult.

In the top-down project (Wang Hip), the agenda setting at the negotiation table was clear: the government made the decision on the project goals, design, budget and implementation. Water supply for agriculture was set as the first priority, with industry and flood control for the town also considered high priority objectives. As noted by Jimenez 
(2016), an authoritative agenda may be practical for fast and manageable success, but negotiating on a pre-set agenda leaves little room for adjustment. In this case the limited information sharing with stakeholders about the project and the top-down decision-making deepened the conflict and opposition.

In the bottom-up project (Klong Klai), relations between stakeholders were already troubled due to a previous (cancelled) project proposal for constructing a dam. Consequently, the participatory platform was viewed as a tool to put the building of the dam back on the agenda, reflecting the continued mistrust by the opponents of the previous project. Implementation of participation faced difficulties as meetings were met with great resistance by some affected people which was manifested by them not participating. So, although designed to increase participation and reduce opposition, the $\mathrm{CBI}$ process proved deficient in practice. Knowledge was not explicitly shared in the planning process. Therefore, social learning clearly did not happen.

While in the top-down project the focus was on informing and negotiating compensation, the bottom-up approach expected to discuss acceptable solutions. Although some acceptable options were raised by the community, the agenda was not clear or trusted by the participants. Thus, the process was hijacked and paralyzed by the lingering effects of the former process and planned project. Additionally, different languages of valorisation were not appreciated in the negotiation process which further reduced trust. Among other things, this led to the insight that mediation is vital for successful participation and plays a crucial role in building an atmosphere of trust, relationships, acceptable agreements, and future collaborations.

In conclusion, participation was difficult to arrange in a situation where there was existing conflict, but it was still necessary to implement for more sustainability. The CBI approach may render projects less efficient in term of time, budget, and lower overall benefits. However, it may also reduce conflict, which would be a long term benefit. Better design of the processes would help discovery of more acceptable outcomes. Applying the framework of Reed (2008), which emphasizes that participation has to have a focus on empowerment, equity, trust, and learning, the $\mathrm{CBI}$ process revealed representation issues in the empowerment of $\mathrm{CBI}$ members who should be held more accountable by their communities, even though they were assigned by community leaders who the stakeholders trust to solve their problems. Moreover, lack of trust affected learning among stakeholders. Increasing participation calls for a standardized approach to more effectively organize representation, assign accountability, and uphold the quality of facilitation in the participatory process. 
Participatory modelling for understanding affected people's perspectives and concerns, and to explore and co-design options for water resources interventions

The second research question addressed was "What role can participatory modelling play in eliciting and reconciling stakeholder perspectives on water resource planning?" A Bayesian Belief Network (BBN) modelling framework was developed to explore stakeholders' views on water resource management issues and interventions. The initial framework began with variables and links between variables and was reviewed through a participatory planning process taking stakeholders' interests and concerns into account. Conditional Probability Tables (CPTs) were built using information elicited from stakeholders, which helped to understand their perspectives. Community perspectives and expert knowledge were combined in BBN workshops to co-create system understanding. Negative perspectives that 'the dam would damage affected people's livelihoods' and that 'livelihoods could barely be restored with low compensation' were included as critical issues that required consideration in early project planning.

Application in the two case study projects (Klong Klai and Wang Hip), made it clear that the participatory BBN development was more practical for stakeholder consultation in bottomup projects, whereas application in a top-down context, in which a decision was already made, was more challenging.

In the top-down planning case (Wang Hip), affected stakeholders insisted on fixed perspectives and expressed strong resistance to the dam. The difficulty of negotiation was evident in the probability of events in the CPTs. In this case, co-design or consultation could not be organized. The BBN was only practical for informing and presenting variables and their relations, and investigating affected stakeholders' perspectives. Participants did not believe in links between the dam and benefits of the dam. Effective and systematic participation before making a decision can enhance the acceptance, if the participation is used to inform options to manage uncertainty and restore livelihoods. However, it also became clear that compensation is not likely to promote acceptance if the compensation rates are low and do not consider long-term impacts. To address these concerns, options for resettlement planning and benefit-sharing need to be identified and considered fair.

In the case where a bottom-up approach was used (Klong Klai), the BBN development process was more practical for stakeholder consultation and co-design. The participatory meetings that were organized for two years before the BBN workshops had built trust between communities. The BBN workshops facilitated policy-makers' understanding of participants' perspectives in relation to intervention options in the early stages of planning. Additionally, participants could more easily understand variables and interactions as well as 
other stakeholders' interests through the links and likelihood indications in the CPTs. This allowed negotiation for benefit sharing. The dam location and inundated area were issues raised by the community, and discussions emerged on land exchanges among (potentially) benefited and affected people. Some critical variables, i.e. compensation and displacement, were omitted from the discussions to avoid conflict in the early planning stages. Uncertainty about farm income after displacement also emerged as a pivotal concern requiring further analysis.

Through sensitivity analysis, it was proven that participation in early planning garnered higher acceptance from the community. The BBN development process was intuitive for the participants, although it needs several iterations before participants understand how CPTs function. The BBN workshop asserted critical variables of displacement and compensation in the co-creation process, when participants trusted the process and had a clear agenda. It is of course important that data for each state of variables and criteria should be adjusted when more concrete data are available Interestingly, increasing compensation may not increase the level of acceptance if the decision has already been made. Therefore, the agenda of compensation should not be ignored in this first stage. Benefit-sharing may be discussed to create potential options at first.

Ex-ante impact assessment of reservoir construction projects for different stakeholders using Agent-Based Modelling

The third research question was "What are the impacts of WRC on affected stakeholders and what are possible solutions for negotiating better outcomes?" An agent-based model was developed to explore the impacts of WRC under various scenarios. Agent-Based Modelling ( $A B M)$ is a practical tool for ex-ante assessment as it enables the combining of various environmental and socio-economic conditions with farmers' behaviour to simulate the outcomes of proposed options. The results, while not all surprising, indicate that $A B M$ is a useful approach for getting a more detailed picture of impacts on different stakeholders.

Without a dam, dryland provides the lowest farm income. Farmers cannot change crops due to water limitations. Satisfaction is limited. With a dam, accumulated income increases for all farmers except affected farmers, who must find new productive land and invest in new tree crops which is difficult due to low compensation. More water storage also stabilizes water supply to the farmers living near the river and downstream.

However, while many parties benefit, the negatively affected people cannot maintain their livelihood and income in the short term, due to involuntary displacement related to construction of the dam. While compensation is requested for farmland and crops, the 
findings revealed that official rules on compensation seemed unfair to affected farmers, with an income loss of almost fifty percent. Extreme decreases in satisfaction of affected stakeholders were observed, caused by uncertainty over their livelihood at the start of resettlement. It can take ten years before satisfaction levels recover. Although relocation decreased satisfaction greatly, investigations revealed that shortening the period of uncertainty by speeding up the negotiation process about compensation helped displaced people to relocate to better quality land and invest in new crops.

The ex-ante assessment of dam planning by applying ABM is helpful for identifying and giving attention to specific groups of stakeholders who experience different opportunities and limitations from a project. Inequitable compensation cannot restore income and sustain livelihoods lost by negatively affected parties. With conventional cost-benefit analysis, the focus is on collective assessment rather than classified groups of stakeholders. The ABM approach allows iterative experimentation with, and gradual improvement of, criteria for compensation, e.g., sharing of benefits, using negotiation to reduce the inequality gap. This is helpful for clarifying opportunities for long term livelihood restoration early-on in the planning process.

\section{Framework for dam building compensation}

The fourth and final research question was: "How can different languages of valorisation in dam planning conflicts be recognized as relevant criteria in a WRC planning framework to enhance participation and compensation to affected people?" This research question is linked to the key objective of proposing a framework for consideration of affected people and critical criteria, language, processes, and practices. It also aimed to assess past performance of compensation of affected communities in water reservoir construction projects in Thailand.

The framework applied considered 1) Representation of affected people in decision making, 2) Assessment of impacts for affected people, 3) Recognition of multiple languages of valorisation, 4) Improvement or restoration of livelihoods and living standards, 5) Monitoring and enforcement, and 6) Possibility of appeal and resolution of potential conflicts or grievances. Moreover, cash compensation was benchmarked using Gross Provincial Product (GPP) in the year of compensation to calculate a comparative index.

Nine dam construction projects in Thailand were evaluated based on the framework. A comparative analysis was made of projects initiated before and after the constitutional change in 2007 promoting participation laws in the country. Compensation for lost assets is based on the Acquisition Act of 1987 that suggests three methods to determine 
compensations. All led to low compensation and often conflicts and fierce opposition to the projects.

The findings of this research show that the participation approach and compensation practices used in Thailand did not lead to livelihoods being restored to at least the same level as before displacement. In the nine projects studied, because of the official compensation rules applied, compensation was significantly below what would be required to restore livelihoods. Among the projects dating from before 2007, participation by affected people mostly started after the projects were opposed. In projects initiated after 2007, participation was performed through Environmental Impact Assessment (EIA) or environment assessments; yet, these projects mostly informed rather than consulted on compensation. The compensation applied the replacement cost method to value lost assets, limiting options for livelihood restoration due to low compensation values for land without title and uncertainty regarding project implementation.

Additionally, the languages of valorisation used by affected people mainly focused on ecosystem and natural values with the intention of opposing dams on that basis, but also included income from fishery that was not considered in the compensation regulations that only focus on land-based income. Although compensation should be directly negotiated in early planning, it is usually negotiated only after the dam construction has been approved. When negotiation on compensation is not on the agenda destruction of environment is used as an argument to oppose dam projects instead.

\section{General conclusions}

Answering the main question "How can Participatory Integrated Assessment (PIA) improve process outcomes of water resource projects in Thailand?" the thesis concludes that the participatory design could be improved by: (1) building trust, (2) presenting clear agenda, (3) allow local solutions as design options, (4) start negotiation about resettlement early in the process, and (5) recognize different languages of valorisation. Furthermore, the use of modelling tools like BBNs and ABM can improve communication and negotiation, by eliciting future effects and impacts of different design options. The thesis also concludes that compensation of involuntary resettled families can be improved by taking into account nonland-based income like from fishery and informal land holdings, and use real prices. Finally, benefit-sharing of the proposed project by local communities could increase their involvement and support. This responds to sustainable development goal with Target 16.7; in order to ensure participatory decision-making for water resource projects benefiting collectively to overall people, and not ignoring vulnerable families. Dams can bring important benefits, but dams can also bring huge negative effects - Effective PIA helps to balance interests of different stakeholders in the design process. 


\section{Acknowledgements}

I would like to thank my family and friends in Thailand for their support in helping, managing, and loving me all along these five years when I was far away from home. Also, my bosses, colleagues, and friends who allowed me to study abroad for a long time and supported me and assisted me to find data sources needed for my thesis.

I would like to thank the Thai community in Wageningen University for their warm welcome, making me feel like I was in Thailand by sharing feelings and experiences far away from home. Many activities, like travelling together and of course eating Thai food, stopped me from becoming homesick.

I would like to give my gratitude to my supervisor team, my promotor Coen Ritsema for accepting me to join the SLM group to work and collaborate with a supervision team and colleagues to develop my own expertise and to be regarded as a PhD candidate from a leading university of the world. I would give many thanks to Luuk Fleskens for being interested in my research topic, choosing me as a part of his projects, supervising me, and believing in me, solving my problems with valuable suggestions. I give my thanks to Jeroen Vos for taking on my research topic for his vital contributions, guiding me with concepts and frameworks, and cheering me up when I was upset from disappointment.

I also like to thank my co-authors Claire Quinn for hinting and contributing on Bayesian Belief Networks, Gert Jan Hofstede for guiding and solving problems on Agent-Based Modelling, and Martijn de Vries for assisting me in writing the code for the modelling. The challenges to accomplish my works were solved by their contributions. Moreover, I would also thank Marnella Van Der Tol, Demie Moore, Klaas Oostindie, and Rianne Maasen for helping me accomplish my tasks.

Unforgettable to thank my friends and colleagues in the SLM group. I would start with my dear office mates: Karrar and Raoul Kpegli, my first office mates, then Kaveh, and Queen of Chinese SLM - Lingtong Gai, loud and joyful voice - Xiaomei Yang, the beauty - Zhenni Wu, and the longest office mate, useful, sunshine, beautiful actress - Vera Felix da Graca Silva.

Next are my friends from South East Asia, my neighbouring countries, who share a similar culture, Coleen Carranza and the long hair guy - Darrell Tang. Then, Dutch colleagues who shared Dutch life styles to me - Corjan Nolet, Daniël van de Craats, and athlete Meindert Commelin. Further away from Thailand, my challenging pingpong competitor - Nicolas Beriot, my first squash coach - Ricardo Teixeira da Silva, the greatest football player in the group - Róger Armando Fallas Corrales, and for teaching me to know Chilean wine - Fabio Corradini.

I was delighted to release my stress by having chats, traveling, shopping, lunch, dinners, sharing weekends and holidays during these years of my PhD life with these friends: a funny gangster friend - Hao Chen, a kind boy in a big man body - Fanrong Meng, my PhD process 
reminder and my first Chilean food chef - Carlos Faundez Urbina, inspiring famous Mirzokhid Mirshadiev, determined life learning and joyful - Yueling Qi, and polite and helpful in a Dutch way enduring my Thai spicy food - Pavan Cornelissen.

I had an impressive trip in Croatia with a Chinese gang tour comprised of my English teacher - Yonghui Yang, questioning girl - Jinfeng Wu, having her own happy sound - Qian Wang, and smiling only - Jiaoyang. Of course, I cannot forget mentioning the gang of SLM newbies who came in almost the last phase of my PhD: a cute-acting hotpot cooker - Hui Ju, giant chicken heart - Nikola Rakonjac, and never innocent like his appearance - Ke Meng.

Moreover, I am thankful to the Royal Thai Government Scholarship Program (offered by OCSC) for the financial support of my thesis research.

many more people who I would like to thank, I apologize if I did not mention you above.

Thank you all.

Chakaphon Singto (Pop) 


\section{About the author}

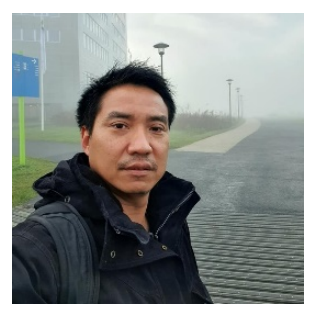

Chakaphon Singto was born on February 23, 1976, in Bangkok, Thailand. He obtained a Bachelor's degree in Business Administration. He first obtained a master's degree in the Master of Management programme at The College of Management at Mahidol University, and subsequently obtained a master's degree in the Land Use and Sustainable Natural Resources Management (SLUSE) Program at Kasetsart University, Thailand.

He worked as a planning and policy analyst for the Royal Irrigation Department (RID) of the government of Thailand. Based on insights from political science and stakeholder analysis, participation was expected to reduce conflicts between policymakers and stakeholders and shared benefits would be promoted through effective participatory processes. His responsibility was to further develop the organization public services. During his career, he earned a full scholarship from the Thai Government to study participation and conflicts in water management. Therefore, he started his PhD in 2015 at the Soil physics and land Management group (SLM), at the Department of Environmental Sciences at Wageningen University.

During his $\mathrm{PhD}$, he arranged workshops with groups of stakeholders to identify their interests and concerns. The results were used to develop frameworks to be used in the planning stage of water projects. He applied social modelling to derive perspectives in conflict situations and to predict impacts on the affected public. He has published two scientific articles, which are part of this thesis. Moreover, he gave oral presentations at the international conferences Water Science for Impact 2018 (Wageningen, the Netherlands) and the American Geophysical Union (AGU) Fall Meeting 2019 (San Francisco, United States of America).

After his PhD graduation, he will continue to work as a government official in Thailand, where he will apply his expertise to find better solutions for government projects by bridging gaps in conflicts of interests.

Chakaphon Singto

Permanent email: chakaphon.singto@gmail.com 


\section{SENSE}

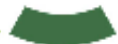

Netherlands Research School for the Socio-Economic and Natural Sciences of the Environment

\section{I P L O M A}

for specialised PhD training

The Netherlands research school for the

Socio-Economic and Natural Sciences of the Environment

(SENSE) declares that

\section{Chakaphon Singto}

born on 23 February 1976 in Bangkok, Thailand

has successfully fulfilled all requirements of the educational PhD programme of SENSE.

Wageningen, 30 November 2020
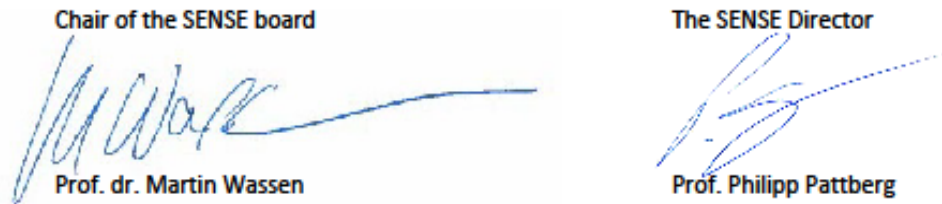

The SENSE Research School has been accrodited by the Royal Netherlands Academy of Arts and Sciences (KNAW)

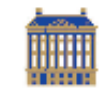

K O

A K A D E M I E V A N W E T E N S C H A P P E N 


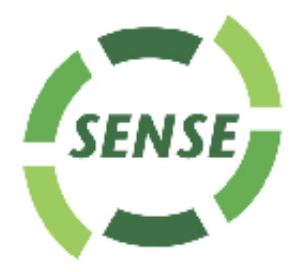

The SENSE Research School declares that Chakaphon Singto has successfully fulfilled all requirements of the educational PhD programme of SENSE with a work load of $45.1 \mathrm{EC}$, including the following activities:

\section{SENSE PhD Courses}

- Environmental research in context (2015)

- Research in context activity: "Initiating and co-organizing two workshops with local stakeholders for Dam Planning Projects in Thailand (13 and 17 June 2017, Thailand)'

- Grasping Sustainability (2018)

Other PhD and Advanced MSc Courses

- Scientific writing, Wageningen Graduate Schools (2015)

- Techniques for writing and presenting a scientific paper, Wageningen Graduate Schools (2016)

- Agent-based modelling for resilience, 8th ESSA/ SiLiCo Summer School in Social Simulation, Wageningen School of Social Science (2017)

- From Science to practise, Achieving Sustainable development, Action research, and Negotiation for water conflict management, IHE Delft (2017)

- Policy and governance theories for analysing water issues, Wageningen School of Social Science (2018)

- Conflicting Demands in European Forests: A wicked problem, PE\&RC and ELLS (2018)

\section{Management and Didactic Skills Training}

- Co organisation of a training course on risk assessment of The Royal Irrigation Department, Thailand (2020)

- Supervising a MSc students with thesis entitled 'Agent-based models to describe Dam consequences'(2019)

\section{Oral Presentations}

- Applying Bayesian Belief Networks (BBNs) with stakeholders to mitigate conflicts surrounding medium-scale reservoir construction projects. International conference Water Science for Impact, 6-18 October 2018, Wageningen, the Netherlands

- Assessment of involuntary resettlement related to dam building: Languages of valorization and outcomes of water resource development projects in Thailand. AGU fall meeting, 13 December 2019, San Francisco, United States of America

\section{SENSE coordinator PhD education}

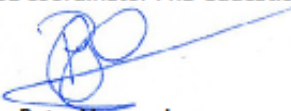

Dr. ir. Peter Vermeulen 


\section{Colophon}

The research described in this thesis was financially supported by: the Royal Thai Government Scholarship Program (offered by OCSC).

Cover design

Thesis layout

Thesis printed by:
Chakaphon Singto

Klaas Oostindie

ProefschriftMaken || Digiforce 